\title{
New observations to identify abnormal impulse formation in the intact heart
}

Citation for published version (APA):

Vos, M. A. (1989). New observations to identify abnormal impulse formation in the intact heart. [Doctoral Thesis, Maastricht University]. Rijksuniversiteit Limburg. https://doi.org/10.26481/dis.19891027mv

Document status and date:

Published: 01/01/1989

DOI:

10.26481/dis. $19891027 \mathrm{mv}$

Document Version:

Publisher's PDF, also known as Version of record

\section{Please check the document version of this publication:}

- A submitted manuscript is the version of the article upon submission and before peer-review. There can be important differences between the submitted version and the official published version of record.

People interested in the research are advised to contact the author for the final version of the publication, or visit the DOI to the publisher's website.

- The final author version and the galley proof are versions of the publication after peer review.

- The final published version features the final layout of the paper including the volume, issue and page numbers.

Link to publication

\footnotetext{
General rights rights.

- You may freely distribute the URL identifying the publication in the public portal. please follow below link for the End User Agreement:

www.umlib.nl/taverne-license

Take down policy

If you believe that this document breaches copyright please contact us at:

repository@maastrichtuniversity.nl

providing details and we will investigate your claim.
}

Copyright and moral rights for the publications made accessible in the public portal are retained by the authors and/or other copyright owners and it is a condition of accessing publications that users recognise and abide by the legal requirements associated with these

- Users may download and print one copy of any publication from the public portal for the purpose of private study or research.

- You may not further distribute the material or use it for any profit-making activity or commercial gain

If the publication is distributed under the terms of Article $25 \mathrm{fa}$ of the Dutch Copyright Act, indicated by the "Taverne" license above, 


\section{New observations to identify}

abnormal impulse formation

in the intact heart 

New observations to identify

abnormal impulse formation in the intact heart 
$$
\text { " }
$$ 


\section{New observations to identify abnormal impulse formation}

\section{in the intact heart}

\section{PROEFSCHRIFT}

ter verkrijging van de graad van doctor aan de Rijksuniversiteit Limburg te Maastricht, op gezag van de Rector Magnificus, Prof. Dr. F.I.M. Bonke, volgens het besluit van het College van Dekanen, in het openbaar te verdedigen

op vrijdag, 27 oktober 1989 om 14.00 uur

door Marc Adriaan Vos

geboren te Tilburg 
Promotor:

Co-promotor:

Beoordelingscommissie: Prof. Dr. R.S. Reneman (voorzitter)

Prof. Dr. M.A. Allessie

Prof. Dr. H.A.J. Struyker Boudier

Prof. Dr. M.R. Rosen

Dr. M. Borgers

CIP-DATA KONINKLIJKE BIBLIOTHEEK, DEN HAAG

Vos, Marc Adriaan

New observations to identify abnormal impulse formation in the intact heart / Marc Adriaan Vos.; [ill. Jet

Leunissen]. - Maastricht : Datawyse. - Ill.

Thesis Maastricht. - With ref. - With summary in Dutch.

ISBN 90-5291-006-5

SISO 605.12 UDC 616.12(043.3)

Subject headings: cardiac arrhythmias / arrhythmogenic mechanisms.

Produktie en layout: Datawyse - Maastricht

Druk: Krips Repro Meppel

Het verschijnen van dit proefschrift (alsmede de verdediging) werd mede mogelijk gemaakt door de financiële steun van:

- RESCAR (stichting ter bevordering van research in de cardiologie),

- Nederlandse Hartstichting.

- University of Maastricht Electrophysiology Fellows Association (UMEFA),

- Interuniversitair Cardiologisch Instituut Nederland en de Wijnand M. Pon Stichting te Leusden,

- Siemens Nederland B.V. en Bayer Nederland B.V.. 
VAN EEN DIER VALT VEEL TE LEREN

Aan mijn ouders, Voor Rian 


\section{Contents}

Chapter 1 Introduction

Chapter 2 Abnormal and normal impulse formation and conduction in the heart

Review of the literature

2.1 Normal impulse formation and conduction

2.2 Arrhythmias

2.3 Identification of mechanisms of cardiac arrhythmias

Chapter 3 Significance of the number of stimuli to induce triggered arrhythmias in the intact heart

Chapter 4 The effect of an entrainment protocol on ouabain-induced ventricular tachycardia

Chapter 5 The in vivo response of ouabain-induced arrhythmias to pacing: acceleration instead of termination

Chapter 6 Premature escape beats: a model for triggered activity in the intact heart?

Chapter 7 Value of programmed electrical stimulation to identify arrhythmias caused by abnormal automaticity in vivo

Chapter 8 Termination of ouabain-induced ventricular tachycardias by flunarizine in conscious dogs

Chapter 9 Flunarizine allows differentiation between mechanisms of arrhythmias in the intact heart

Chapter 10 General Discussion with possible guidelines for the cardiologist to distinguish among mechanisms of cardiac arrhythmias

Summary

Samenvatting

Nawoord

Curriculum Vitae 


\section{Introduction}

Cardiac arrhythmias are one of the main causes of morbidity and mortality in many parts of the world. During the last decades, our knowledge on arrhythmias has increased considerably, because of the development of new methods by which arrhythmias can be studied systematically. An important contribution has been the introduction of programmed electrical stimulation, which allows the reproducible initiation and termination of many clinically occurring arrhythmlas. This and other recently developed techniques, have provided the basis for more individualized options for treatment. At present, treatment can be primarily pharmacological, surgical, or electrical, but also frequently combinations are necessary.

In spite of these developments, clinicians are still frequently confronted with disappointing results, like recurrences of the arrhythmia, side effects or pro-arnhythmic effects of drugs, and (unfortunately) arrhythmic death. While many drugs have been developed over the years, the ideal anti-arrhythmic drug both in terms of efficacy and side-effects is not available. Hopefully, drugs will be developed having increased specificity, enabling them to exert their effect: 1) on cardiac and not on non-cardiac tissue, 2) on arrhythmias without affecting pump function, 3) on diseased rather than on healthy cardiac tissue, 4) on refractoriness without affecting conduction velocity or vice versa, and 5l against specific mechanlsms of cardiac arrhythmias.

Knowledge of triggered activity and abnormal automaticity as mechanisms of arrhythmias has mostly been derived from observations in isolated tissue preparations. This in contrast to reentry, which because of programmed electrical stimulation and cardiac activation mapping has extensively been studied in the intact human heart. This led to the assumption that reentry is the most frequent mechanism of clinical arrhythmias. Because other arrhythmogenic mechanisms have been demonstrated, however, under a number of pathophysiological conditions, it is conceivable that they may also be clinically important. To be informed about the role of triggered activity and abnormal automaticity in clinically occurring arrhythmlas, better Identification of these mechanisms is required. This can be realized by studying the effects of programmed electrical stimulation, drugs, and/or changes in the autonomic nervous system. To answer these questions, reliable intact heart models of these arrhythmogenic mechanisms have to be developed. 
This thesis reports on the value of these techniques to initiate, identify, and terminate ventricular arrhythmias based on different arrhythmogenic mechanisms in conscious dogs with chronic atrio-ventricular block. Especially triggered activity caused by delayed afterdepolarizations and abnormal automaticity were studied.

In chapter 2, the literature concerning the different mechanisms for cardiac arrhythmias is reviewed starting with a short introduction of the normal activation of the heart. Chapters 3-7 discuss the value of programmed electrical stimulation to study triggered activity (chapters 3-6) and abnormal automaticity (chapter 7 ). In chapter 3 , findings are reported on initiation of triggered arrhythmias, while chapter 4 describes observations seen during. pacing of these tachycardias using an entrainment protocol. Chapter 5 discusses the inability to terminate triggered arrhythmias by programmed electrical stimulation. In dogs with an idioventricular rhythm, overdrive pacing can result in the induction of premature escape beats. Data are presented suggesting that these beats are based on triggered activity (chapter 6). These observations suggest that this simple model can be used to study triggered activity in the intact heart. In chapter 7 , the effect of overdrive pacing on arrhythmias resulting from abnormal automaticity is discussed. Chapters 8 and 9 report on the value of flunarizine to identify arrhythmogenic mechanisms. Flunarizine, a calcium antagonist, was found to specifically terminate arrhythmias resulting from triggered activity. Using our findings, guidelines are given (chapter 10) which can be of help to identify the specific underlying mechanism of arrhythmias in the human heart. 
Abnormal and normal impulse
formation and conduction in the heart

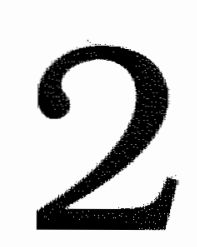

Review of the literature 


\subsection{NORMAL IMPULSE FORMATION AND CONDUCTION}

The heart is composed of atrial muscle, ventricular muscle and specialized automatic and conducting fibers. To pump blood optimally, it is essential that these tissues are activated and contract in a certain sequence. Automaticity, the ability to initiate spontaneous rhythmic action, is a property of the sinus nade, some parts of the atria, the AV-junction, and the His-Purkinje system (1). Usually, the sinus node is dominant, i.e. this pacemaker regulates the activity of other heart cells. When sinus node activity fails, subsidiary pacemakers become manifest to assure continuation of pump function.

In the subsequent section normal impulse conduction and generation will be reviewed in relation to their significance for our study of ventricular tachycardias based on abnormal impulse formation.

\section{NORMAL CONDUCTION}

The cardiac impulse originates in the sinus node and spreads through the atria, the AV-node, the ventricular conducting system and the ventricles, until the entire heart is activated. This sequence of events is repeated 60 to 100 times per minute in the normal adult human heart. There is a delay in conduction in the AV-node, which allows the atria to contract ahead of the ventricles, thereby enhancing ventricular filling and contraction. Impulse conduction occurs because cardiac cells are excitable: they respond to a stimulus which, when sufficiently strong to reach threshold, generates an action potential (figure 1, left panel).

The action potential in normal working atrial and ventricular muscle cells consists of 5 phases: 1) phase $4=$ resting phase, 2) phase $0=$ rapid depolarization, 3) phase 1 = early rapid repolarization, 4) phase 2 = plateau phase $_{\text {. }}$ and 5) phase $3=$ final rapid repolarization. These phases are the result of passive ion fluxes because of electrochemical gradients which are continuously reestablished by active ion pumps and exchange mechanisms (2). The normal intra- and extracellular concentrations of important electrolytes like potassium $\left(\mathrm{K}^{+}\right)$, sodium $\left(\mathrm{Na}^{+}\right)$, and calcium $\left(\mathrm{Ca}^{2+}\right)$ regulating the electrical potential of the cell membrane, are listed in table 1. Also the transmembrane 
Table 1. Intracellular and extracellular ion concentrations in cardiac muscle

\begin{tabular}{lrrl}
\hline Ion & \multicolumn{1}{l}{ Extra } & \multicolumn{1}{l}{ Intra } & \multicolumn{1}{l}{$\mathrm{E}_{\mathrm{I}}$} \\
\hline $\mathrm{Na}$ & $145 \mathrm{mM}$ & $15 \mathrm{mM}$ & $+60 \mathrm{mV}$ \\
$\mathrm{K}$ & $4 \mathrm{mM}$ & $150 \mathrm{mM}$ & $-94 \mathrm{mV}$ \\
$\mathrm{Ca}$ & $2 \mathrm{mM}$ & $10^{-7} \mathrm{mM}$ & $+129 \mathrm{mV}$ \\
\hline
\end{tabular}

$\mathrm{E}_{\mathrm{l}}=$ equilibrium potential for a particular ion. From Sperelakis (2)

Table 2. Properties of transmembrane potentials in mammalian hearts

$\begin{array}{lllll}\text { sinus node } & \text { atrial } & \text { AV-nodal } & \text { Purkinje } & \text { Ventricular } \\ \text { cell } & \text { muscle cell } & \text { cell } & \text { aber } & \text { muscle cell }\end{array}$

\section{Resting potential}

$(\mathrm{mV})$

-50 to $-60 \quad-80$ to $-90 \quad-60$ to $-70 \quad-90$ to $-95 \quad-80$ to -90

\section{Action potential}

amplitude (mV)

overshoot (mV)

60 to 70

110 to 120

70 to 80

120

110 to 120

duration ( $\mathrm{ms}$ )

0- 10

30

5 to 15

30

30

$\operatorname{Vmax}(\mathrm{W} / \mathrm{s})$

100 to $300 \quad 100$ to $300 \quad 100$ to 300

1 to $10 \quad 100$ to $200 \quad 5$ to 15

300 to 500

200 to 300

500 to 700

100 to 200

Propagation velocity

(m/s)

$<0.05$

0.3 to 0.4

0.1

2 to 3

0.3 to 0.4

modified from Speralakis (2)

potentials of each electrolyte are calculated when this respective lon would accordingly be in equilibrium without the presence of other electrolytes (Nernst equation).

\section{1) Phase 4 = resting phase or diastolic membrane potential}

Transmembrane potential during diastole is -50 to $-95 \mathrm{mV}$, depending on the cell type (table 2). This means that the inside of the cell is 50 to $95 \mathrm{mV}$ negative in relation to the outside of the cell membrane. Responsible for this potential difference is the multi-ionic distribution across this membrane. The altered transmembrane gradient is (re)established by pumps like the enzyme 


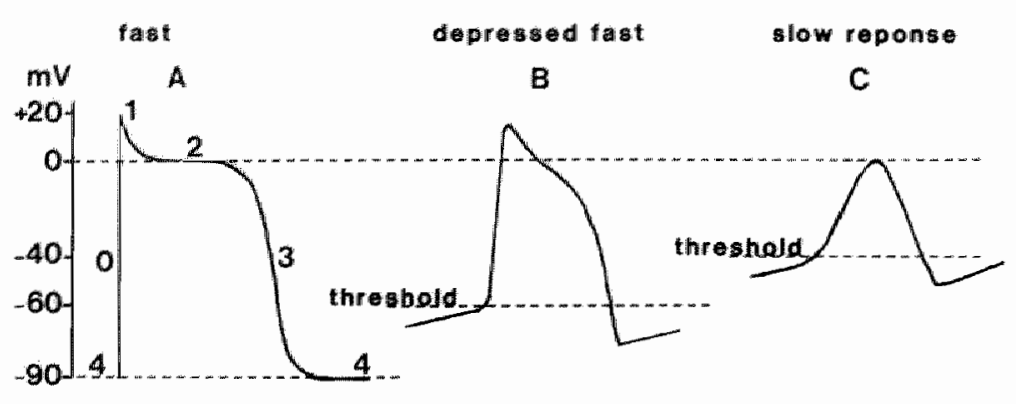

working and conduction flbres in atria and ventricle

$$
\begin{gathered}
\mathrm{Na}^{+} \text {lon } \\
0.5 \text { to } 5 \mathrm{~m} / \mathrm{sec} \text { cond. velocity }
\end{gathered}
$$

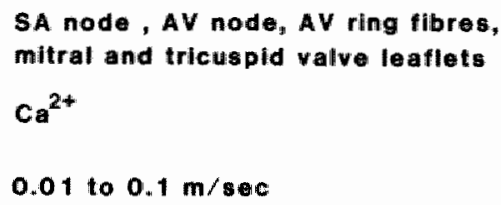
mitral and tricuspid valve leaflets$$
\mathrm{Ca}^{2+}
$$

0.01 to $0.1 \mathrm{~m} / \mathrm{sec}$

Figure 1. Action potentials representing fast (left), depressed fast (middle), and slow response. See text.

$\mathrm{Na}^{+} / \mathrm{K}^{+}$ATP-ase, which pumps $\mathrm{Na}^{+}$out and $\mathrm{K}^{+}$into the cell. This transport is electrogenic: $3 \mathrm{Na}^{+}$-ions for $2 \mathrm{~K}^{+}$-ions are moved against their respective electro-chemical gradient.

\section{2) Phase $0=$ rapid depolarization or upstroke}

A stimulus delivered to excitable tissue evokes an action potential characterized by a sudden voltage change (figure 1, left panel). In normall atrial and ventricular muscle and the His-Purkinje system this upstroke of the action potential is caused by a sudden increase in membrane conductance to $\mathrm{Na}^{+}$. The rate at which depolarization occurs during phase 0 is called V-max (table 2). Because these actions potentials have very rapid upstrokes and large $V$-max, they are termed fast responses. Slow responses, which occur in the normal sinus- and AV-node (figure 1, right panel), are mediated by a slow $\mathrm{Ca}^{2+}$-current as the low membrane potential causes inactivation of the $\mathrm{Na}^{+}$-channels in these cells (3). 


\section{3) Phase 1 = early rapid repolarization}

This phase is well defined and separated from phase 2 in Purkinje fibres and some muscle cells. Partial repolarization is induced by inactivation of the fast inward and activation of an outward current, carried by $\mathrm{K}^{+}$and possibly also related to chloride ions moving intracellularly.

\section{4) Phase 2 = plateau phase}

During the plateau phase, the outward currents are balanced by inward currents, including the slow $\mathrm{Ca}^{2+}$-current, and the $\mathrm{Na}^{+}$window current (4). During phase $2, \mathrm{Ca}^{2+}$-entry enables the cardiac muscle to contract.

\section{5) Phase 3 = final rapid repolarization}

Repolarization proceeds rapidly due to inactivation of the slow inward current and activation of an outward $\mathrm{K}^{+}$-current $\left(\mathrm{I}_{\mathrm{k}}\right)$, so that extracellular movement of positive charges increases. The net membrane current becomes outward and the membrane potential shifts in a negative direction.

\section{NORMAL AUTOMATICITY (IMPULSE GENERATION)}

Automaticity is caused by a gradual fall in membrane potential starting directly following repolarization. This reflects a gradual shift in the balance between in- and outward currents, favouring a net inward current. This phase 4 or pacemaker depolarization results in a continuous decrease in membrane potential until threshold is reached (figure 1, right panel).

\section{Sinus- and AV-node automaticity}

The ionic mechanism responsible for phase 4 depolarization in the sinus node, AV-node, and perhaps in cells around the mitral and tricuspid valves (1) is still under investigation. It is hypothesized that automaticity in these cells is dependent on: 1) decay of the outward $\mathrm{K}^{+}$-current $\left.(5), 2\right)$ the slow inward $\mathrm{Ca}^{2+}$-current (6), and/or the If current (7). More recently, the possible role of the slow inward current was further elucidated (8). There are two different calcium channels, $\mathrm{Ca}^{2+}$-Longlasting $\left(\mathrm{Ca}^{2+}-\mathrm{L}\right)$ and $\mathrm{Ca}^{2+}$-Transient $\left(\mathrm{Ca}^{2+}-\mathrm{T}\right)$. present in the sinus node (8). The channels of the T-type have a low threshold of activation $(-50$ to $-60 \mathrm{mV})$ and become inactivated rapidly, while 
L-type channels have a higher threshold (around $-40 \mathrm{mV}$ ) and become inactivated more slowly. These latter channels support the functional roles commonly ascribed to $\mathrm{Ca}^{2+}$-channels.

Both channels contribute to phase 4 depolarization of the sinus node. It has been proposed that the initial phase of the pacemaker potential is mainly generated by a decaying conductance of the $\mathrm{K}^{+}$-current and the latter phase is produced by sequential activation of both $\mathrm{Ca}^{2+}$-currents, first $\mathrm{Ca}^{2+}-\mathrm{T}$ followed by $\mathrm{Ca}^{2+}-\mathrm{L}$ (8). The existence of these two calcium channels was first discovered in ventricular tissue (9). As will be discussed later, there are differences in the way calcium-antagonists influence both channels.

\section{Ventricular impulse formation}

Specialized fibers of the atria and the His-Purkinje system have pacemaker activity based on fast responses (1). The ionic mechanism underlying phase 4 depolarization in Purkinje fibers is most likely an inward $\mathrm{Na}^{+}$-current called If (7) which increases in time, while, in contrast to sinus- and AV-node, the outward $\mathrm{K}^{+}$-current remains constant.

\section{HIERARCHY AMONG NORMAL CARDIAC PACEMAKERS}

Dominance of the sinus node is provided by two actions: 1) higher rate of impulse generation, and 2) overdrive suppression. Driving a pacemaker faster than its intrinsic rate results in inhibition of spontaneous activity (figure 2). The amount of overdrive suppression is related to the rate and the duration of the preceding rhythm, either spontaneous or induced by electrical stimulation (10). Suppression is mediated by enhanced activity of $\mathrm{Na}^{+} / \mathrm{K}^{+}$ATP-ase. To summarize the normal activation of the heart, the action potentials of the different tissues are shown in relation to the timing of the surface electro(cardio)gram (figure 3 ).

\section{RESPONSE TO DRUGS}

Apart from the ability of anti-arrhythmic drugs to suppress or prevent arrhythmias, they can also affect normal impulse formation and conduction. Classification of these anti-arrhythmic drugs is frequently based on their electrophysiological effect on normal cardiac cells (11). They can be divided 


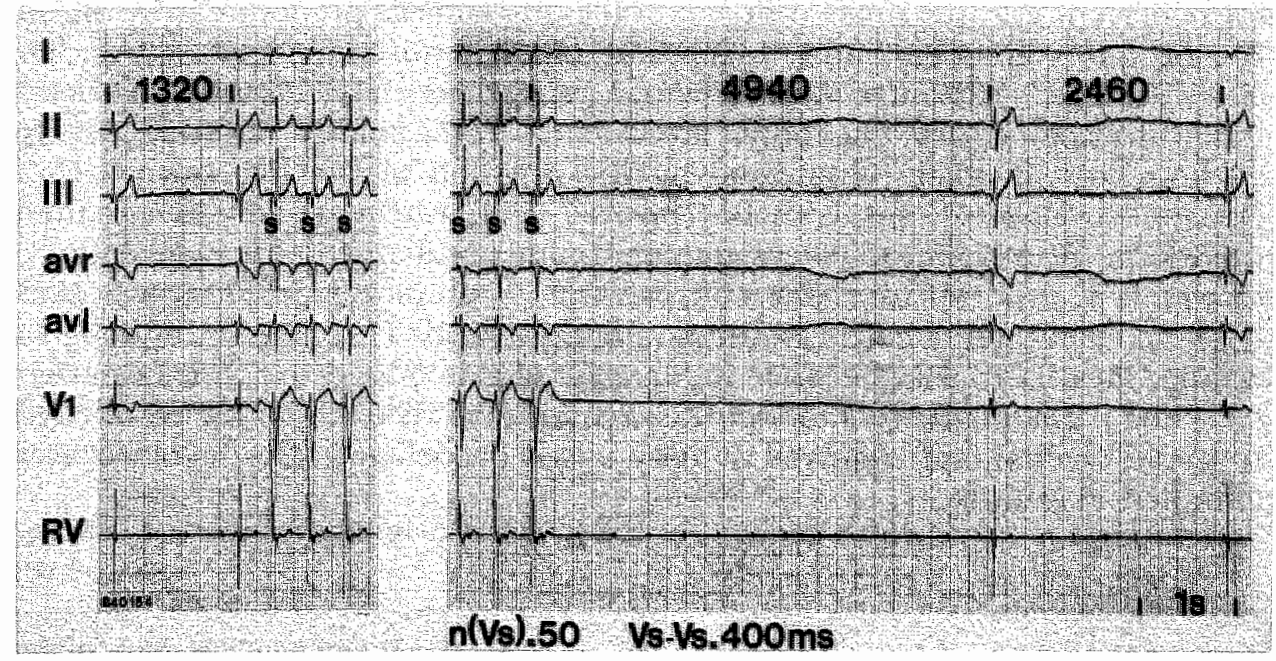

Figure 2. Overdrive suppression of the idioventricular rliythm.

Six ECG-leads and local electrogram are shown. The spontaneous ventricular rhythm with a R-R interval of $1320 \mathrm{~ms}$ is overdrven (S) using 50 stimuli and an interstimulus interval of 400 ms. Following stimulation, marked overdrive suppression is seen lasting 4940 ms.

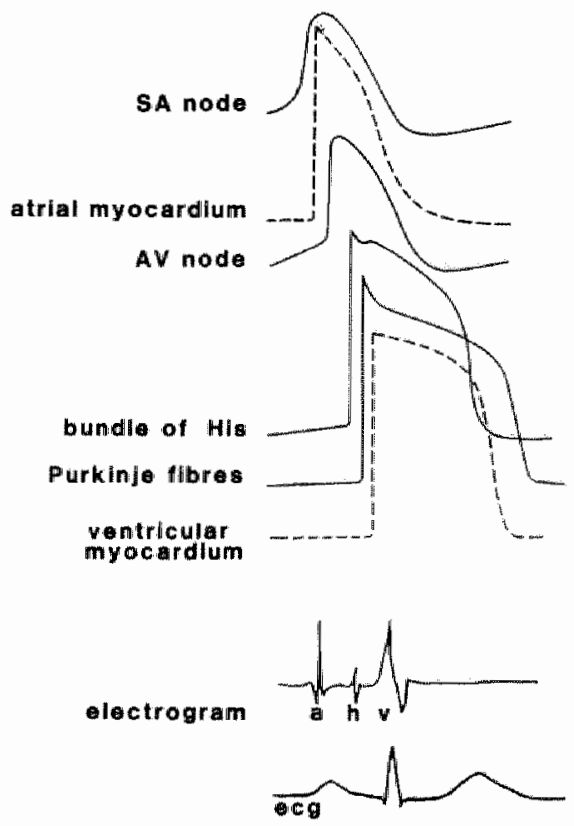

Figure 3. The different action potentials, which occur during normal activation of the heart. are shown in relation to ECG and a local electrogram. 
into different groups: those that exert blocking actions predominantly on $\mathrm{Na}^{+}$. $\mathrm{K}^{*}$, or $\mathrm{Ca}^{2+}$-channels, and those that block $\beta$-adrenergic receptors. This classification is of limited value because many drugs have actions that belong to multiple categories. Secondly, not all drugs in the same class have identical effects. This is nicely illustrated by the reaction of the two inward $\mathrm{Ca}^{2+}$. channels to calclum-antagonists. The $\mathrm{Ca}^{2+}-\mathrm{L}$ channels are sensitive to manipulations by calcium-blockers like verapamil and nifedipine, while $\mathrm{Ca}^{2+}-\mathrm{T}$ channels are almost insensitive $(8,12) . \mathrm{Ca}^{2+}-\mathrm{T}$ channels are, however, effectively blocked by the calcium-antagonist flunarizine (13). The latter drug was studied in this thesis, because its specific effects suggested that flunarizine could be a diagnostic tool to identify arrhythmias resulting from the arrhythmogenic mechanism triggered activity based on delayed afterdepolarizations (chapters 8 and 9).

\subsection{ARRHYTHMIAS}

An arrhythmia is any abnormality in rate, regularity, or site of origin of the cardiac impulse or a disturbance in conduction of that impulse such that the normal sequence of activation of the atria and ventricles is altered (14). Therefore, arrhythmias result either from abnormalities in impulse initiation or from abnormalities in impulse conduction or a combination of both (1). In table 3 , the different arrhythmogenic mechanisms are listed.

\section{ABNORMAL AUTOMATICITY}

Working atrial and ventricular myocardial cells (fast response) do not normally show spontaneous diastolic depolarization. When the resting membrane potential of atrial or ventricular cells is reduced from $-90 \mathrm{mV}$ to less than about $-70 \mathrm{mV}$ (figure 1 , middle panel), spontaneous depolarization may occur causing repetitive impulse generation $(15,16)$. Also, cells like Purkinje fibers which are automatic at normal levels of membrane potential (normal automaticity), show a different form of automaticity when diastolic membrane potential is reduced (abnormal automaticity) $[17,18)$. Abnormal automaticity 
Table 3. Mechanisms of cardtac arrhythmtas

$\begin{array}{ll}\text { Abnormal impulse formation } & \\ \text { Abnormal automaticity } & \text { - high } \\ & \text { - intermediate } \\ & \text { - low potential } \\ \text { Triggered activity } & \text { - early afterdepolarizations } \\ \end{array}$

Abnormal impulse conduction

Reentry

Abnormal impulse formation and conduction

Parasystole

Modified from Hoffman and Rasen (1)

is therefore defined as spontaneous impulse generation from a reduced diastolic potential in cardiac fibers, normally showing a high diastolic potential (1).

The ionic basis for phase 4 depolarization under these conditions has not been identified satisfactorily (14). Next to a decrease in repolarizing $\mathrm{K}^{+}$current, it has also been suggested that inward currents like the fast sodium or the slow calcium channel are involved. Their contribution is dependent on the diastolic membrane potential. The less negative this potential, the greater the involvement of the slow inward current. Whether the slow $\mathrm{Ca}^{2+}-\mathrm{T}$ channel plays a role in abnormal automaticity occurring in depolarized cells is unknown, but it is not unlikely since $\mathrm{Na}^{+}$-channels are inactive at membrane potentials at which $\mathrm{Ca}^{2+}-\mathrm{T}$ channels are still functioning (12). In this respect, the effect of flunarizine, which blocks $\mathrm{Ca}^{2+}-\mathrm{T}$ channels, on these arrhythmias is of interest (chapter 9).

Diastolic depolarization leading to abnormal automaticity can be achieved by application of cellular currents (15), and observed after exposure to barium salts $(17,19)$, in Purkinje fibers 24 hours after infarction $(17,18,20,21)$ and in digitalized Purkinje fibers (22). 


\section{TRIGGERED ACTIVITY}

The term triggered activity, initially introduced by Cranefield and Aronson (23), is impulse generation caused by afterdepolarizations. These are transient depolartzations of the membrane potential during or after an action potential and their occurrence is dependent on this action potential (23). Although triggered activity as a cause for arrhythmias had been recognized earlier in this century (24-26), it was not until the 1970's, that this mechanism and its implications were studied extensively. Afterdepolarizations can occur during or after the repolarization phase of the action potential. The former are called early and the latter delayed afterdepolarizations (figure 4).

\section{Early Afterdepolarizations}

Early afterdepolarizations (EAD's) occur during phase 2 or 3 of an action potential that has been initiated from a high level of membrane potential, usually between -75 and $-90 \mathrm{mV}(3)$. They appear as a change in membrane potential in a positive direction relative to the expected membrane potential during repolarization. Following induction of an $\mathrm{EAD}$ normal repolarization may occur or when threshold is reached, another impulse may be initiated at the reduced level of membrane potential, possibly leading to further rhythmic activity (27).

Early afterdepolarizations may be caused by a fall in $\mathrm{K}^{+}$-conductance with repolarization, but probably also require the presence of a steadystate inward current. At least part of that inward current may be carried by non-inactivated $\mathrm{Na}^{+}$-channels, but the involvement of the slow $\mathrm{Ca}^{2+}$-channel is more likely $(28,29)$.

EAD's can be induced with a vartety of interventions which lengthen the duration of the action potential (3). These include: bradycardia (27), hypokalaemia (30), cesium-chloride $(27,28,31), \mathrm{N}$-acetyl procainamide (32), quinidine (30), $\mathrm{Ca}^{2+}$-current agonist Bay K 8644 (29), and by exposure to aconitine and veratrine (3).
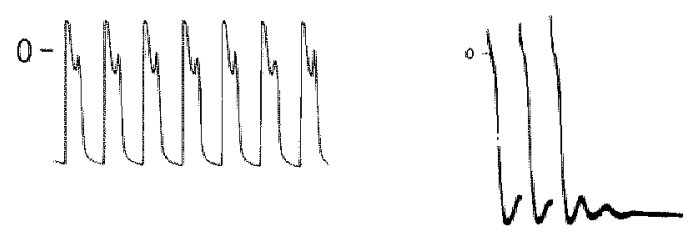

Figure 4. A cesium-induced early (left) and a ouabain-induced delayed afterdepolartzation. Calibrations: $20 \mathrm{mV}$ and $1 \mathrm{sec}$. (79. printed with permission from American Heart Association). 


\section{Delayed Afterdepolarizations}

Delayed afterdepolarizations (DAD's) are oscillations of the diastolic membrane potential occurring after complete repolarization of the preceding action potential (3). When their amplitude is large enough a nondriven (triggered) impulse arises. This depolarization is followed by another DAD. When this one also reaches threshold, sustained rhythmic activity can appear.

DAD's occur under conditions in which there is a large increase in intracellular $\mathrm{Ca}^{2+}$-concentration. The possible mechanism by which a calcium overload may cause DAD's has been discussed in several publications (33, 34). It is hypothesized that DAD's result from an transient inward current carried across the membrane by $\mathrm{Na}^{+}$. This current is modulated by the intracellular increase in $\mathrm{Ca}^{2+}(33)$.

This arrhythmogenic mechanism is studied most extensively in the setting of digitalis intoxication (3,35-37). It may occur under other conditions, however. such as after catecholamines administration (38-41), the first day(s) after myocardial infarction $(20,21,42)$, reperfusion $(43-45)$, hypokalaemia $(46-47)$. sodium free and calcium rich solution (48), and hypertrophy (49). In the conscious dog, we will discuss the possible induction of triggered beats by fast and short stimulation-trains in the absence of any medication (chapter 6).

\section{REENTRY}

In a heart driven by the sinus node, the conducting impulse dies out after sequential activation of the atria and ventricles, because of refractoriness of recently activated tissues. Reentry, or circus movement of excitation, occurs when an impulse does not die out, but finds a pathway of excitable flbers over which it may return to reexcite part or all of the heart $(1,14)$. For reentry to occur the following requirements have to be fulfilled: 1) cardiac tissue has to be in or has to be brought to a state of inhomogeneity, i.e. differences must exist in refractorinesss and conduction velocity, 2) this must lead to unidirectional block in one pathway of cardiac tissue and slowing of impulse conduction in another pathway, which 3) enables the impulse to reenter the former pathway leading to reexcitation of the heart (figure 5).

Different types of reentrant excitation can be distinguished: 1) circus movement excitation involving an anatomical barrier (50,51), 2) leading circle mechanism (52,53), 3) anisotroplc reentry (54-56), and 4) combinations of these types. In the leading circle and in anisotropic reentry a functionally determined area of conduction block is present. The different forms of reentry have the following characteristics (56): 1) the reentrant pathway in anatomical reentry is fixed, while in the two functional circuits the pathway is determined by electrophysiological properties of the myocardium and there- 

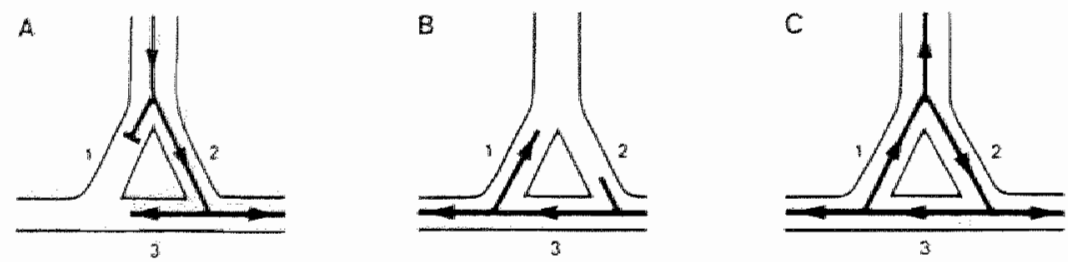

Figure 5. Mechanism of reentry.

Panel A shows arrival of an impulse at the site of division in two pathways. The impulse is blocked in pathway 1 and exclusively conducted over pathway 2. Panel B shows how the Impulse coming from 2 reenters the distal portion of pathway 1. If the proximal portion of pathway 1 has recovered, the impulse is able to conduct back to the site of origin. If this mechanism perpetuates (panel $\mathrm{C}$ ), a regular reentry tachycardia results. $(37$, printed with permission from Vewé publishers).

fore variable, 2) in anatomical and anisotropic reentry an excitable gap is present, which is absent in leading circle reentry, 3) the rate in the anatomical form is proportional to conduction velocity and length of the pathway, while in leading circle reentry, the rate is proportional to the duration of the refractory period, and in anisotropic reentry to the refractory period and the duration of the excitable gap, 4) anatomical and anisotropic reentrant tachycardias are stable and longlasting, while leading circle reentrant tachyarrhythmias are not stable and tend to terminate spontaneously.

Different pathological conditions may lead to reentry as ischemia $(57,58)$, myocardial infarction (54-56,59-61), and reperfusion (44). Also congenital atrio-ventricular connections play a role in reentry $(51,62,63)$. 


\subsection{IDENTIFICATION OF MECHANISMS OF CARDIAC ARRHYTHMIAS}

Because arrhythmogenic mechanisms can be active under different pathophysiological conditions (see above), it is frequently difficult to identify the mechanism responsible for clinically occurring cardiac arrhythmias. Especially, the clinical relevance of abnormal automaticity and triggered activity has to be determined (64). From a theoretical point of view, mechanisms of arrhythmias can be studied by direct or indirect means (table 4). In vitro, the use of micro-electrode techniques or mapping of a reentrant circuit may provide sufficient evidence of the mechanism involved. In the human heart. however, it is not possible to record intracellular potentials and detailed mapping of a reentrant tachycardia is only occasionally possible during surgery (63). Therefore, in most human arrhythmilas, study of their mechanism can only be done indirectly.

In this chapter, we will review the information provided by two of these methods: 1) programmed electrical stimulation (PES), and 2) the administration of anti-arrhythmic drugs. Both methods were used in the investigations reported in this thesis. Validation of these methods comes from experiments performed in isolated tissue and in animal models in which the (predominant) arrhythmogenic mechanism could be identified. In the intact heart, we consider digitalis-induced arrhythmias as a model for triggered activity resulting from DAD's $(3,22,36,37)$, while interventions prolonging the duration of the action potential are possible models based on triggered activity caused by EAD's $(3,31,65,66)$. Abnormal automaticity is considered to be the pre-

Table 4. Methods for studying mechanlsms of arrhythmas

\begin{tabular}{ll}
\hline Direct & - Intracellular recordings of diastolic membrane potential \\
and afterdepolartzation \\
- mapping of a reentry circuit \\
Indirect & - recordings of monophasic action potentials \\
- body surface signal averagting techniques \\
- programmed electrical stimulation \\
- drugs specifically affecting mechanisms of arrhythmias
\end{tabular}


dominant mechanism active in arrhythmias spontaneously occurring 16-24 hours following LAD-occlusion in the canine heart $(21,22,32)$. For reentrant tachycardias, we have restricted the discussion to two animal models, although we are aware that many others exist: 1) pacing induced atrial flutter around an anatomical barrier $(67,68)$, and 2) ventricular tachycardia in the chronic phase of the myocardial infarction $(54,56,69-73)$. Both models possess an excitable gap.

Also, some clinical studies have been included when data are presented from similar pathological conditions as described above. This concerns mainly reentrant arrhythmias.

\section{RESPONSE OF THE DIFFERENT ARRHYTHMOGENIC}

\section{MECHANISMS TO PES}

Programmed electrical stimulation has been introduced in clinical cardiology for the study of supraventricular tachycardias by Durrer et al. (51) and Coumel et al. (74) in 1967 and to study ventricular tachycardias by Wellens et al. (59) in 1972. Since its introduction, PES has been increasingly employed to study patients with cardiac arrhythmias in order to: 1) localize the site of origin or pathways of the tachycardia, 2) elucidate their mechanism. 3) assess action and efficacy of anti-arrhythmic drugs, and 4) to develop new treatment modalities like surgery, electrical and chemical ablation and anti-tachycardia pacing (59-64,74-77). The value of PES as a predictor of drug efficacy is still a matter of investigation (78). Also, the reliability of PES to identify the different arrhythmogenic mechanisms is questionable (79).

Because of its relevance for our studies, the present knowledge concerning PES in regard to specific mechanisms of cardiac arrhythmias will be reviewed. Experiments performed in vitro will be discussed separately from those done in the intact heart. The following parameters will be discussed:

1. Initiation. The ability to initiate ectopic beats or arrhythmias by critically timed extrastimuli (with or without preceding drive) and by regular overdrive pacing is discussed in relation to interstimulus interval and/or number of stimuli. Also, on the effect of variations in pacing on the behavior of the first postpacing interval is reported.

2. Termination. The ability to terminate arrhythmias by critically timed extrastimuli (with or without preceding drive) and overdrive pacing is discussed in relation to interstimulus interval and/or number of stimuli. Secondly. the behavior of the first postpacing interval and the cycle length of the arrhythmia after pacing is described. 


\section{In vitro experiments}

\section{Abnormal automaticity}

1. Arrhythmias resulting from abnormal automaticity appear spontaneously. Three types of automaticity were recognized according to their diastolic membrane potential: high $(>-70 \mathrm{mV})$, intermediate (between -60 and $-70 \mathrm{mV}$ ) and low $(<-60 \mathrm{mV})$ potential automaticity (20). The rate of the arrhythmia is dependent on the level of the diastolic membrane potential. The less negative the membrane potential, the higher is the rate of the arrhythmia (20).

2. Single premature stimuli result in resetting or slight prolongation of the first postpacing interval independent of the resting membrane potential $(21,80)$, but not in termination.

The effect of overdrive pacing depends on the level of membrane potential (20). Overdrive stimulation ( $15 \mathrm{~s}$ ) resulted in suppression of high potential, and no suppression of low potential automaticity (20-22). The amount of overdrive suppression of the intermediate forms was related to rate and number of stimuli during overdrive pacing. Faster and longer pacing trains presumably further hyperpolarize the pacemaker fiber by activation of the $\mathrm{Na}^{+} / \mathrm{K}^{+} \mathrm{ATP}$ ase. Pacing did not modify the cycle length of the tachycardia postpacing: control rates were reestablished within two to five cycles (20).

\section{Triggered activity resulting from EAD's}

1. Induction of EAD-induced arrhythmias is bradycardia dependent. Thus pacing using slower rates increases: 1) the amplitude of an EAD until a critical cycle length is attained, 2) the chance to induce triggered beats, and $3)$ the occurrence of sustained rhythms $(27,29,65)$. Single stimull are not effective unless applied after long pauses. The behavior of the first postpacing interval is rather complicated. Increasing the interstimulus interval results in: 1) no change, or 2) lengthening of the first postpacing interval, while this interval shortens when measured in manifest action potentials based on EAD's $(27,65)$. Neither the relevance of the number of stimuli initiating EAD's nor its effect on the first postpacing interval have been investigated.

2. Termination of these arrhythmias occurs following premature stimull and rapid overdrive pacing $(27,29,30,65)$, but no study has quantifled these findings. According to Damiano et al. (27), termination is dependent on the maximal diastolic potential: the more negative this membrane potential, the higher the chance to terminate the tachycardia. However, recent studies have 
reported termination of these arrhythmias by overdrive pacing at membrane potentials less than $-35 \mathrm{mV}(29,65)$. Data concerning the behavior of the first postpacing interval or rate of the arrhythmia postpacing are not available.

\section{Triggered activity resulting from DAD's}

1. Irrespective of their cause, induction of DAD-induced arrhythmias is tachycardia dependent $(38,41,42,47,48,81,82)$. Thus during programmed electrical stimulation, decreasing the interstimulus interval will increase 1) the amplitude of the DAD, 2) the chance to induce triggered beats, and 3) the occurrence of sustained rhythms. Characteristic for digitalis-induced DAD's is the induction of more than one DAD (figure 6 ). The first DAD has a first postpacing interval about equal to the interstimulus interval, the second being approximately twice the preceding interval. The amplitude of the first DAD shows an increase on reducing the interstimulus interval from 1000 to $500 \mathrm{~ms}$. Following shorter intervals the amplitude rapidly decreases. The second DAD shows the opposite behavior: increasing at shorter interstimulus intervals reaching a maximum at $200 \mathrm{~ms}$. Catecholamine-induced DAD's only show one DAD (41).

The relevance of the number of stimull to initiate DAD's is more controversial. While there is no disagreement about the increase in amplitude of the DAD through 10 stimuli, inconsistent results are given for higher numbers of stimulil. Several studies report no further increase in amplitude of the DAD nor shortening of its first postpacing interval $(47,48,81,82)$, while others do $(38,42,49)$.

2. Termination using single extrastimuli can occur although it is seen infrequently $(41,42,81)$. Long episodes of overdrive at short cycle lengths can terminate triggered arrhythmias successfully $(41,42,81$ ). Shortening of the first postpacing interval on reducing the interstimulus interval is characteristic for DAD-induced triggered activity $(38,41,42,47,48,81,82)$. The behavior of the arrhythmia postpacing needs further investigation.

\section{Reentry}

1-2. Reentry is most extensively studied in the intact heart (see below). In vitro, only few studies, using the earlier described models, have been published in which the response of reentrant tachycardias to programmed electrical stimulation is reported $(56,68)$. Arrhythmias could be initiated and terminated by extrastimuli and overdrive pacing. No data on the incidence of initiation and termination in relation to different pacing modes is available, nor does information about the behavior of the first postpacing interval exist. 
A
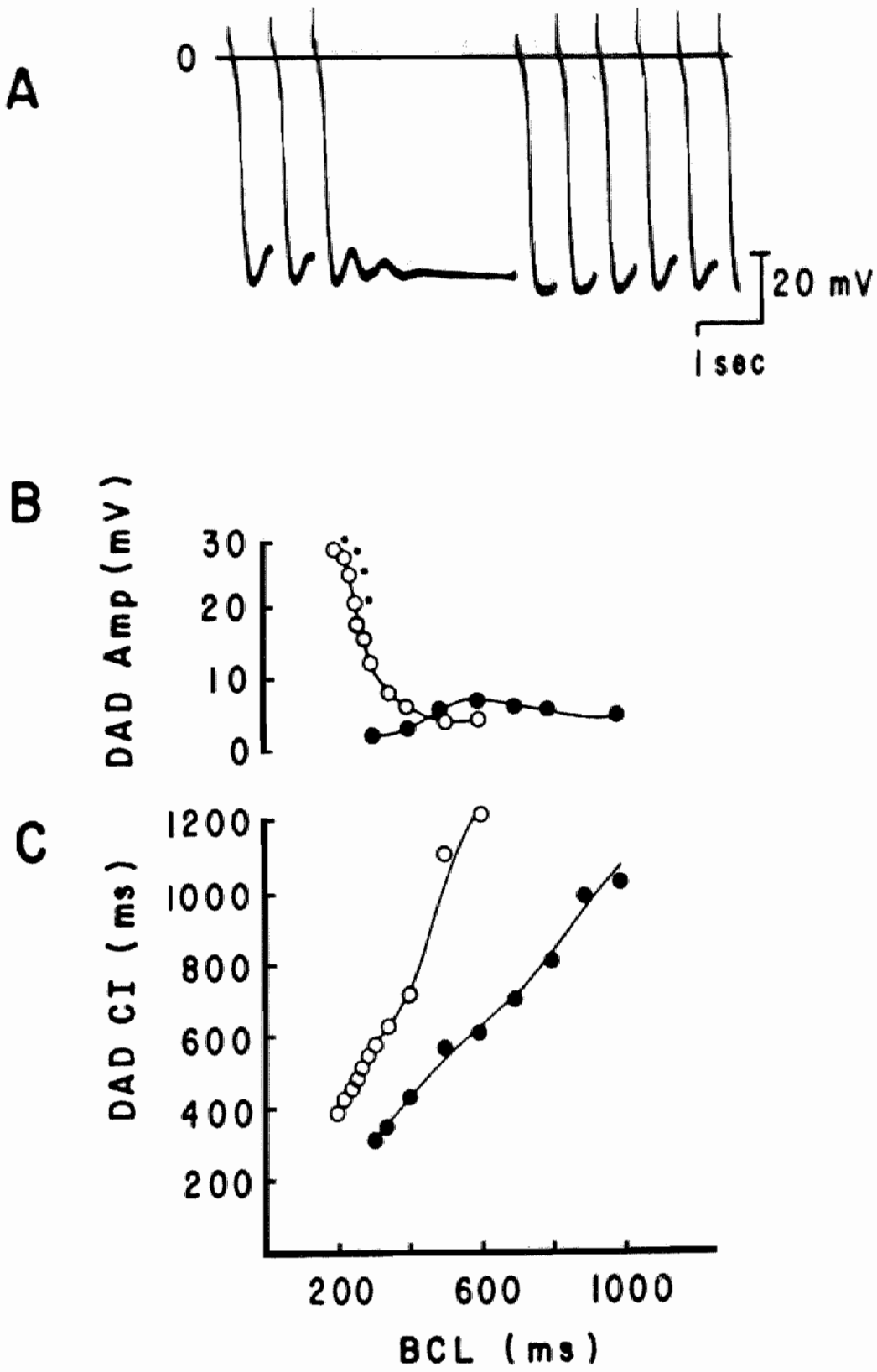

Figure 6. Digitallis-induced delayed afterdepolarkzations (DAD's).

Panel A shows the accurrence of two DAD's. The relationship of the ampllitude (panel B), and the coupling interval (CI in panel $C$ ) of the $D A D$ to the basic drive cycle length (BCL) is presented. Black symbols is DAD-1, while the open symbols represent DAD-2. See Text. (75, printed with permission from Futura Publishing Company). 


\title{
Experiments performed in the intact heart
}

\begin{abstract}
Abnormal automaticlty
2. Abnormal automaticity in the intact heart has been studied in the $16-24$ hours infarct model $(21,22,83)$. These studies have reported the following results. The cycle length of arrhythmias is shorter than in vitro $(21,22)$. Termination by way of PES has never been observed $(21,22,83)$. The protocols consisted of extrastimuli, trains of 10 stimuli, and stimulation for 10 to $60 \mathrm{~s}$ using interstimulus $\mathbb{1 n t e r v a l s}$ up to $200 \mathrm{~ms}$. The first postpacing interval and the cycle length of the arrhythmia postpacing were not modified by pacing $(21,22,83)$. These findings suggest that these arrhythmias occurred from a low or intermediate diastolic membrane potential. To study the value of PES for differentiating abnormal automaticity from triggered activity resulting from DAD's in the intact heart, we have further quantified the response of these arrhythmias to electrical stimulation in conscious dogs having complete AV-block (chapter 7).
\end{abstract}

\section{Triggered activity resulting from EAD's}

1. Arrhythmias resulting from EAD's have been studied in the intact heart by adminstration of anthopleurin-A (65), and quinidine in combination with locally applied aconitine (66). The majority of ventricular tachyarrhythmias induced was polymorfic. Studying the effect of PES, it was found that lengthening of the first postpacing interval occurred on increasing the interstimulus interval (65).

2. These arrhythmias elther terminated spontaneously or degenerated into ventricular fibrillation (65). Pacing at short cycle lengths abolished the ocurrence of EAD's and the corresponding arrhythmias $(31,65)$. No data were presented considering incidence of termination in relation to different pacing modes.

Clinically, it has been suggested that EAD's may play a role in tachycardias of the QT-prolongation syndrome or Torsade des Pointes $(84,85)$. Examples of these tachycardias in the intact heart as a consequence of EAD's have been reported in several studies $(31,65,66)$.

\section{Triggered activity resulting from DAD's}

1. In the intact heart, initiation of ouabain-induced ventricular arrhythmias is promoted by pacing at fast rates (86-90). Depending upon the dose of ouabain, single ectopic beats, non-sustained, and sustained ventricular 
tachycardias can be induced. The former are termed repetitive ventricular responses (86), or accelerated ventricular escape beats (87). In contrast to the pacing rate, the relevance of the number of stimuli to induce ouabain-induced arrhythmias is not well known. Therefore, we have studied this question in detail (chapter 3). The first postpacing interval of the triggered beats is directly related to the interstimulus interval $(87,89,90)$. Recently, Malfatto et al. (90) showed that this concordant relation was not restricted to ouabaininduced triggered arrhythmias, but was also present in two other types of DAD-dependent tachycardias: 1) arrhythmias induced 24-48 hours following myocardial infarction, and 2) atrial tachycardias induced by catecholamines.

2. The response of DAD-dependent arrhythmias to pacing has been investigated in several studies (22,89-92). All studies report a concordant relation between the first postpacing interval and the inter- or extrastimulus interval. Furthermore, it was demonstrated by our group that: 1) the first postpacing interval is mainly dependent on the interval of the last paced beat $(91), 2)$ this interval is independent of the site of stimulation $(91,92)$, and 3) its QRS-configuration is related to the site of stimulation (92).

Clinically similar observations have been described during digitalis intoxication (93).

We have further characterized the response of ouabain-induced ventricular tachycardia to PES (chapter 5). More specifically, we report on the ability to terminate these tachycardias and on the behaviour of rate of the VT postpacing in relation to different pacing modes.

\section{Reentry}

1. Evidence that arrhythmias induced by PES in the chronic phase of myocardial infarction are based on reentry is quite extensive $(54,59-61,69-$ $73,76.83)$. Initiation can be achieved by critically timed extrastimuli and sometimes by regular pacing. Initiation is feasible within an individually varying width of the zone of the premature stimulus interval. A slow or very fast basic pacing rate and increasing the number of stimuli facilitates the initiation of reentry (61). During initiation, an inverse relation between prematurity of the extrastimulus initiating the tachycardia and the first postpacing interval has been described $(61,63,76,94)$.

2. At a critical extrastimulus or overdrive interval, the tachycardia can also be reproducibly terminated. Before termination occurs, continuous resetting (entrainment) of the tachycardia can be demonstrated (95-100). During transient entrainment all components of the tachycardia circuit are accelerated to the faster rate, with resumption of the intrinsic rate of the tachycardia when stimulation is ceased. The response to increasing prematurity of an extrastimulus is an increasing, flat or mixed slope of the first postpacing interval, but never a decreasing one (96). Pacing at different rates and for a 
longer time results in constant and progressive fusion between the paced and the tachycardia complexes except for the last captured beat which is entrained but not fused $(97-100)$. Although entrainment seems to be a specific phenomenon for reentry, it is not known whether the described surface $\mathbb{E C G}$-criteria can also be found in other arrhythmogenic mechanisms. Because this knowledge may be of importance for the differentiation between reentrant tachycardias and other mechanisms of arrhythmias, this question was studied in detail (chapter 4 ).

\section{THE EFFECT OF DRUGS ON THE}

\section{ARRHYTHMOGENIC MECHANISMS}

The avallable anti-arrhythmic drugs can be divided into those that exert blocking actions predominantly on $\mathrm{Na}^{+}, \mathrm{K}^{+}$, or $\mathrm{Ca}^{2+}$-channels (11). Although useful, this classification has some limitations because: 1) drugs in a particular group do not have identical physiological properties, 2) drugs may exhibit actions on multiple ionic channels depending on dosage, and tissue type, and 3) some drugs require specific conditions, like ischemia, or calcium overload. before exerting an effect.

The effect of drugs on mechanisms of cardiac arrhythmias will be discussed separately for experiments performed in vitro and in the intact (animal) heart. Drugs are evaluated on their ability to: 1) slow the rate, 2) terminate or suppress, and 3) to prevent (re)induction of the arrhythmia. The following anti-arrhythmic drugs will be discussed:

- lidocaine, (n-acetyl)procainamide, ethmozin, propafenone, and flecainide (class 1)

- amiodarone and d-sotalol (class 3)

- verapamil and nifedipine (class 4)

- doxorubicin.

Information is presented especially in regard to the ability of these drugs to be used as a tool to identify different arrhythmogenic mechanisms. 


\section{In vitro experiments}

\section{Abnormal Automaticity}

To discuss the effect of drugs on abnormal automaticity, a relevant distinction is made between $\mathbf{A}$ ) arrhythmias originating from a high or intermediate diastolic membrane potential ( $>-60 \mathrm{mV}$ ) and $\mathrm{B}$ ) from a low diastolic membrane potential $(<-60 \mathrm{mV})$.

A) Lidocaine $(21,101,102)$, ethmozin (21), and verapamil (101) increased the cycle length of the arrhythmias occurring from high or intermediate membrane potentials. Suppression of all arrhythmias was only observed following ethmozin (21), while lidocaine was not (101) or only partially effective (102). Also verapamil was not able to suppress these arrhythmias (101).

Amiodarone prevented the occurrence of these tachycardias (111), while doxorubicin had no effect (22).

B) The cycle length of the tachycardias arising from a low membrane potential increased with lidocaine $(101,103,104)$, procainamide (107), ethmozin (103), verapamil $(16,101,104,113)$, and nifedipine (17). Suppression occurred after administration of ethmozin (103), verapamil $(16,104,113)$ and nifedipine (17). Lidocaine $(101,103,104)$ and procainamide $(16,107)$ did not suppress this form of automaticity. Amiodarone prevented the occurrence of these arrhythmias (111).

\section{Triggered activity induced by EAD's}

Induction of EAD's was prevented when lidocaine $(29,30,65)$, ethmozin (29). or verapamil (29) was added to the tissue bath.

\section{Triggered activity induced by DAD's}

Lidocaine $(21,105,106)$, procainamide $(107-109)$, ethmozin $(21,103,109)$, amiodarone (112), verapamil $(39,40,105,106,108,113)$, nifedipine $(17,108$, 114), and doxorubicin $(22,115)$ were all effective in: 1) decreasing the amplitude of DAD's, and 2) decreasing the number of triggered beats.

Procainamide was partially effective when added to preparations in which bursts of triggered beats were present. In half of the fibers the duration of the burst was diminished, while in the other half no effect was observed (107). 


\title{
Reentry
}

Procainamide prevented the reappearance of sustained ventricular activity in healed myocardial infarction of cat ventricles by premature stimuli (110).

\section{Experiments performed in the intact heart}

\begin{abstract}
Abnormal Automaticity
In ventricular arrhythmias occurring $16-24$ hours after myocardial infarction, the rate was reduced by lidocaine $(21,83,116,117)$, (n-acetyl)procainamide (83,116), ethmozin $(21,122,123)$, amiodarone (124), verapamil $(116,117)$, and nifedipine (117). Only ethmozin has been reported to be effective in suppressing these arrhythmias $(21,123)$. Lidocaine was described to be effective in one study (117), and partially effective in another (83), while other studies reported no suppressing effect $(21,116)$. Similarly, procainamide has been described efficacious (116), partially effective (83) or without effect (32). The arrhythmias were also partially suppressed by amiodarone, while verapamil $(116,117)$ and nifedipine (117) were never succesful. Nelther termination nor an increase in rate of the tachycardia was observed following doxorubicin administration (22).
\end{abstract}

\section{Triggered activity induced by EAD's}

Only lidocaine has been reported to be effective in abolition of EAD"s-induced arrhythmias in the intact heart (65).

\section{Triggered activity induced by DAD's}

Lidocaine $(117,118)$, procainamide (118), verapamil $(117,118)$, nifedipine $(117,118)$, and doxorubicin (22) were able to reduce the rate and terminate the ouabain-induced arrhythmias in the intact heart. 


\section{Reentry}

The cycle length of reentrant atrial flutter was increased by lidocaine ( 119 , 120), procainamide (121), propafenone (119), flecainide (119), d-sotalol (119. 120). With the exception of lidocaine, all drugs effectively terminated these reentrant atrial arrhythmias. Lidocaine could not prevent reinduction of these arrhythmias (120), while d-sotalol was partially effective (120).

The rate of the ventricular tachycardias studied by Davis et al. (83) was decreased following lidocaine, procainamide, and verapamil. Administration of these drugs did neither result in termination, nor could they prevent reinduction by $\mathrm{PES}(83)$.

Clinically, procainamide was able to slow the rate and terminate reentrant tachycardias, while it was partially effective preventing reinduction (125). In the same study, verapamil was not able to slow the rate or terminate these ventricular tachycardias (125). 


\section{REFERENCES}

1. Hofman $\mathrm{BF}$, and Rosen MR Cellular mechanisms for cardiac arrhythmias. Circ Res 1981; 49: 1-15.

2. Sperelakis $N$. Origin of the cardiac resting potential. In Handbook of Physiology, The cardiovascular system. Bethesda, Maryland, American Physiological Society 1979.

3. Cranefleld PF, and Aronson RS. Cardiac arthythmias: The role of triggered activity and other mechanisms. Futura Publishing Company, Mount Kisco, New York, 1988.

4. Baumggarten CM, and Fozzard HA. The resting and pacemakers potentials, in "The heart and the cardiovascular system", eds Fozzard HA et al., Raven Press, New York, 1986: 601-626.

5. Yanagihara $K$, and Irisawa $H$. Potasslum current during the pacemaker depolarization in rabbit sino-atrlal nodle cell. Pnuger Arch 1980; 388: 255-600.

6. Noma $A$, Irisawa $H$, Kokubun $S$, Kotake $H$, Nishimura $M_{\text {, }}$ and Watanabe J. Slow current systems in the AV-node of the rabbit heart. Nature 1980; 285: 228-229.

7. Difrancesco D. A new interpretation of the pacemaker current in calf Purkinje fiber. $J$ Physiol 1981; 314: 359-376.

8. Hagiwara N. Irisawa $\mathrm{H}_{n}$ and Kameyama M. Contribution of two types of calcium currents to the pacemaker potentials of rabbit sino-atrial node cells. J Physiol 1988; 395: 233-253.

9. Nillus B, Hess P, Lansman JB, and Tsien RW. A novel type of cardiac calcium channel in ventricular cells. Nature $1985 ; 316: 443-446$.

10. Vassalle M. The rellationships among cardlac pacemakers. Circ Res 1977; 41: 269-277.

11. Vaughan-Willams EM. The classification of antiarrhythmic actions reassessed after a decade of new drugs. J Clin Pharmacol 1984: 24: 129-147

12. Bean BP. Two kinds of calcium channels in atrlal cells. Differences in kinetics, selectivity and pharmacology. J Gen Physiol 1985; 86: 1-30.

13. Tytgat $J$. Vereecke $J$, and Carmeliet E. Differential effects of verapamil and flunarizine on cardiac L-type and T-type channels. Arch Pharmacol 1988; 337: 690-692.

14. WIt $\mathrm{AL}_{\text {, }}$ and Rosen MR. Cellular electrophysiology of cardiac arrhythmias in Tachycardias:' Josephson ME and Wellens. HJJ (eds). Lea and Febiger, Philadelphia 1984; 1-27. 


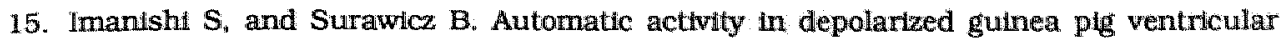
myocardium: characterlistics and mechanisms. Circ Res 1976; 39: $751-759$.

16. Hordof A, Edie R, Malm J, Hoffman B, and Rosen M. Electrophysiologic properties and response to pharmacologic agents of fibers from diseased human atria. Circulation 1976: 54: 774-779.

17. Dangman $K$, and Hoffman BF. Effects of nifedipine on electrical activity of cardiac cells. Am J Cardiol 1980; 46: 1059-1067.

18. Frledman PL, Steward JR, Fenoglio jr. JJ, and Wit AL. Survival of subendocardlal Purkinje fibers after extensive myocardial infarction in dogs. Circ. Res. 1977; 42: 73-84.

19. Toda N. Barium-induced automaticity in relation to calctum ions and norepinephrine in the rabbit left atrium. Circ Res 1970; 27: 45-57.

20. Dangman $\mathrm{KM}_{*}$ and Hoffman BF. Studies on overdrive stimulation of canine cardiac Purkinje fibers: Maximal diastolic potential as a determinant of the response. $J$ Am Coll Card 1983; 2: $1183-1190$.

21. LeMarec $H$, Dangman KH, Danillo $P$, and Rosen MR. An evaluation of automaticity and triggered activity in the canine heart one to 4 days after myocardial infarction. Circulation 1985: $71: 1224-1236$.

22. LeMarec $H$, Spinelli $W$, and Rosen MR The effects of doxorubicin on ventricular tachycardia. Circulation 1986; 74: 881-889.

23. Cranefield PF. Action potentlals, afterpotentials and arrhythmias. Circ Res 1977; 41 : 415-423.

24. Rothberger $\mathrm{CJ}_{n}$ and Winterberg $H$. Ueber den Einfluss von Strophantin auf die Reizblldungsfaehigkeit der automatische Zentren des herzens. Pnuegers Arch 1913; 150: $217-261$.

25. Segers $M$. Le battement auto-entretenu du coeur. Arch Int Pharmacoldyn 1974; 75: 144-156.

26. Bozler E. The inttiation of impulses in cardiac muscle. Am J Physiol 1943; 138: 273-282.

27. Damiano BP, and Rosen M. Effects of pacing on triggered activity induced by early afterdepolarizations. Cinculation 1984; 69: 1013-1025.

28. Marban $\mathbb{E}_{n}$ Robinson SW, and Wier WG. Mechanisms of arrhythmogenic delayed and early afterdepolarizations in ferret ventricular muscle. J Clin Invest 1986: 78: 1185-1192. 
29. January $C T$, Riddle $J M$, and Salata $\mathfrak{J} J$. A model for early afterdepolarizations: Induction with the $\mathrm{Ca}^{2+}$ channel agonist Bay K 8644. Circ Res 1988; 62: 563-571.

30. Foden DM. and Hoffiman BF. Action potential prolongation and induction of abnormal automaiticty by low quinidine concentrations in canine Purkinje fibers: relationship to potassium and cycle length. Circ Res 1985; 56: 857-866.

31. Levine JH, Spear JF, Guarnier T, Weisfeldt ML, de Langen CDJ, Becker LC, and Moore EN. Cestum-chloride-Induced long GT-syndrome: demonstration of afterdepolarizations and triggered activity in vivo. Circulation 1985; 72: 1092-1103.

32. Dangman $\mathrm{KH}$, and Hoffman BF. In vivo and in vitro antiarrhythmic and arrhythmogenic effects of $n$-acetyl procatnamide. J Pharmacol Exp Ther 1981; 217;851-862.

33. Kass RS. Tsien RW. and Weingart R. Ionic basis of transient inward current induced by strophantidin in cardiac Purkinje fibers. J Physiol 1978; 281: 209-226.

34. Orchaird CH, Eisner DA, and Allen DG. Oselllations of intracellular $\mathrm{Ca}^{2+}$ in mammallan cardlac muscle. Nature 1983; 304: 735-738.

35. Ferrier GR. Digitalis arrhythmias: nole of oscillatory afterpotentials. Prog Cardiovasc Dis 1977: $19: 459-474$.

36. Rosen MR, and Danillo P. Digitals induced delayed afterdepolarizations. In "The slow inward current and cardiac arrhythmias", eds. Zipes D, Balley J, and Elharrar V. Martinus Nijhoff Publishers, The Hague 1980; 417-435.

37. Gorgels APM. Ventricular impulse formation and the influence of digitalis intoxication. Thesis, University of Limburg. 1985.

38. Wald RW, and Waxman MB. Pacing induced automaticity in sheep Purkinje fibers. Circ Res 1981; $48: 531-538$.

39. Wit Al, and Cranefteld PF. Triggered activity in cardiac muscle fibers of the simian mitral valve. Ctrc Res 1976:38:85-98.

40. WIt AL, and Cranefleld PF. Triggered and automatic activity in the canine coronary sinus. Circ Res $1977 ; 44: 435-445$.

41. Johnson N, Danilo P. Wit AL, and Rosen MR. Characteristlcs of initiation and termination of catecholamine-induced triggered activity in atrial fibers of the coronary sinus. Circulation 1986: 74: 1168-1179.

42. El-Sherif N. Gough WB, Zeiler RH, and Mehra R. Triggered ventricular rhythms in 1-day-old myocardial infarction in the dog. Cire Res 1983: 52: 566-579. 
43. Fernier GR, Moffat MP, and Lukas A. Possible mechandsms of ventricular arrilythmias elicited by ischemta followed by reperfuston. Circ Res 1985; 56: 184-194.

44. Pogwizd SM, and Corr PB. Electrophysiologic mechantsms underlying arrthythmlas due to reperfusion of ischemil myocardium. Circulation 1987; 76: 404-426.

45. Thandroyen FT, McCarthy J. Burton KP, and Ople LH. Ryanodine and caffeine prevent ventricular arrhythmias during acute myocardial ischemia and reperfusion in rat heart. Circ Res 1988; 62: 306-314.

46. Eisner DA, and Lederer WJ. Inotropic and arrhythmogenic effects of potassium-depleted solutions on mammalian cardtac muscle. J Physilol 1979; 294: 255-277.

47. Hiraoka M, Okamoto $\mathrm{Y}$, and Sano $\mathrm{T}$. Oscillatory afterpotentlals in dog ventricular muscle fibers. Circ Res $1981 ; 48: 510-518$.

48. Cranefleld PF, and Aronson RS. Initiation of sustained rhythmic activity by single propagated action potentials in canine cardiac Purkinje fibers exposed to sodium free solution or to ouabain. Circ Res $1974 ; 34: 477-481$.

49. Aronson RS. Afterpotentials and triggerd acttvity in hypertrofled myocardium from rats with renal hypertension. Circ Res $1981 ; 48: 720-727$.

50. Mines GR. On circulating excitations in heart muscles and their posstble relation to tachycardia and flbrillation. Trans R Soc of Canada, Section V 1914: 43-53.

51. Durrer D, Schoo L, Schullenburg RM, and Wellens HJJ. The role of premature beats in the Initiation and termination of supraventricular tachycardia in the Wolff-ParkinsonWhite syndrome. Circulation 1967; 34: 644-662.

52. Moe GK. On the multiple wavelet hypothesis of atrial fibrillation. Arch Int Pharmacol Ther 1962; 140: 183-188.

53. Allessie MA. Bonke FTM , and Schopman FJG. Circus movement in rabbit atrial muscle as a mechanism of tachycardia. III. The "leading circle" concept: a new model of circus movement in cardiac tissue without the involvement of anatomic obstacle. Circ Res 1977; 41: 9-18.

54. Dillon SM, Allessie MA. Ursell PC, and Wit AL. Influences of anilsotropic tissue structure on reentrant circuits in the epicardial border zone of subacute infarets. Ctrc Res 1988: 63: $182-206$.

55. WIt AL. Anisotropic reentry: a model of arrhythmilas that may incessiltate a new approach to antiarrhythmic drug development. In "Lethal arrhythmilas resulting from myocardial ischemla and Infarction", eds: Rosen MR, and Pallu J. Kluwer Academic Publishers, Boston/Dordrecht 1989: 199-213. 
56. Schally MJ. Anlsotropic conduction and ventricular tachycardia. Thesis, Untversity of Limiburg 1988.

57. Janse MJ, van Capelle FJL, Morsink H, Kleber AG, Wilhs-Schopman F, Cardinal R, Naumann d'Alnoncourt $C$, and Durrer D. Flow of "injury" current and patterns of excitation during early wentricular arrhythmias in acute reglonal myocardial ischemia in tsolated procine and cantne hearts; evidence for two different arrhythmogenic mechanisms. Circ Res 1980; 47: 151-165.

58. Pogwizd SM, and Corr PB. Reentrant and non-reentrant mechanisms contribute to arrhythmogenesis during early myocardial ischemia: Results using three-dimensional mapping. Clrc Res 1987; 61: 352-371.

59. Wellens HJJ. Schuilenburg RM, and Durrer D. Electrical stimulation of the heart in patients with ventricular tachycardla. Circulation 1972; 46: 216-226.

60. Wellens HJJ, Lie KI, and Durter D. Further observations on ventricular tachycardia as studled by electrical stimulation of the heart. Chronic recurrent ventricular tachycardia and ventricular tachycardia during acute myocardial infarction. Circulation 1974; 49; 647-653.

61. Wellens HJJ, Duren DR, and Lie KI. Observations on mechanisms of ventricular tachycardia in man.Circulation 1976: 54; 236-244.

62. Wellens HJJ, Brugada P, and Penn OC. The management of preexcitation syndromes. JAMA 1987; 257: 17, 2325-2333.

63. Josephson ME, and Harken AH. Surgical therapy of arrhythmias in "Cardlac Therapy". eds: Rosen MR, and Hoffman BF, Martinus Njhoff Publishers, The Hague, the Netherlands, 1983: $337-385$.

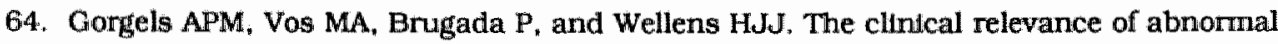
automatictty and triggered activity in "Cardlac Arrhythmias: Where to go from here ?" eds:" Brugada $\mathbf{P}_{\text {" }}$ and Wellens HJJ (eds), Mount Kisco NY. Futura Publishing Company Inc.* 1987: $147-169$.

65. El-Sherif N, Zetler RH, Craelius W, Gough WB, and Henkdn R. GT-prolongation and polymorphic ventricular tachycardilas due to bradycardia dependent early afterdepolarkations. Circ Res 1988; 63: 286-305.

66. Lelchter D, Danllo Jr. P, Boyden P, Rosen TS, and Rosen MR. A canine model of torsades de pointes. PACE 1988; 11:2235-2245.

67. Frame LH, Page RL, and Hoffman BF. Atrlal reentry around an anatomic barrier with a partially refractory excitable gap. Circ Res 1986; 58: 495-511 
68. Frame LH, Page RL. Boyden PA, Fenogllo J; and Hoffman BF; Circus movement in the canine atrium around the tricuspid ring during experimental atrial nutter and during reentry in vitro. Circulation 1987; 76: 1155-1175.

69. Karagueuzian HS, FenoglHo WJ, Weiss MB, and Wit AL. Protracted ventrlcular tachycardia Induced by premature stimulation of the canine heart after coronary artery occlusion and reperfusion. Circ Res 1979; 44: 833-846.

70. Michelson EL, Spear JF, and Moore EN. Electrophystologic and antomic correlates of sustained ventricular tachyarrhythmias in a model of chronic myocardial infarction. Arn $J$ Cardiol, 1980: 45: 583-590.

71. Wit AL, Allessie MA, Bonk FIM, Lammers W. Smeets J, and Fenoglio J. Electrophyslologic mapping to determine the mechanism of experimental ventricular tachycardia initiated by premature impulses. Experimental approach and Inittal results demonstrating reentrant excitation. Am J Candiol 1982; 49: 167-185.

72. Cardinal R, Savard P. Carson DL, Peryy JB, and Pagé P. Mapping of ventricular tachycardta induced by programmed stimulation in canine preparations of myocardial infarction. Circulation 1984; 70: 137-149.

73. Garan H. Fallon JT, Rosenthal S. and Ruskin JN. Endocardial, intramural, and epicardial activation patterns during sustained monomorphic ventricular tachycardia in late canine myocardial infarction. Circ Res 1987; 60: 879-897.

74. Coumel Ph, Cabrol P, Fabiato A, Gourgon R, and Slama R. Tachycardie permanente par rhythme reciproque. Arch Mall Coeur 1967; 60: 1830-1834.

75. Brugada P, and Wellens HuJ. Cardlac arrhythmlas: Where to go from here ? Futura Publishing Company Inc., Mount Kisco New York, 1987.

76. Josephson ME, Horowitz LN, Farshidl A, and Kastor JA, Recurrent sustained ventricular tachycardia, 1. Mechanism. Circulation 1978; 57: 431-441.

77. Brugada P, de Swart H. Smeets JLRM, and Wellens HJJ. Transcoronary termination of ventricular tachycardlas. Circulation 1989; 79: 475-483.

78. Brugada P. Lemery $R$, Talajic $M$, Della Bella $P$. and Wellens HJJ. Treatment of patlents with ventricular tachycardia or fibrillation: The first lesson of the Parallel study in "Cardiac arrhythmias Where to go from here?" eds: Brugada P, and Wellens HJJ Futura Publishing Company, Mount Kisco, New York, 1987: 457-470.

79. Rosen MR. Is the response to programmed electrical stimulation diagnostic of mechanisms of arrhythmilas ? Circulation 1986; 73: II 18-27. 
80. Dangman $\mathrm{KH}_{4}$ and Hoffman BF. The effects of single premature stimull on automatic and triggered thythms in isolated canine Purkinje flbers. Circulation 1985: $71: 813-822.81$. Moak .JP and Rosien MR Induction and termination of triggered acturity by pacting in Lsolated canine Purkinje fibers. Cinculation 1984; 69: 149-162.

82. Ferrier $\mathrm{G} \mathrm{R}_{4}$ Saunders $\mathrm{JH}_{\text {, }}$ and Mendez $\mathrm{C}$. A cellular mechanism for the generation of ventricular arrhythmias by acetylstrophantin. Circ Res 1973: 22: 600-609.

83. Dawts J, Glassman R, and Wit AL. Method for evaluating the effects of antiarrhythmic drugs on ventricular tachycardlas with different electrophystologic characteristics and different mechanisms in the infarcted canine heart. Am J Cardiol 1982: 49: 1176-1 184.

84. Brugada P, and Wellens HuJ. Early afterdepolarizations: role in conduction block. "prolonged repolarization dependent reexcitation", and tachyarrhythmias in the human heart. PACE, 1985; 8: 889-895.

85. Cranefleld PF, and Aronson RS. Torsade de polntes and other pause-Induced ventricular tachycardlas: The short-long-short sequence and early afterdepolartzations. PACE. 1988; 11: 670-678.

86. Lown $\mathrm{B}$, Cannon $\mathrm{RL}$, and Rossi M. Electrical stimulation and digitalis drugs: repetitive responses in diastole. Proc Soc Exp Blol Med 1967; 126: 698-701.

87. Zipes DP, Arbel E, Knope RF, and Moe GK. Accelerated cardiac escape rhythms caused by ouabain intoxication. Am J Cardiol 1974: 33: 248-253.

88. Wittenberg SM, Gandel $P_{n}$ Hogan PM, Kreuzer W, and Klocke FJ. Relationship of heart rate to ventricular automaticity in dogs during ouabain administration. Circ Res 1972; 30: $167-176$.

89. Gorgels APM, de Wit B, Beekman HDM, Dassen WRM, and Wellens HJJ. Triggered activity Induced by pacing during digitalis intoxication: observations durling programmed electrical stimulation in conscious dogs with chronic complete AV-block. PACE 1987; 10: 13091321 .

90. Malfatto G, Rosen TS, and Rosen MR. The response to over-drive pacing of triggered atrial and ventricular arrhythmias in the canine heart. Circulation 1988; $77: 1139-1148$.

91. Gorgels APM, Beekman HDM, Brugada P. Dassen WRM, Richards DA, and Wellens HJJ. Extrastimulus-related shortening of the first postpacing interval in digitalis-induced ventricular tachycardia: observations during programmed electrical stimulation in the conscious dog. J Am Coll Cardlol: 1983: 840-857. 
92. Gorgels APM. De Wit B, Beekman HDM, Dassen WRM, and Wellens HWd. Effects of different modes of stimulation on the morphology of the first QRS-complex following pacing during digitalis-induced ventricular tachycardia: observations in the conscious dog with chronic complete AV-block. PACE 1986; 9; 842-859.

93. Vanagt $\mathrm{EJ}$ " and Wellens $\mathrm{H} / \mathrm{J}$. The electrocardiogram in digitalls intoxication in "What's new in electrocardiography", eds: Wellens HJJ, and Kulbertus HE, Martinus Nyhoff Publishers, The Hague, The Netherlands, 1981: 315-343.

94. Brugada $\mathrm{P}$, and Wellens HJJ" The role of triggered activity in clinical arrythmias in "Frontiers of cardiac electrophysiology", eds: Rosenbaum M, and Elizar M, Martinus Nijhoff Publishers. The Hague. The Netherlands 1983: 195-216.

95. Wellens HJJ. Pathophysiology of ventricular tachycardia in man. Arch Int Med 1975; 135: $473-479$.

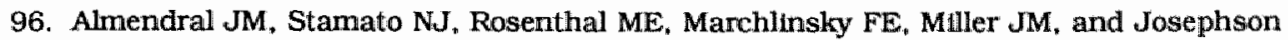
ME. Resetting response patterns during sustalned ventricular tachycardia: relationship to the excitable gap. Cinculation $1986 ; 74: 722-730$.

97. Waldo AL, Maclean WAH, Karp RB, Kouchoukos NT, and James TN. Entrainment and interruption of atrial flutter with atrial pacing. Studies in man following open heart surgery. Circulation 1977; 56: 737-45.

98. Okumura K, Olshansky B, Henthorn RW, Epstein AE, Plumb VJ, and Waldo AL. Demonstration of the presence of slow conduction during sustained ventricular tachycardia in man: use of transient entralnment of the tachycardia. Circulation 1987; 75: 369-375.

99. Waldo AL, Olshansky B, Okumura $K$, and Henthorn RW. Current prespective on entrain" ment of tachyarrhythmias. In "Cardiac arrhythmias; where to go from here?" "eds: Brugadia P. and Wellens HJJ. Futura Publishing Company, Mount Kisco, New York, 1987; 17 1- 189 ,

100. Brugada $P_{n}$ and Wellens HJJ. Entratnment as an electrophysiologic phenomenon. I Am Coll Cardiol 1984: 3: $451-454$.

101. Mary-Rabine L, Hordof $A J$, Danilo P Jr, Malm JR, and Rosen MR Mechanisms for impulse Initiation in isolated human atrial fibers. Circ Res 1980; 47: 267-277.

102.Allen JD, Brennan FJ, and Wit AL. Actions of lildocaine on transmembrane potentials of subendocardial Purkinje fiber surviving in infarcted canine heart. Circ Res 1978; 43: 470-481.

103. Dangman $\mathrm{KH}$, and Hoffinan BF. Antiarrhythmic effects of ethmozin in cardiac Purkinje flbers: Suppression of automaticity and abolition of triggering. $J$ Pharmacol Exp Therap 1983; $227: 578-586$. 
104. Imanish S, MoAlluster $\mathrm{RG}^{\mathrm{B}}$, and Surawicz $\mathrm{B}$. The effects of verapamil and lidocaine on the autornatic depolarizations in guinea pig ventricular myocardium. J Phamacol Exp Therap 1978: 207: $294-303$.

105. Rosen MR, and Danilo P. Effects of tetrodotoxin, lldocaine, verapamill and AHR-2666 on ouabain induced delayed afterdepolartzations in canine Purkinje fibers. Circ Res 1980; 46: $117-124$

106. Karagueuztan HS, and Katzung BG. Relative inotropic and arrhythmogentc effects of five cardiac sterolds in ventricular myocardium: osclllatory afterpotentials and the role of endogeneous catecholamines. J Pharmacol Exp Therap 1981; 218: 348-356.

107. Dangman $\mathrm{KH}$. Effect of procainamide on automatic and triggered impulse initiation in Isolated preparations of canine cardlac Purkinje flber. J Cardlovasc Pharmacol 1988; 12 : 78-87.

108. Endou K, Yamamoto H, and Sato TG. Comparison of the effects of calcium channel blockers and antlarthythmic drugs on digitalis induced ascillatory afterpatentials on canine Purkinje fiber. Jpn Heart J 1987: 719-735.

109. Hewett $K$, Gessman $L$, and Rosen MR. Effects of procainamide, quinidine, and ethmozin on delayed afterdepolartzations. Eur J Pharmacol 1983; 96: 21-28.

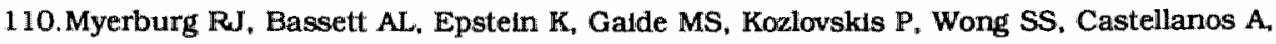
and Gelband $H$. Electrophysiological effects of procainamide $n$ acute and healed experimental ischemic injury of cat myocardium. Circ Res 1982; 50: 386-393.

111. Mason JW. Hondeghem LM, and Katzung BG. Block of unacttvated sodium channels and of depolarization-induced automaticity in guinea pig papillary muscle by amiodarone. Circ Res 1984; 55: $277-285$.

112. Ohta $M_{*}$ Karagueuzian HS, Mandel WJ, and Peter T. Acute and chronic effects of amlodarone on delayed afterdepolarkations and triggered automaticity in rabbit ventricular myocardium. Am Heart J 1987; 113: 289-295.

113. Amerinı S, GlottIA, and MuguelliA. Effect of verapamil and diltiazen on calcium dependent electrical activity in cardiac Purkinje fibers. Br J Pharmacol 1985; 85: 89-96.

114. Gough WB, Zeller $\mathrm{RH}_{\text {" }}$ and El-Sherif $\mathrm{N}$. Effects of nifedipine on triggered activity in 1-day-old myocardial infarction in dogs. Am J Cardiol 1984; 53: 303-306.

115. BInah 0 , Cohen IS, and Rosen MR. The effects of adriamycin on normal and ouabain tonic canine Purkinje and ventricular muscle flbers. Circ Res 1983; 53: 655-662. 
116. Hashimoto $\mathrm{K}$, Satoh $\mathrm{H}$. Shibuja $\mathrm{T}$, and Ima $\mathrm{S}$. Canine-effective plasma concentrations of antiarrhythmic drugs on the two-stage coronary ligation arrhythmta. J Pharmacol Exp Therap 1982; $223 ; 801-810$.

117. Bergey JL, McCallum JD. and Nocella K. Antlarrihythmic evaluation of verapamul, nifediptne, perhexdline and SKF 525-A in four canine models of cardlac arrhythmias. Eur J Pharmacol 1981; 70: 331-343.

118. Hashimoto $K_{1}$ Mitsuhash1 $H$, Aktyama $K$, and Komorl S. Do antl-arrhythmic drugs act on the site of abnormal impulse generation or act on normal myocardium. Jpn Circ J 1987; 51: 196-202.

119. Hoffman B, and Spinelli W. Pharmacological mechanisms in the treatment of arrhythmias due to $\mathbb{s}$ schemia and infarction. In "Lethal arrhythmias resulting from myocardial ischemia and infarction", eds: Rosen MR, and PaltIY. Kluwer AcademicPress, Boston 1989: 281 -291.

120. Feld GK, Venkatesh N, and Singh BN. Pharmacologic conversion and suppression of experimental atrial flutter differing effects of $\mathrm{D}$-sotalol, quinidine, and lidocaine and signiffcance of changes in refractoriness and conduction. Circulation 1986: 74: 197-204.

121. Wu KM, and Hoffman BF. Effect of procainamide and n-acetylprocainamide on atrial flutter: studies in vivo and in vitro. Cinculation 1987; 76: 1397-1408.

122. Rosenshtraukl LV. Anyukhovsky EP. Nesterenko W, Undrovimas AI, Shugushev KK, Portnoy VF, and Burnahev NA. Electrophysiologic aspects of moricizine HCL. Am J Cardiol $1987 ; 6: 27 \mathrm{~F}-34 \mathrm{~F}$.

123. Danilo P Jr, Langan W, Rosen MR, and Hoffman BF, Effects of the phentothlazine analog EN 313 on ventricular arrhythmlas in the dog. Eur J Pharmacol 1977; 45: 127-139.

124. Nattel $S_{n}$ Dawles $M$, and Mackenzle $G$. The antlarrhythmic efflcacy of amtodarone and desethylamladiarone, alone and in combination, in dogs with acute myocardial infarction. Circulation 1988: 77: 200-208.

125. Wellens HJJ, Băr FWMH, Lie KI, Düren DR, and Dohmen HJ. Elfect of procalnamide, propranolol, and verapamil on mechanism of tachycardia in patients with chronic recurrent ventricular tachycardia. Am J Cardiol 1977; 40: 579-585. 


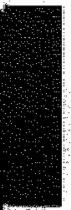


Significance of the number of stimuli to induce triggered arrhythmias in the intact heart

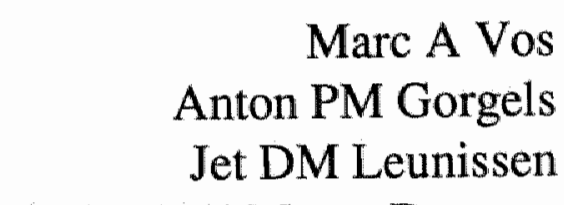
Roland TAM van Deursen Hein JJ Wellens

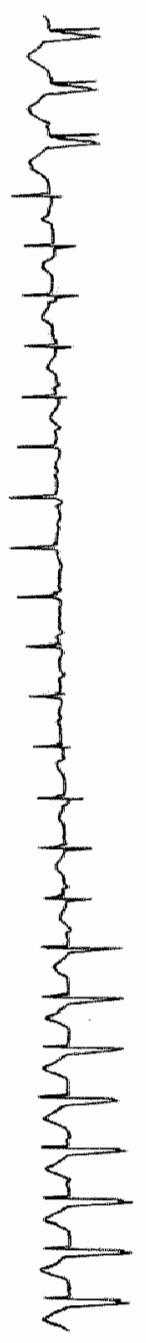




\title{
Significance of the number of stimuli to induce triggered arrhythmias in the intact heart
}

\begin{abstract}
Ouabain-Induced arrhythmias are a well known model to study triggered activity resulting from delayed afterdepolarizations. In the intact heart, initiation of these arrhythmias is promoted by pacing. especlally at fast rates. However, the relevance of the number of stimuli is unknown. In consclous dogs with formalin induced AV-block, we tnvestigated the effect of variations in pacing mode on: 1) the behavior of non-sustained triggered rhythms at progressive levels of ouabain intoxication, and 2) the induction of sustained ventricular tachycardila (VT).

A total of 20 experiments were analyzed. Ouabain was administered as a bolus of $40 \mu \mathrm{g} / \mathrm{kg}$ followed by continuous infusion. Every 15 minutes the pacing protocol was repeated, with a maximum of 10 , until completion or induction of VT. When VT could not be Initiated, the experiment was repeated at least one week later adding $5-10 \mu \mathrm{g} / \mathrm{kg}$ ouabaln to the bolus. This was repeated untu VT could be induced. Four interstimulus intervals: 200, 400,600, and 800 ms and seven different numbers of stimuli: $5,10,20,35,50,100$, and 150 were given in two pacing protocols. The effect of these protocols on: 1) the number of induced beats per stimulation-train, 2) their first postpacing interval, and 3) induction of VT were studied.

Initiation of VT occurred after $75 \pm 42 \mathrm{~min}$. The bolus of ouabain to induce VT was inversely related to the body weight of the animals. Progression of ouabain intoxication resulted in: 1) a significant increase in the number of induced beats per stimulation-train, and 2) a Significant shortening of the first postpacing interval. Stimulation with faster rate and/or more stimull resulted in: 1) a significantly pronounced increase in the number of induced beats at the higher levels, and 2) a significantly shorter first postpacing interval at successive levels of ouabain intoxication. As a result, induction of VT was more frequently observed following pacing with a high number of stimull ( $\geq 50$ stimull: $88 \%$ ), using short interstimulus intervals ( 5400 ms: $100 \%$ ).

In concluston, induction of VT in the presence of ouabain is promoted by pacing using shorter Intervals and a higher number of stimuli.
\end{abstract}




\section{INTRODUCTION}

During the last two decades, triggered activity resulting from delayed afterdepolarizations (DAD's) has received increasing attention as a mechanism responsible for cardiac arrhythmias (1). Usually, programmed electrical stimulation has been used for induction of triggered activity. Irrespective of the cause, e.g. ouabain or catecholamine-induced, pacing rate has been emphasized as an important factor to initiate arrhythmias resulting from DAD"s (2-4). Both in vitro and in vivo studies have shown that shortening of the interstimulus interval results in: 1) an increase in amplitude of DAD, 2) increased incidence, 3) shortening of the first postpacing interval, and 4) in an increased number of triggered beats postpacing (5-10).

The literature, however, is not unanimous on the effect of the number of stimuli on inducing triggered arrhythmias. It has been described that DAD"s induced by ouabain show an increase in amplitude on increasing the number of stimuli up to 10 , but a further increase did not seem to modify the attained $\mathrm{DAD}$-amplitude nor the length of the first postpacing interval (2). On the other hand, catecholamine-induced DAD's demonstrated an inverse relation between the number of stimuli and the first postpacing interval and a concordant rellation between the number of stimuli and the number of induced triggered beats (10).

To determine the relevance of the number of stimuli to induce triggered arrhythmias in the intact heart, we investigated the effect of different modes of pacing on: 1) the behavior of non-sustained triggered arrhythmias at progressive levels of ouabain intoxication, and 2) induction of sustained ventricular tachycardia (VT). For this purpose, conscious dogs with surgically induced AV-block were used. This model allows detailed study of ventricular impulse formation without interference by conducted sinus node impulses.

\section{METHODS}

\section{Preparation of study animals and methods of registration}

Mongrel dogs with a body weight between $15-37 \mathrm{~kg}$ (mean \pm SD: $25 \pm 6 \mathrm{~kg}$ ) were used. Through a right thoracotomy, complete atrio-ventricular block was induced by injecting formalin $37 \%$ in the region of the bundle of His (11). During this procedure two electrodes were fixed intramurally into the basal free wall of the right and the apex of the left ventricle. The electrodes were 
exteriorized through the skin of the neck. Proper care of the animals was taken during and following surgery according to the requirements of the American Society of Physiology.

All animals were studied in the conscious state without premedication. The experiments were performed after a recovery period of two weeks to avoid episodes of spontaneous ventricular tachycardias, which are known to occur after creation of AV-block (12-13). Six electrocardiographic leads and one local electrogram were simultaneously registered. Pacing was performed mostly on the right ventricle using a programmable stimulator having a synchronizing circuit. Unipolar stimuli were applied using a stimulus strength of twice dilastolic threshold. With a computerized QRS-complex detection system (14), values of R-R intervals were instantaneously displayed on a monitor screen. Before infusion of ouabain, all stimulation-trains used in the pacing protocol were given at least once under control conditions.

\section{Initiation protocol of ventricular tachycardia}

Ouabain was infused continuously $(0.072 \mu \mathrm{g} / \mathrm{kg} / \mathrm{min})$ following a loading dose of $40 \mu \mathrm{g} / \mathrm{kg}$ 1.v. administered in one minute (15). Stimulation was started 15 minutes after this loading dose. Because ouabain reaches a stable plasma concentration after approximately 30 minutes (15), the experiments in which VT occurred within this period were excluded for analysis. The complete stimulation protocol was given within 15 minutes and repeated maximally 10 times per experiment. When this protocol falled to induce VT, the experiment was repeated at least one week later using a larger loading dose of ouabain (increment of $5-10 \mu \mathrm{g} / \mathrm{kg}$ ) and a higher continuous infusion rate $10.090-$ $0.108 \mu \mathrm{g} / \mathrm{kg} / \mathrm{min}$ ) until VT was induced.

During pacing both the interstimulus intervals and the number of stimuli were varied. After each stimulation-train enough time (45 - 90 s) was allowed for recovery of the rhythm to the prepacing state. Two pacing protocols were used. In protocol A (designed to study the effect of changing the interstimulus intervall one set of 8 stimulation-trains with 4 different interstimulus intervals $(200,400,600$ and $800 \mathrm{~ms})$ were given using 10 or 50 stimuli. In protocol $B$ (designed to study the effect of changing the number of stimuli). 14 stimulation-trains were delivered using $5,10,20,35,50,100$, and 150 stimull with interstimulus intervals of 200 or $400 \mathrm{~ms}$. The sequence of stimulation-trains per set was random.

\section{Data analysis}

To quantify the effect of interstimulus intervals and number of stimuli, these parameters were related to: 1) the number of induced beats per stimulationtrain $_{*}$ 2) their first postpacing interval, and 3) the induction of sustained VT. For the purpose of this study an induced ectopic beat was defined as a 
QRS-complex having a first postpacing interval shorter than the last spontaneous idioventricular intervall prepacing. Ouabain-induced VT was defined as an arrhythmia having a cycle length shorter than $600 \mathrm{~ms}$ and consisting of at least 150 beats.

To correct for variation between dogs in their progression of ouabain intoxication, the time to onset of VT was given in 5 time periods consisting of $0-20 \%$. $20-40 \%, 40-60 \%, 60-80 \%, 80-100 \%$ of the time interval from the beginning of pacing to onset of VT. The data are presented using these 5 time periods.

Data concerning the effect of the four interstimulus intervals on inducing triggered rhythms in protocol $A$ were analyzed by taking the two number of stimuli together. Similarly, to compare the effect of the number of stimuli, the data of protocol B are presented in 4 groups: 5-10, 20-35, 50, and 100-150 stimuli without differentiating between the two interstimulus intervals used.

\section{Statistical analysis}

Analysis of variance (ANOVA) was used to investigate statistical significance between groups. When appropriate Student's t-test for (un)paired events was applied. Also, Chi-square testing was used to evaluate significance when data were expressed in percentages.

\section{RESULTS}

A total of 24 experiments, in which VT occurred, were analyzed. We had to exclude data from 4 animals because of spontaneous onset of VT (i.e. within 30 miutes after the bolus of ouabain was administered). In the 20 remaining experiments, VT was induced after $75 \pm 42 \mathrm{~min}$ of pacing (mean \pm standard deviation). In figure 1, an example of initiation of VT is presented. It is shown that using the same stimulation-train, progression of ouabain intoxication (expressed in time to onset VT and corresponding percentual level) results in: 1) an increase in number of induced beats per stimulation-train, and 2) a reduction of the first postpacing interval.

The dosage of ouabain needed to induce VT was body weight dependent: the lower the body weight, the higher the required dosage (figure 2). A mean bolus of $46 \pm 6 \mu \mathrm{g} / \mathrm{kg}$ of ouabain was administered.

Protocol A consisted of 407 stimulation-trains in 11 experiments, while 464 stimulation-trains were given in protocol B. Quantification of the findings led to the following results: 

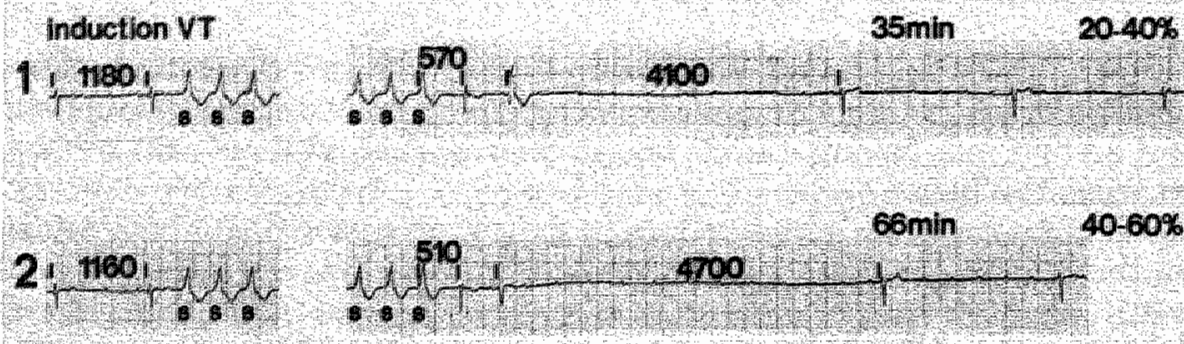

$4060 \%$
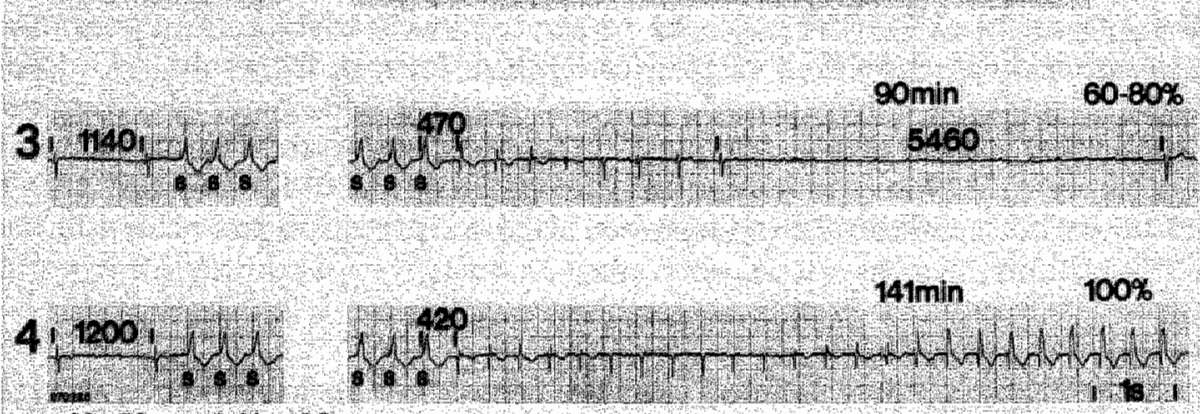

$\mathrm{nNa}, 50$

\section{V V $400 \mathrm{~ms}$}

Figure 1. Induction of ventricular tachycardia by ouabain infusion and electrical stimulation. Pacing (S) was performed from the basal part of the right ventricle using 50 stimuli and interstimulus intervals of $400 \mathrm{~ms}$. The four panels show progressive degrees of ouabain Intoxication as indicated by: 1) the time interval following ouabain administration and 2) the levell of intoxication, expressed by the percentual time to onset VT. In panel $1(20-40 \%)$, two triggered beats are Induced. The first postpacing interval measures $570 \mathrm{~ms}$. Following the second beat overdrive suppression is seen. At 40-60\% of time to VT (pane1 2), stimulation augain resulted in two triggered beats but with a shorter first postpacing interval of $510 \mathrm{~ms}$. As shown in panels 3 and 4 , there is a further reduction of the first postpacing interval and the number of induced beats increases (panel 3), resulting in induction of sustained ventricular tachycardia after 141 minutes (panel 4).

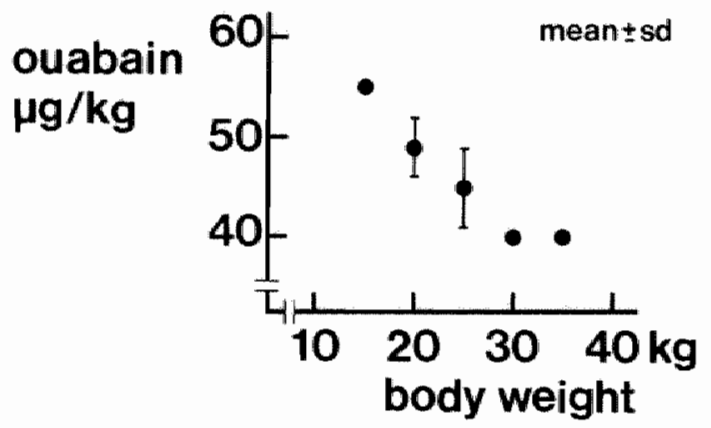

Figure 2. The bolus of ouabain required to induce ventricular tachycardias in relation to the body weight of the dogs.

On the vertical axis the bolus of ouabain is shown needed to induce ventricular tachycardia. Hortzontally the body weight of the animals is presented. It is shown that at higher body weights the bolus of ouabaln required to induce the arrhythmias is reduced. 


\section{The effect of ouabain intoxication on the idioventricular rhythm}

Directly following the bolus of ouabain, a marked increase in spontaneous $R-R$ cycle length of the idioventricular rhythm is noticed from $1310 \pm 330$ (control) to $1460 \pm 310 \mathrm{~ms}$ ( $\mathrm{p} \leq 0.001$ ). Thereafter a gradual decrease in spontaneous cycle length occurred to $1250 \pm 240 \mathrm{~ms}$ just before onset of VT (period $80-100 \%$ ), this value being not significantly different from the control value.

\section{The effect of progressive ouabain intoxication on the number of induced beats and the first postpacing interval.}

In tables $1-4$, the results of the two protocols on number of induced beats and length of the first postpacing interval are presented. Independent of the variations in pacing, ouabain intoxication (columns) resulted in: 1) a significant increase in number of induced beats per stimulation-trains (tables 1 and 3), and 2) a significant reduction in length of the first postpacing interval (tables 2 and 4). The only exception was pacing using an interstimulus interval of $800 \mathrm{~ms}$ (tables 1 and 2).

Table 1. The effect of shortening the interstimulus interval on the number of ectoplc beats per stimulation-train during progressive ouabain intoxication.

Interstimulus interval

$200 \quad 400 \quad 600 \quad 800 \quad$ ANOVA

\begin{tabular}{crrrrl} 
Time to VT (\%) & & & & & \\
$0-20 \%$ & $1.8 \pm 1.7$ & $2.3 \pm 2.1$ & $2.6 \pm 2.2$ & $1.9 \pm 1.1$ & NS \\
$20-40 \%$ & $3.7 \pm 7.6$ & $3.2 \pm 4.2$ & $2.6 \pm 1.7$ & $2.3 \pm 3.1$ & NS \\
$40-60 \%$ & $4.3 \pm 8.6$ & $3.0 \pm 2.5$ & $8.0 \pm 21.7$ & $2.2 \pm 1.3$ & NS \\
$60-80 \%$ & $9.0 \pm 9.3$ & $10.0 \pm 11.9$ & $10.5 \pm 13.8$ & $2.7 \pm 2.3$ & NS \\
$80-100 \%$ & $54.4 \pm 42.7$ & $54.0 \pm 39.2$ & $18.9 \pm 26.0$ & $4.8 \pm 3.0$ & $\mathrm{p} \leq 0.001$ \\
ANOVA & $\mathrm{p} \leq 0.001$ & $\mathrm{p} \leq 0.001$ & $\mathrm{p} \leq 0.05$ & $\mathrm{NS}$ & \\
\hline
\end{tabular}

mean \pm sd; NS = non significant; Time to $\mathrm{VT}=$ time interval in percentages to induce sustained ventricular tachycardia.; ANOVA = analysis of varlance 
Table 2. The effect of shortening the intersitimulus interval on first postpacing intervall during progressife ouabain intoxication.

\begin{tabular}{|c|c|c|c|c|c|}
\hline & \multicolumn{5}{|c|}{ Interstimulus interval } \\
\hline & 200 & 400 & 600 & 800 & ANOVA \\
\hline \multicolumn{6}{|c|}{ Time to VT $(\%)$} \\
\hline $0-20 \%$ & $790 \pm 250$ & $870 \pm 300$ & $1000 \pm 380$ & $1220 \pm 240$ & $\mathrm{p} \leq 0.001$ \\
\hline $20-40 \%$ & $620 \pm 170$ & $720 \pm 200$ & $850 \pm 160$ & $1100 \pm 120$ & $\mathrm{p} \leq 0.001$ \\
\hline $40-60 \%$ & $630 \pm 190$ & $670 \pm 200$ & $800 \pm 180$ & $1050 \pm 90$ & $p \leq 0.001$ \\
\hline $60-80 \%$ & $520 \pm 160$ & $560 \pm 100$ & $710 \pm 140$ & $1130 \pm 140$ & $p \leq 0.001$ \\
\hline $80-100 \%$ & $470 \pm 110$ & $480 \pm 90$ & $700 \pm 100$ & $1000 \pm 80$ & $\mathrm{p} \leq 0.001$ \\
\hline ANOVA & $\mathrm{p} \leq 0.001$ & $p \leq 0.001$ & $\mathrm{p} \leq 0.001$ & NS & \\
\hline
\end{tabular}

abbrevlations : see table 1

The effect of shortening the interstimulus interval in relation to different levels of ouabain intoxication.

Only at the highest level of ouabain intoxication (table 1, row $80-100 \%$ ), the number of induced beats per stimulation was found to be related to the interstimulus interval. At that level a reduction of the interstimulus interval from 800 to $200 \mathrm{~ms}$ resulted in an significant increase in the number of induced beats ( $p \leq 0.001)$.

The first postpacing interval (table 2) significantly reduced at all levels of intoxication ( $\mathrm{p} \leq 0.001$ ) on shortening the pacing intervals from 800 to 200 ms.

Induction of VT was also interstimulus interval dependent (p $\leq 0.001$ ). It was never observed following 600 and $800 \mathrm{~ms}$, but onlly after interstimulus intervals of 400 (in 6 out 11 experiments), and $200 \mathrm{~ms}$ (in the remaining 5 experiments).

\section{The effect of increasing the number of stimuli in relation to different levels of ouabain intoxication.}

Only at the higher levels ( $\geq 60 \%$ ) of ouabain intoxication, we observed a significantly more pronounced increase in number of induced beats per stimulation-train on increasing the number of stimuli from 5-10 to $100-150$ (table 3). 
Table 3. The effect of increasing the number of stimull on number of ectoplc beats per stimulation-train during progressive oulabain intoxication.

Number of stimuli

\begin{tabular}{llll}
\hline $5-10$ & $20-35$ & 50 & $100-150$
\end{tabular}

Time to VT $(\%)$

$\begin{array}{rrrrrl}0-20 \% & 1.6 \pm 1.0 & 1.4 \pm 0.5 & 1.6 \pm 1.0 & 2.1 \pm 2.1 & \text { NS } \\ 20-40 \% & 1.9 \pm 1.5 & 1.9 \pm 1.3 & 3.1 \pm 4.5 & 2.1 \pm 2.3 & \text { NS } \\ 40-60 \% & 1.8 \pm 0.9 & 3.1 \pm 3.5 & 4.1 \pm 2.9 & 4.7 \pm 6.1 & \text { NS } \\ 60-80 \% & 2.5 \pm 1.6 & 6.3 \pm 12.3 & 13.3 \pm 18.9 & 10.2 \pm 14.2 & \mathrm{p} \leq 0.05 \\ 80-100 \% & 12.8 \pm 18.9 & 22.3 \pm 22.0 & 46.0 \pm 33.2 & 58.4 \pm 31.9 & \mathrm{p} \leq 0.001 \\ \text { ANOVA } & \mathrm{p} \leq 0.001 & \mathrm{p} \leq 0.001 & \mathrm{p} \leq 0.001 & \mathrm{p} \leq 0.001 & \end{array}$

abbreviations: see table 1.

Table 4. The effect of increasing the number of stimuli on first postpacing interval during progresstve ouabain intoxication.

Number of stimuli

\begin{tabular}{llll}
\hline $5-10$ & $20-35$ & 50 & $100-150$
\end{tabular}

Time to VT $(\%)$

$\begin{array}{rrrlll}0-20 \% & 960 \pm 210 & 760 \pm 180 & 660 \pm 160 & 630 \pm 180 & \mathrm{p} \leq 0.001 \\ 20-40 \% & 1020 \pm 230 & 700 \pm 190 & 620 \pm 190 & 520 \pm 110 & \mathrm{p} \leq 0.001 \\ 40-60 \% & 920 \pm 200 & 600 \pm 160 & 500 \pm 80 & 500 \pm 90 & \mathrm{p} \leq 0.001 \\ 60-80 \% & 900 \pm 260 & 620 \pm 180 & 560 \pm 160 & 470 \pm 100 & \mathrm{p} \leq 0.001 \\ 80-100 \% & 730 \pm 270 & 530 \pm 120 & 480 \pm 120 & 480 \pm 130 & \mathrm{p} \leq 0.001\end{array}$

ANOVA $\quad \mathrm{p} \leq 0.001 \quad \mathrm{p} \leq 0.001 \quad \mathrm{p} \leq 0.05 \quad \mathrm{p} \leq 0.05$

Independent of the level of intoxication (table 4), It was found that the first postpacing interval of the triggered beats significantly decreased ( $p \leq 0.001)$, on increasing the number of stimuli from 5-10 to 100-150.

Initiation of VT was observed only once when pacing was performed with less than 50 stimuli, i.e. after 5-10 stimull. No difference was seen between the higher number of stimuli (following 50 stimuli in 4 of the 9 experiments, and after 100-150 stimuli in the remaining 4 experiments). So, induction of VT was dependent on the number of stimuli ( $p \leq 0.001$ ). 


\section{DISCUSSION}

It is known, that th can take several hours before ouabain induces ventricular arrhythmias in the intact heart (16). Pacing at faster rates can accelerate the occurrence of arrhythmias $(5,17-19)$ or will enable induction of tachycardias at lower dosages of glycosides (19). In this study, the relevance of the number of stimuli was investigated. It was found that similar to pacing with fast rates, an increase in the number of stimull resulted in: 1) a more pronounced increase in triggered beats (at the higher). 2) a shorter first postpacing interval (at successive levels of ouabain intoxication), and 3) induction of VT.

We used an animal model consisting of conscious dogs with chronic complete AV-block. This allows study of arrhythmias at the ventricular level, without interference of normally conducted sinus beats. Using our pacing protocol, it was found that the dosage of ouabain, required to induce VT, was inversely related to the body weight.

Several authors have quantified the significance of the pacing rate to induce DAD-dlependent arrhythmias in vitro $(2-4,6,8)$. In the intact heart, it was demonstrated that the concordant relation between the first postpacing interval and the interstimulus intervals was characteristic for triggered activity resulting from DAD's $(7,9,20-22)$. Also in this study this concordant relation was present and found to be independent of the level of ouabain Intoxication (table 2). The expected concomitant increase in number of induced beats on reducing the interstimulus interval was, however, only seen at high levels of ouabain in the period just preceding the induction of VT $(80-100 \%$, table 1$)$.

Another interesting finding was the effect of a high number of stimuli on inducing VT. In contrast to the rate of pacing, this variable has not been studied in the intact heart and rarely in vitro $(2,6,10)$. In ouabain-induced DAD's, an increase in amplitude of DAD's has been described for up to 10 stimuli (2). A further increase in the number of stimuli did not result in a higher incidence of the triggered beats nor in a shorter first postpacing interval. This is in contrast to a study by Wald et al. (10), who found that in catecholamine-induced DAD's increasing the number of stimuli resulted in: 1) a shorter first postpacing interval, and 2) an increase in number of induced beats. In our study, similar observations were made. Increasing the number of stimuli from 5-10 to 100-150 resulted in: 1) a more pronounced increase In the number of triggered beats, 2) a shorter first postpacing interval, and 3) increased likellhood to induce VT.

A possible explanation for the described discrepancies could be the variations in activation of the $\mathrm{Na}^{+} / \mathrm{K}^{+}$ATP-ase under these circumstances. Normally, pacing will result in overdrive suppression $(23,24)$. A (high) toxic dosage of ouabain will lead to inactivation of the $\mathrm{Na}^{+} / \mathrm{K}^{+}$ATP-ase, increased intracellular sodium concentration, intracellular calcium overload by the $\mathrm{Na}^{+} / \mathrm{Ca}^{2+}$ exchange, and the induction of DAD's and possibly triggered beats (25). It could very well be that the degree of inhibition of the $\mathrm{Na}^{+} / \mathrm{K}^{+}$ATP-ase in vitro 
markedly exceeds that ever attained in the intact heart. In support of this hypothesis is the fact that such observations as severe diastolic depolarization, impairment of conduction, and loss of excitability often seen in vitro as a result of ouabain intoxication, are not produced in vivo (1). It seems conceivable, therefore, that the number of paced beats will only be a decisive factor when the $\mathrm{Na}^{+} / \mathrm{K}^{+}$ATP-ase is only partially inactivated by ouabain. In the intact heart, additional factors may contribute to the initiation of triggered arrhythmias. Catecholamines or less specifically the activity of the autonomic nervous system have to be considered (26-27). This is supported by the observation that in anaesthetized dogs, the amount of ouabain (40-50 $\mu \mathrm{g} / \mathrm{kg}$ ) capable of initiating VT in our experiments only results in single ectopic beats $(19,26)$. It is in this setting that factors creating the greater burden for $\mathrm{Na}^{+} / \mathrm{K}^{+}$ATP-ase, such as higher number of stimuli, may be capable to induce (earlier) triggered beats and arrhythmias. The overdrive suppression still seen in our experiments after the induction of triggered beats (figure 1), is in agreement with the hypothesis, that the $\mathrm{Na}^{+} / \mathrm{K}^{+}$ATP-ase is still (partially) active.

When the above described model of triggered activity is more representative for the clinical situation, it opens new possibilities to apply electrical stimulation to identify mechanisms of arrhythmias, especially those leading to triggered activity resulting from DAD's. Our results indicate that the induction of a tachycardia following a (prolonged) acceleration in rate suggests a DAD-dependent arrhythmia, while the initiation by extrastimuli is in favor of reentry as the arrhythmogenic mechanism (28).

In conclusion, induction of VT in the presence of ouabain is promoted by pacing using shorter intervals and higher number of stimuli. 


\section{REFERENCES}

1. Craniefleld PF, and Aronson RS. Cardiac arrhythmias: the role of triggered activity and other mechanisms. Futura Publishing Company Inc, Mount Kisco, New York, 1988.

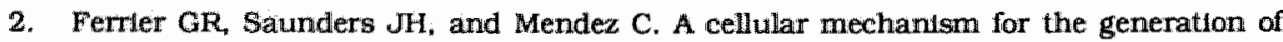
ventricular arrhythmlas by acetylstrophantidin. Circ. Res. 1973; 32: 600-609.

3. Wit AL; and Cranefield PF. Triggered activity in cardiac muscle fibers of the simian mitral valve. Clrc. Res: 1976; 38: 85-98.

4. Rosen MR, and Dantlo P. Effects of tetrodoxin, lldocaine, verapamil, and AHR-2666 on ouabain-induced delayed afterdepolarizations in canine Purkinje fibers. Circ. Res. 1980; 46: $117-124$.

5. Wittenberg SM, Gandel P, Hogan PM, Kreuzer W, and Klocke FJ. Relationship of heart rate to ventricular automaticity in dogs during ouabain administration. Circ. Res. 1972; 30: $167-176$.

6. Moak JP, and Rosen MR. Induction and termination of triggered activity by pacing in isolated canine Purkinje fibers. Circulation 1984; 69: 149-162.

7. LeMarec $\mathrm{H}$, Dangman $\mathrm{KH}$, Danilo $\mathrm{P}$, and Rosen MR. An evaluation of automatictity and triggered actwlty in the canine heart one to 4 days after myocardial infaretion. Circulation 1985; 71 : $1224-1236$.

8. Johnson N, Danilo P, Wit AL, and Rosen MR. Characteristics of initiation and termination of catecholamine-Induced triggered activity in atrial fibers of the coronary sinus. Circulation 1986; $74: 1168-1179$.

9. Gorgels APM, de Wit B, Beekman HDM, Dassen WRM, and Wellens HJJ. Triggered activity Induced by pacing during digitalis intoxdcation: observations during programmed electrical stimulation in the conslous dogs with chronic complete atrioventricular block. PACE 1987; 10: 1309-1321.

10. Wald RW, and Waxman MB. Pacing-induced automaticity in sheep Purkinje flbers. Circ. Res. 1981: 48: 531-538.

11. Steiner $C$, and Kovallk TW. A simple technique for production of chronic complete heart block in dogs. J. Appl. Physiol. 1968; 25: 631-632.

12. Vassalle $M$, Knob RE, Cummins M, Lara GA, Castro C, and Stuckey JH. An analysis of fast tdioventricular rhythm in the dog. Circ.. Res. 1977; 41: 218-226. 
13. Ivento JP. Provet J, Danilo P. and Rosen MR. Fast and slow idioventricular rhythms in the canine heart; a study of their mechanism using antiarrhythmic drugs and electrophysiologlc testung. Am. J. Cardiol. 1982; 49: 1909-1916.

14. Van der Steld A, Dassen W, Gorgels A, Beekman $H_{n}$ and Wellens H.J. Flexdble multiprocessor system to support electrophysiological investigation in animals. Computers in Cardiol. 1984: 525-528.

15. Rhee HM, Dutta S, and Marks BH. Cardlac Na/K ATP-ase activity during positive inotropic and toxic actions of ouabatn. Eur. J. Pharmacol. 1976; 37:141-153.

16. Vasalle $M$, Greenspan $K$, and Hoffman $B F$. An analysis of arrhythmilas induced by ouabain in tntact dogs. Circ. Res. 1963; 13: 132-148.

17. Davis LD. Effect of changes in cycle length on diastolic depolarization produced by ouabain In canine Purkinje fibers. Circ. Res. 1973: 32: 206-214.

18. Hagemejer $F$, and Lown $B$. Effect of heart rate on electrically Induced repetitive ventricular responses in the digltalized dog. Circ. Res. 1970: $27: 333-344$.

19. Wittenberg $S M_{n}$ Streuli $F$, and Klocke FJ. Acceleration of ventricular pacemakers by transient increases in heart rate in dogs during ouabain administration. Circ. Res. 1970; 26:705-716.

20. Gorgels APM, Beekman HDM, Brugada P, Dassen WRM, Richards DAB, and Wellens HJJ. Extrastimulus related shortening of the first postpacing interval in digitalis induced ventricular tachycardia. J. Am. Coll. Cardiol. 1984; 1: 840-857.

21. LeMarec H, Spinelli $W$, and Rosen MR. The effects of doxorubicine on ventricular tachycardia. Circulation 1986; $74: 881-889$.

22. Malfatto $G_{*}$ Rosen TS, and Rosen MR. The response of overdrive pacing of triggered atrtall and ventricular arrhythmlas in the cantne heart. Circulation 1988: 77: 1139-1148.

23. Lange G. Action of driving stimull from intrinsic and extrinstc souces on in situ cardlac pacemakers. Circ. Res. $1965 ; 17: 449-459$.

24. Vasalle $M$, Cummins $M$, Castro $C$, and Stuckey JH. The relattonship between overdrtve suppression and overdrive excitation in ventricular pacemaker in dogs. Circ. Res. 1976; 38: $367-374$.

25. Kass RS, Lederer WJ. Tslen RW, and Weingart R. Role of calctum ion in transtent inward currents and afterdepolarizations induced by strophantidin in cardlac Purkinje fibers. J. Physiol. 1978; 28: 187-208 
26. Kevanis LR, and Kelly RJ. Effect of autonomic neural blockade on verapamil-induced suppresstion of the acceleration ventricular escape beat in ouabain-treated dogs. J. Pharmacol. Exp. Therap. 1978; 206: 259-267.

27. Roberts J, Kellher GJ, and Lathers CM. Role of adrenergic influences in digitalis-induced ventricular arrhythmia. Life Sciences 1976; 18:665-678.

28. Wellens HUJ, Value and limitations of programmed electrical stmulation of the heart in the study and treatment of tachycardia. Circulation 1978; 57: 845-853. 
The effect of an entrainment protocol on ouabain-induced ventricular tachycardia

\author{
Marc A Vos \\ Anton PM Gorgels \\ Jet DM Leunissen \\ Pedro Brugada \\ Hein JJ Wellens
}




\title{
The effect of an entrainment protocol on ouabain-induced ventricular tachycardia
}

\begin{abstract}
Overdrive stimulation of reentrant ventricular tachycardias [VT) may result in entrainment and/or termination of these arrhythmias. We investigated whether surface ECG criteria of entralnment can also be observed in non-reentrant VT: ouabatn-Induced tachycardias which are considered to be based on delayed afterdepolarizations.

In 9 conscious dogs, having surglcally induced complete AV-block, pacing was performed using trains of 20 stimull from a site distant to the site of origin of the VT. The pacing intervals were shortened in steps of 5-10 ms untll complete capture from the pacing site or termination of the VT was obtained.

Durting stimulation varlable fusion was seen and complete capture of the ventricles from the pacing site accurred after just a slight decrease in pacing cycle length $(20 \pm 10 \mathrm{~ms})$. Overdrive stimulation resulted only in 1 out of 58 stimulation-trains in termination of VT. Following stimulation it was observed that: 1 ) the length of the first postpacing interval was significantly longer ( $\mathrm{p} \leq 0.001$ ) than both the mean prepacing VT cycle length and the interstimulus interval, 2) a change in QRS-configuration occurred after 57\% of the stimulation-trains, 3) the VT accelerated slightly in comparison to the prepacing rate ( $p \leq 0.05$ ), and 4) the length of the frst postpacing intervall and the mean $R-R$ interval of the VT postpacing were directly related to the interstimulus interval ( $r=0.82$ and 0.97 respectively).

In conclusion, overdrive stimulation of ouabain-induced arrhythmias did not result in entralnment nor in termination of the tachycardla. Instead other responses were seen that may be of help in differentlating between arrhythmias caused by delayed afterdepolarizations and reentry.
\end{abstract}

Presented at North American Society of Pacing and Electrophysiology, PACE 1988;

8: 154

Published in PACE 1989; 12: 1485-1493 


\section{INTRODUCTION}

Although many reentrant arrhythmias can be initiated and terminated by programmed electrical stimulation (1), arrhythmias based upon other mechanisms may show a similar response (2).

Therefore other criteria using programmed stimuli have been sought to differentiate between arrhythmogenic mechanisms. The possibility to transiently entrain a tachycardia suggests a reentry mechanism with an excitable gap (3-13). As pointed out by Waldo et al. (13) during transient entrainment all components of the tachycardia circuit are accelerated ("entrained") to the faster pacing rate, with resumption of the intrinsic rate of the tachycardia when stimulation is ceased. When the pacing site and the tachycardia exit site are located in different positions in the heart, pacing at different rates results in constant and progressive fusion between the paced and the tachycardia complexes except for the last captured beat which is entrained but not fused. Finally, at a critical pacing rate, the tachycardia will be interrupted.

During pacing phenomena other than transient entrainment can also occur. The site of origin of the tachycardia (whatever the mechanism of the arrhythmia) may not be penetrated at all by the paced stimuli (protected site of origin or "concealed perpetuation" of the tachycardia) (14). Secondly, the arrhythmia may be modulated but not transiently entrained by stimulation. Thus. while the observation of transient entrainment supports a reentry mechanism, failure to demonstrate transient entrainment does not mean that the arrhythmia is necessarily based upon a mechanism different from reentry. Interestingly, there are no studies addressing the reversed question, that is: Can a non-reentrant tachycardia show phenomena during electrical stimulation which fulfill the criteria for transient entrainment?

The present study was undertaken to study whether a non-reentrant arrhythmia: ventricular tachycardia (VT) caused by delayed afterdepolarizations due to digitalis intoxication (15-17) could be transiently entrained.

\section{METHODS}

Experiments were performed in 9 mongrel dogs of either sex having a body weight between $16-32 \mathrm{~kg}$. Through a right thoracotomy electrodes were fixed intramurally into the free wall of the right and the apex of the left ventricle. Atrio-ventricular block was induced by injecting formalin $37 \%$ in the region of the bundle of His (18). The experiments were performed after a recovery period of at least one week to avoid episodes of spontaneous VT which are 
known to occur during the early postoperative period (19). Six electrocardiographic leads and one local electrogram were simultaneously registered with an ink jet recorder (Siemens Elema).

\section{Induction of ventricular tachycardia}

A combination of ouabain and pacing was used to induce the VT. Electrical stimulation was performed with a programmable stimulator, having a synchronizing circuit. Unipolar stimuli were given with a stimulus strength twice the diastolic threshold.

Under control conditions, pacing was performed to register the paced QRSconfigurations. Trains of 10 and 50 stimuli were given using interstimulus intervals of $200,400,600$ and $800 \mathrm{~ms}$. This pacing protocol was repeated continuously after ouabain was administered. Ouabain was given intravenously as a bolus ( $45 \pm 6 \mu \mathrm{g} / \mathrm{kg}$ ) followed by a continuous infusion (20).

\section{Pacing protocol during ventricular tachycardia}

Pacing was performed from the site distant to the origin of the VT as assessed by the tachycardia configuration, i.e. from the right ventricle when the tachycardia emerged from the left ventricle and vice versa $(5,10)$. Trains of 20 stimuli were given, while the interstimulus interval was shortended in steps of 5-10 ms starting closely to the cycle length of VT, until complete capture of the ventricle was obtained or termination was observed. Thereafter this procedure was repeated once.

The following observations and measurements were made:

\section{Before stimulation}

1) The cycle length of the spontaneous VT by calculating the mean of 10 subsequent QRS-intervals before stimulation.

2) The gRS-configuration of the VT.

\section{During stimulation}

The QRS-complexes were classiffed according to their configuration:

1) Identical to the spontaneous ventricular rhythm in case the stimuli failed to capture

2) identical to the paced $Q R S$-complexes and

3) fusion between the spontaneous and paced beats.

\section{After stimulation}

1) The first postpacing QRS-configuration and its interval.

2) The rate of the VT with the same QRS-morphology as before pacing (mean of 10 subsequent QRS-intervals).

3) The occurrence of termination of the VT. 


\section{CONTROL}

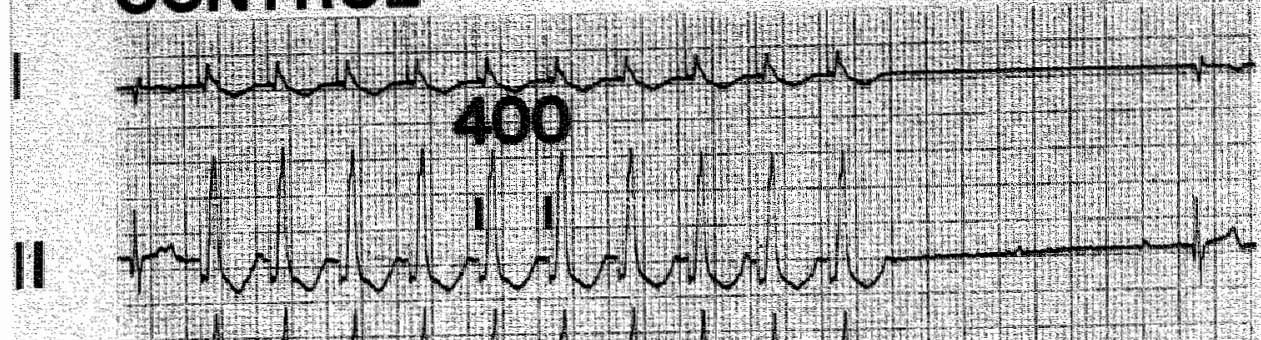

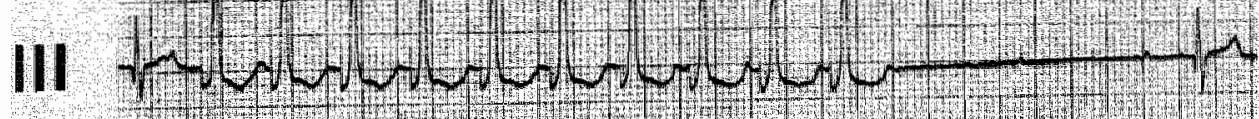

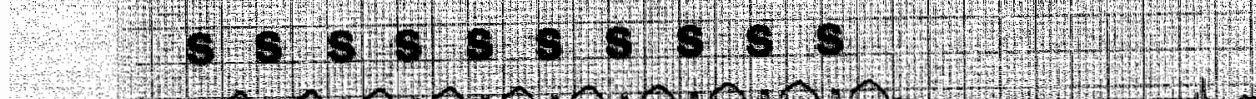

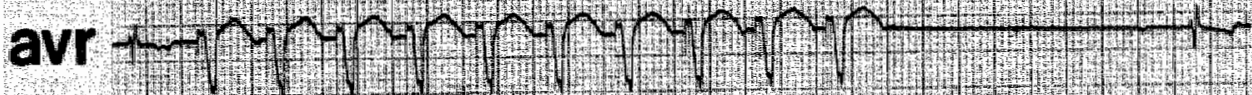

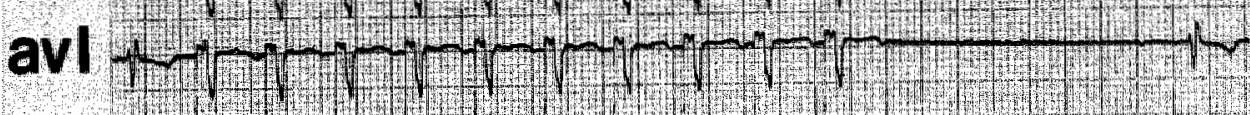
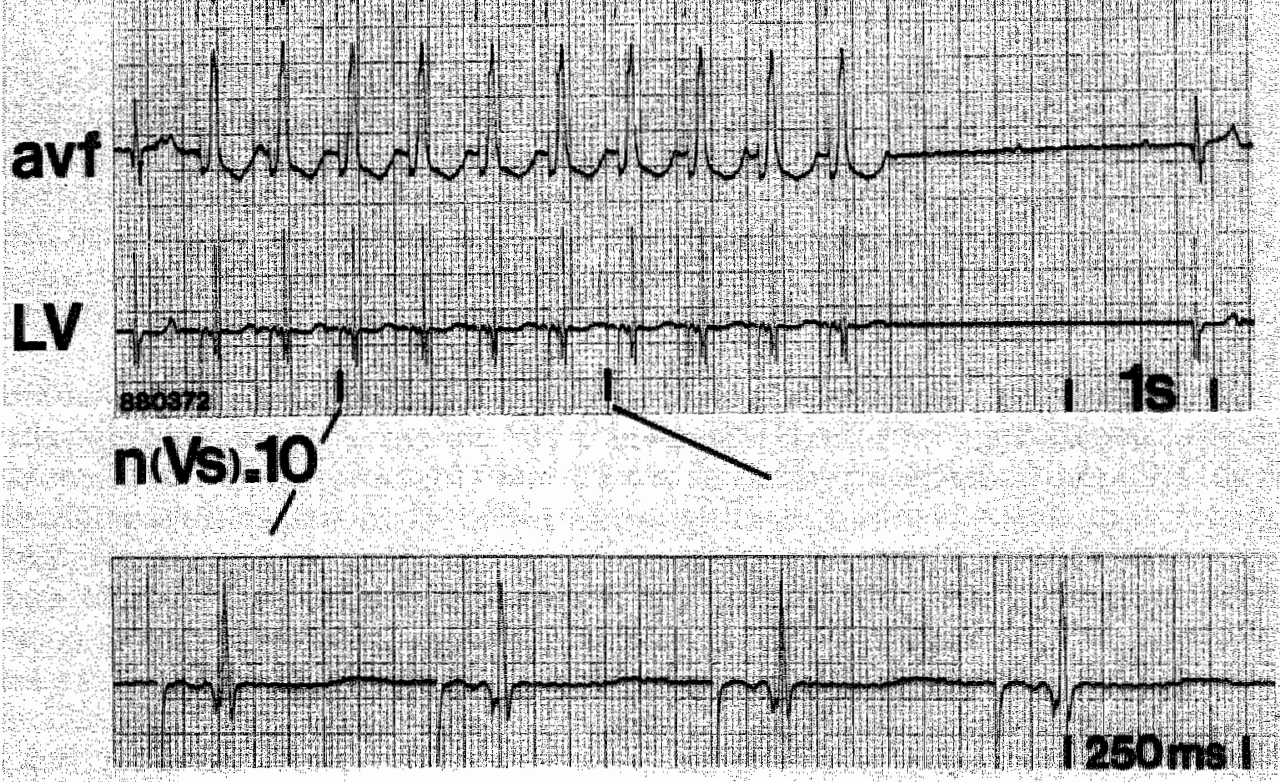

Figure 1. QRS-configuration during pacing before induction of a ventricular tachycardia (control).

Six surface ECG leads and a local electrogram at the left ventricular apex are recorded simultaneously. Paper speed is $25 \mathrm{~mm} / \mathrm{s}$ except for the bottom trace: Complete AV-block is present and the ventricular escape rhythm has a narrow gRS-complex. Pacing is done from the basal part of the right ventricle. Ten stimuli (S) are given with interstimulus intervals of $400 \mathrm{~ms}$. See text. 


\section{Statistics}

Student's $t$-test for paired events were performed when appropriate.

\section{RESULTS}

At the start of the stimulation procedure the spontaneous tachycardia cycle length in the 9 dogs was $390 \pm 70 \mathrm{~ms}$ (range $270-510 \mathrm{~ms}$ ). In 5 animals the QRS-conflguration suggested an origin in the basal part of the right ventricle. while in the other dogs the ectopic focus presumably was located near the apex of the left ventricle. A total of 58 stimulation-trains were given. In figure 1 the GRS-configuration of the paced gRS-complexes are shown during control conditions, i.e. without the presence of the VT. The paced QRS-complexes have a left bundle branch block pattern with intermediate electrical axis. The left ventricular apex electrogram shows activation $70 \mathrm{~ms}$ after the stimulus artefact.

Ouabain administration results in a VT with a R-R interval of $320 \mathrm{~ms}$. The results of pacing during VT using interstimulus intervals of 320,315 and 310 $\mathrm{ms}$ are shown in figure 2,3 and 4 , respectively. In figure 2 , stimulation induces continuous changes in QRS-configuration (variable fusion), probably due to simultaneous activation of the ventricles from the pacing site and the site of origin of VT. Following stimulation the original tachycardia continues at the same rate and the first postpacing interval is only slightly prolonged ( $340 \mathrm{~ms})$.

Variable fusion is also seen in figure 3 . In comparison to figure 2 there is more dominance of the ventricles by the pacing site (progressive fusion). Also the local left ventricular electrogram shows variable fusion. Only the QRS-configuration of the last paced electrogram is identical to the configuration in control conditions (figure 1) suggesting complete capture of the site of origin from the pacing site. After pacing the first postpacing interval is prolonged (380 ms) and a change in QRS-configuration is seen. This different QRS-complex remains during 10 beats after which the original VT resumes at its original rate.

Figure 4 shows again variable fusion in the first beats; thereafter both ventricles are dominated by the pacing site (see figure 1 for comparison). Also the site of origin of VT, is captured from the pacing site, as is suggested by the change in configuration of the local electrogram which is identical to the one in control conditions. Again the first postpacing interval is prolonged ( $380 \mathrm{~ms}$ ) and the first postpacing QRS-morphology is different. In addition, the original tachycardia accelerates slightly resulting in a mean cycle length of $310 \mathrm{~ms}$. The above described observations are typical for the response of ouabaininduced tachycardia to pacing. In none of the 9 experiments was constant 


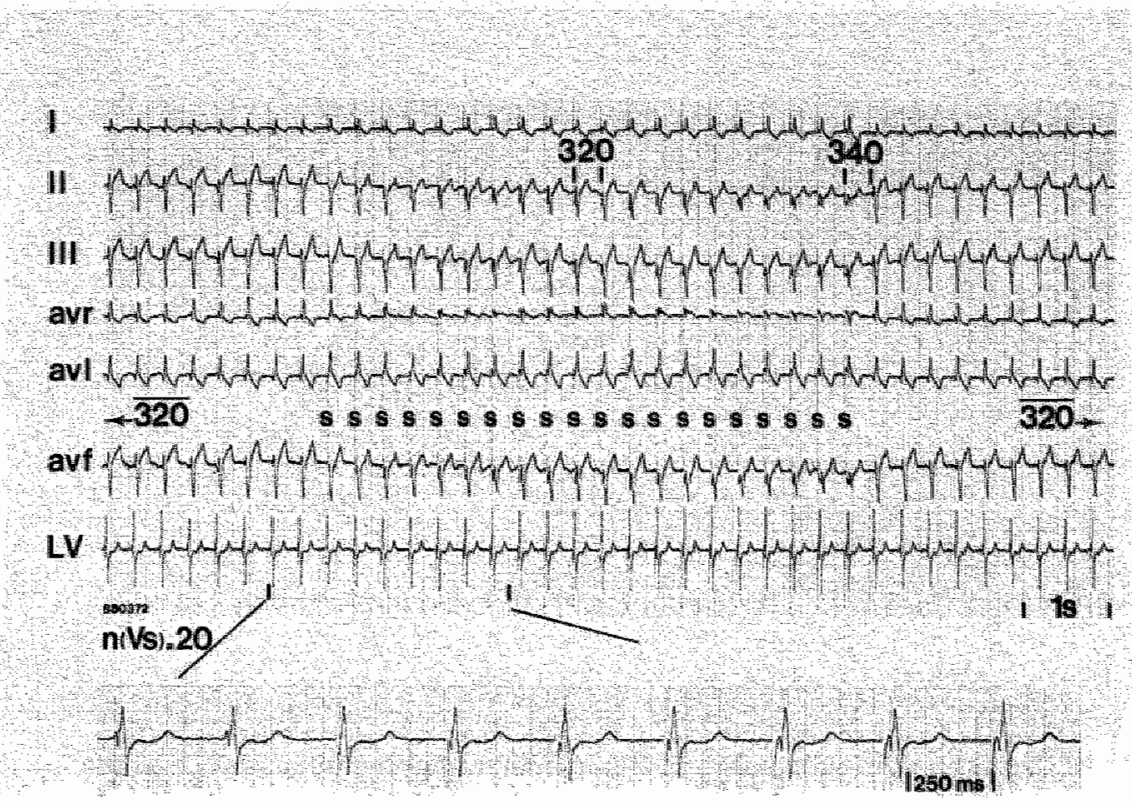

Figure 2. The effect of overdrive stimulation on ouabain-Induced ventricular tachycardia (VT). Figure is arranged similarly to figure 1 . The mean cycle length before stimulation equals 320 ms. Pacing is done from the basal part of the right ventricle. Twenty stimull are given using an interstimulus intervals of $320 \mathrm{~ms}$. During pacing variable fusion is seen. The first postpacing interval $(340 \mathrm{~ms})$ is slightly longer than the prepacing and the interstimulus intervals. Following stimulation the original VT resumes. See text.

fusion observed during overdrive stimulation. Instead, variable fusion was seen with complete capture of the tachycardia focus after only a slight decrease in pacing intervals $(20 \pm 10 \mathrm{~ms})$. The mean cycle length of VT before stimulation was $360 \pm 60 \mathrm{~ms}$. Complete dominance of the spontaneous tachycardia by the pacing site was achieved at $340 \pm 60 \mathrm{~ms}$, being 0.94 of the spontaneous VT before stimulation.

After pacing the following results were obtained: 1) the first postpacing interval was $400 \pm 80 \mathrm{~ms}$ being significantly longer than the spontaneous tachycardia cycle length ( $360 \pm 60 \mathrm{~ms}, \mathrm{p} \leq 0.001), 2)$ a direct relation was found $(r=0.82)$ between the first postpacing interval and the interstimulus interval (figure 5 , left panel): decreasing the pacing cycle length resulted in shortening of the first postpacing interval, 3) the temporary induction of QRS-complexes with a different configuration than the spontaneous tachycardia in $33(57 \%)$ of the stimulations (figure 4$), 4$ ) the cycle length of VT decreased from $360 \pm 60$ to $350 \pm 70 \mathrm{~ms}$ ( $p \leq 0.05$ ). This acceleration continued after every stimulation-train resulting in a decrease in cycle length from $390 \pm 70 \mathrm{~ms}$ before the pacing procedure had started to $340 \pm 60$ (p s $0.001)$ after completion of the stimulation protocol, 5) the mean cycle length 


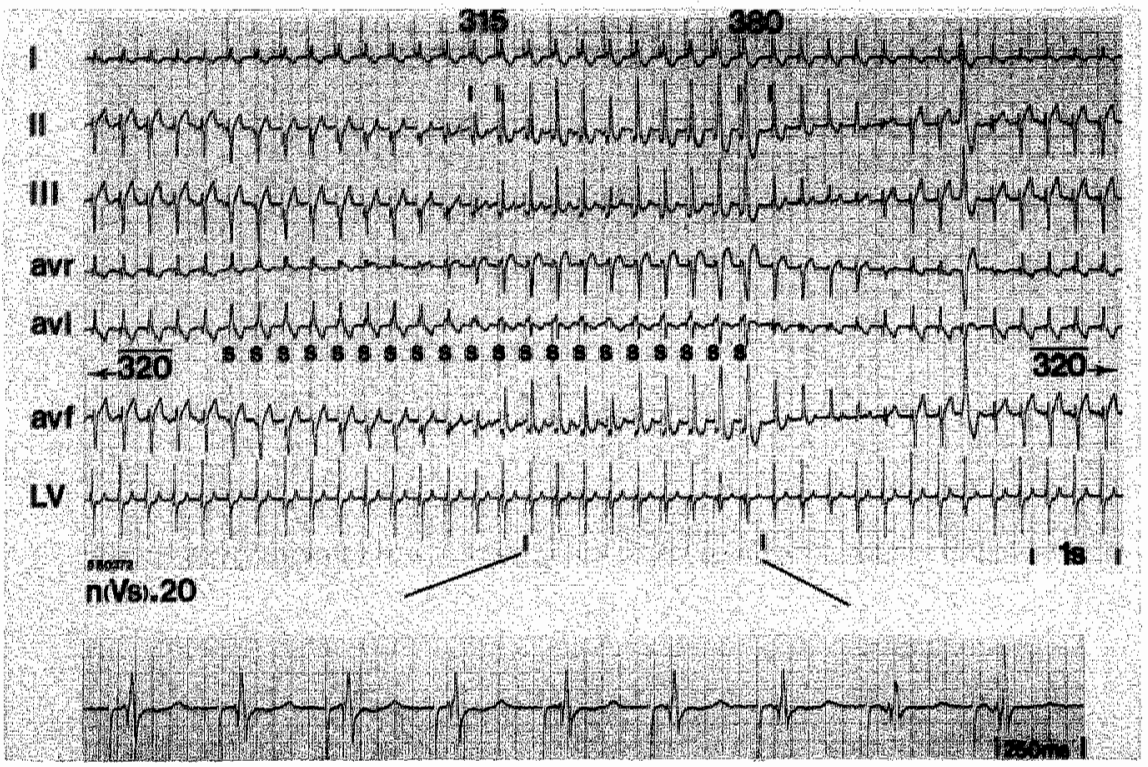

Figure 3. Overdrive stimulation diuring VT with interstimulus intervals of $315 \mathrm{~ms}$.

Again variable fusion is seen. At the end of stimulation the pacing site dominates ventricular activation. After pacing the first postpacing interval is prolonged [ $380 \mathrm{~ms}$ ] and a (temporary) change in GRS-configuration is seen, untll the original VT regalins control of ventricular activation. See text.

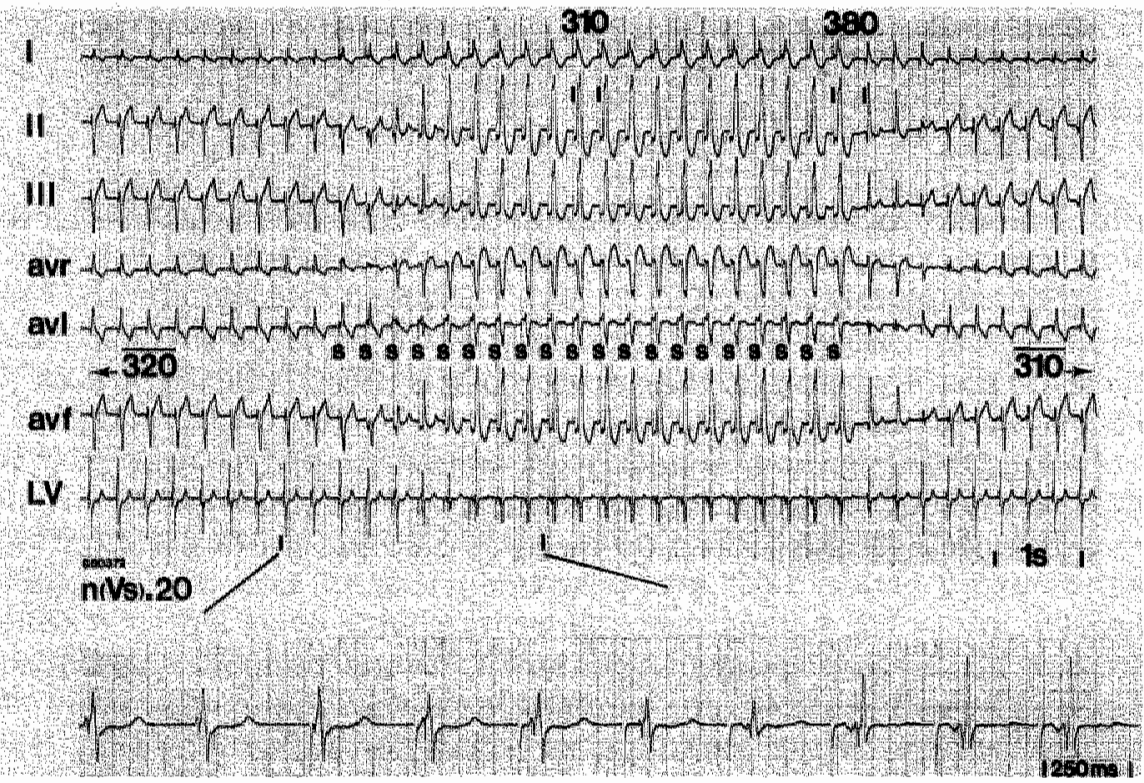

Figure 4. Overdnve stimulation during VT with interstimulus intervals of $310 \mathrm{~ms}$.

Now the pacing site dominates ventricular activation already from the $7^{\text {th }}$ sttmulus. Only the first beats show vartable fusion. The first postpacing interval is prolonged $(380 \mathrm{~ms})$ and a different $\mathrm{QRS}$-morphology is seen following pacing. The original VT accelerates slightly resulting in a mean cycle length of $310 \mathrm{~ms}$. See text. 


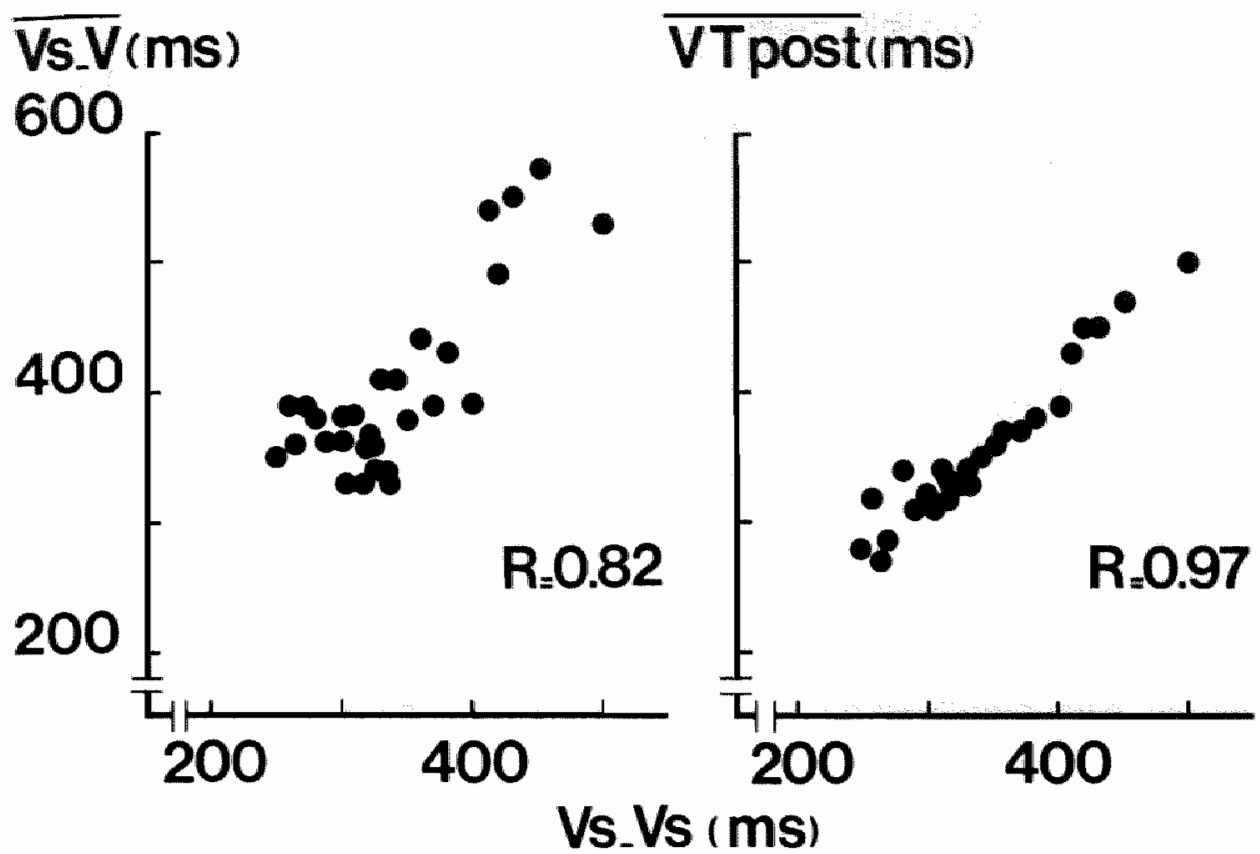

Figure 5. Relation between the interstimulus interval (Vs-Vs on the horizontal axis) and the first postpacing interval (Vs-V in left panel) and the mean cycle length of VT postpacing (VT post in right panell).

Both variables ane directly related to the interstimulus interval. See text.

of VT postpacing was directly related $(r=0.97)$ to the interstimulus interval (figure 5, panel 2), and 6) overdrive stimulation resulted only once in termination of the VT.

\section{DISCUSSION}

This study was performed to evaluate the response to overdrive stimulation of tachycardias which are likely based on delayed afterdepolarizations (15$17,21)$. A pacing protocol was applied which is frequently used to demonstrate transient entrainment (3-13).

Constant fusion was difficult, if ever, demonstrable. Fusion was varlable because of beat to beat variation in ventricular activation when the paced activation failed to enter the site of origin of the tachycardia. The other possibility was that capture of the site of origin of VT resulted in modification 
in spontaneous VT cycle length. Once the tachycardia focus was captured, fusion was no longer observed, but the QRS-complexes and the electrogram near the site of origin were completely determined by the pacing site. This already occurred using interstimulus intervals $10 \mathrm{~ms}$ shorter than the cycle length of the spontaneous VT (figure 4 , and 5). This is in contrast to the interval range (entrainment zone) at which reentrant tachycardias can be entrained $(4,8-11)$.

The events following pacing also revealed modification of the original tachycardia. The duration of the first postpacing interval was significantly longer than the R-R interval of the original tachycardia. In addition, following stimulation different $\mathrm{QRS}$-complexes were frequently induced, having a configuration suggesting fusion between activation from the pacing site and the original VT morphology. These findings which have been discussed previously in detall by our group (16) are different from the behavior of reentrant tachycardias. The change in QRS-configuration is likely to be explained by the induction of a new VT by the stimulation procedure while the original VT also continues. We have previously described (16), that the configuration of the postpacing QRS-complexes is dependent on the interstimulus interval and the number of stimuli: the faster and the longer the stimulation-train the more the QRS-configuration becomes similar to the paced QRS-complex. The relatively slow pacing rates $(0.94 \pm 0.05 \times$ VT pre) used in this study may explain why in only $57 \%$ of the stimulation-trains different $\mathrm{QRS}$-complexes were seen. So, entrainment could not be observed in ouabain-induced tachycardias.

It should be noticed that this behavior of the QRS-configuration is typical for global intoxication of the heart. Whether it will occur when delayed afterdepolarizations only arise in localized areas in the heart remains questionable.

Overdrive stimulation did, however, result in responses which we consider to be specific for triggered activity resulting from delayed afterdepolarizations. The progressive shortening of the first postpacing interval on decreasing the interstimulus interval (figure 5) has been described as such (17,21). Due to the AV-block, we were able to study the behaviour of the VT without interference of the sinus rhythm. This allows accurate assessment of termination or perpetuation of VT. That we could not terminate VT by overdrive stimulation was a new observation. Instead overdrive acceleration of the original VT was the rule. This decrease in $R-R$ interval remained until a new, shorter pacing interval accelerated the tachycardia even further. Also the response of the cycle length of the tachycardia to reductions in interstimulus intervals was similar to that of the first postpacing interval (figure 5). Both observations are in contrast to reentrant tachycardias and may be useful to differentiate between both arrhythmogenic mechanisms.

Fallure to terminate VT is also in contrast to results of in vitro experiments (22), in which tachycardia could be terminated in up to $89 \%$ of the stimulation-trains. Several aspects may explain these differences. First, the mean VT cycle length in the in vitro study was longer than in our study. Secondly, the high success rate of termination in vitro was achieved using overdrive pacing 
for 15 and $60 \mathrm{~s}$ at cycle lengths less or equal to $300 \mathrm{~ms}$. We also used such fast pacing rates in 17 stimulation-trains $(30 \%)$ although our duration of pacing was shorter. More recently, we stimulated ouabain-induced VT at rates up to twice as fast as the rate of the arrhythmias using durations of 15 , 60 and $120 \mathrm{~s}$ (23). Still we were not able to terminate these arrhythmias. Instead overdrive acceleration was again observed, now even more pronounced. Third, in our experiments in the intact heart frequently a new VT was induced originating more closely to the stimulation site. This new VT may have been involved in reinitiation or perpetuation of the original VT. Finally, overdrive stimulation may result in a blood pressure drop and a subsequent increase in sympathetic tone leading to acceleration instead of termination of VT. Certainly, further study is required to unravel the different components involved in the continuation of ouabain-induced VT following overdrive stimulation.

In conclusion, overdrive stimulation of delayed afterdepolarizations induced tachycardias did not result in entrainment nor in termination. Instead specific responses were observed which could be of help in the differentiation of arrhythmias caused by delayed afterdepolarizations and reentry. 


\section{REFERENCES}

1. Wellens HUJ. Value and limitations of programmed electrical stimulation of the heart in the study and treatment of tachycardia. Circulation $1978 ; 57: 845-853$.

2. Wit AL, Wigglins JR, and Cranefield PF. Some effects of electrical stimulation on impulse Initiation in cardlac fibers; its relevance for the determination of the mechanisms of clinical cardiac arrhytmilas. In: "The conduction system of the heart", eds: Wellens HJJ, Lle KJ, and Janse MJ, Stenfert Kroese Leiden 1978; 9: 163-181.

3. Waildo AL, Maclean WAH, Karp RB, Kouchoukos NT, and James TN. Entrainment and interruption of atrial flutter with atrial pacing. Studies in man following open heart surgery. Circulation $1977 ; 56: 737-745$.

4. Brugada $P$, Waldo $A$, and Wellens HJJ. Transient entralmment and interruption of atrloventricular node tachycardla. J Am Coll Cardiol 1987; 9: 769-775.

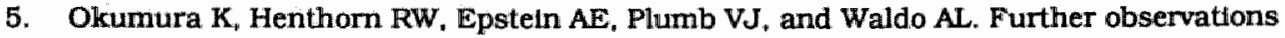
In translent entrainment: Importance of pacing site and properties of the components of the reentry circult. Circulation 1985; 72: 1293-1307.

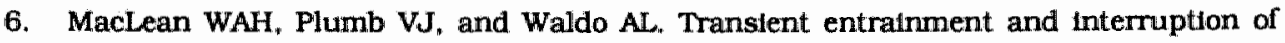
ventricular tachycardia. PACE 1981; 4"."358-366.

7. Anderson KP, Swerdlow CD, and Mason JW. Entrainment of ventricular tachycardia. Am J Cardilol 1984; 54: 335-340.

8. Okumura K, Olshansky B. Henthorn RW, Epstein AE, Plumb VJ, and Waldo AL. Demonstration of the presence of slow conduction during sustatned ventricular tachycardia in man: use of transient of entrainment of the tachycardia. Circulation 1987; 75: 369-378.

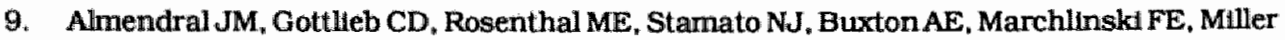
$\sqrt{ } \mathrm{M}$, and Josephson ME. Entrainment of ventricular tachycardia: explanation for surface electrocardiographic phenomena by analysis of electrograms recorded within the tachycardta circuit. Circulation 1988; 72: 569-580.

10. Mann DE, Lawric GM, Luck JC, Grifnn JC, Magro SA, and Wyndham CRC. Importance of pacing site in entralnment of ventricular tachycardia. J Am Coll Cardiol 1985; 5: 781-787.

11. Kay NG, Epstein $\mathrm{AE}$. and Plumb VJ. Incidence of reentry with an excitable gap in ventricular tachycardia: a prospectic evaluation utllizing transient entrainment. J Am Coll Cardiol 1988; $11: 530-538$.

12. Brugada P, and Wellens HJJ. Entratnment as an electrophysiologtc phenomenon. J Am Coll Cardiol $1984 ; 3: 451-454$. 
13. Waldo AL, Olshansky B, Okumura $\mathrm{K}$, and Henthorn RW. Current prespective on entrainment of tachyarrhythmias. In "Cardiac arrhythmias; where to go from here?", eds Brugada P, and Wellens HJJ, Futura Publishing Company Inc., Mount Kilsco, New York, 1987; 171-189.

14. Josephson ME, Horowitz LN, Farshidi A, and Kastor JA. Sustalned ventricular tachycardia: evidence for protected localtzed reentry. Am J Cardiol 1978; 42: 416-424.

15. Rosen MR, Gelband HM, and Hoffman FB. Correlation between effects of ouabain on the canine electrocardiogram and transmembrane potentlals of isolated Purkinje fibers. Circulation $1973 ; 47: 65-72$.

16. Gorgels APM, de WIt B, Beekman HDM, Dassen WRM, and Wellens HJJ. Effect of different modes of stimulation on the morphology of the first QRS-complex following pacing during digitalis induced ventricular tachycardia. PACE 1986; 9: 842-859.

17. Gorgels APM" de Wit B, Beekman HDM, Dassen WRM, and Wellens HuJ. Triggered activity Induced programmed electrical stimulation in the consclous dog with chronic complete atrioventricular block. PACE 1987; 10: 1309-1321.

18. Steiner C, and Kovallk TW. A single technique for production of chronic complete heart block in dogs. J Appl Physiol 1968; 25: 632-633.

19. Ilvento JP, Provet J, Danilo P, and Rosen MR. Fast and slow idioventricular rhythms in the canine heart; a study of their mechanism using antiarrhythmilc drugs and electrophysiologic testing. Am J Cardiol 1982; 49: 1909-1916.

20. Rhee HM, Dutta $S$, and Marks BH. Cardiac $\mathrm{Na}^{+} / \mathrm{K}^{+}$ATP-ase activity during positive inotroplc and toxic actions of ouabain. Eur J Pharmacol 1976; 37; 141-153.

21. Gorgels APM, Beekman HDM, Brugada P. Dassen WRM, RIchards DAB, and Wellens HJJ. Extrastimulus related shortening of the first postpacing interval in digitalis induced ventricular tachycardia. J Am Coll Cardiol 1983; 1: 840-857.

22. Moak JP. and Rosen MR. Induction and termination of triggered activity by pacing in isolated camine Purkinje fibers. Circulation 1984; 69: 149-162.

23. Vos MA, Leunissen HDM, Van Deursen RT, Gorgels APM, and Wellens HJJ. Stimulation during ouabain-Induced ventricular tachycardia in the intact heart does not result in termination but in acceleration. Circulation 1988; 78: 157 (abstract). 


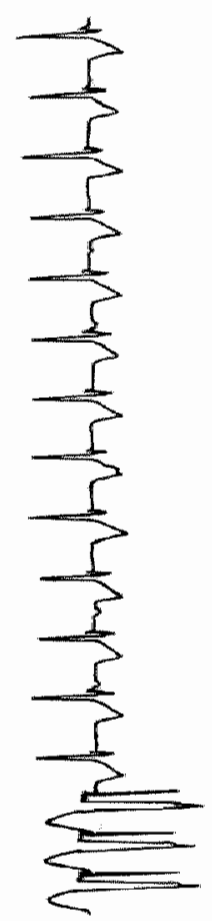

\title{
The in vivo response of ouabain- induced arrhythmias to pacing: acceleration instead of termination
}

\author{
Marc A Vos \\ Anton PM Gorgels \\ Jet DM Leunissen \\ Hein JJ Wellens
}

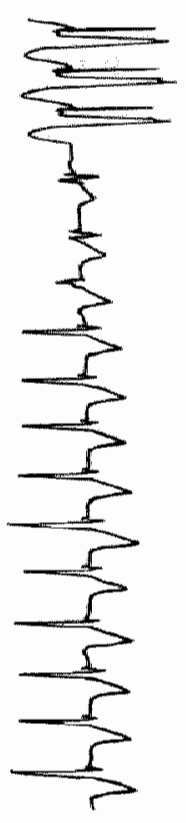




\title{
The in vivo response of ouabain-induced arrhythmias to pacing: acceleration instead of termination
}

\begin{abstract}
In vitro, arrhythmias resulting from triggered activity based on delayed afterdepolarizations can reproductbly be terminated by pacing. We studied the effect of similar pacing protocols on ouabain-induced ventricular tachycardia (VT) in the intact canine heart.

The experiments were performed in consclous dogs having surgically induced AV-block. The pacing protocol included 1, 2, or 20 stimuli, and also continuous stimulation during 15, 60 . and $120 \mathrm{~s}$ with interstimulus intervals varying between 500 and $200 \mathrm{~ms}$. A total of 331 stimulation-trains were given. The cycle length of the ouabaln-Induced VT was compared before and after pacing.

The mean R-R interval of the induced VT was $380 \pm 80 \mathrm{~ms}$. Termination wras only observed In $3 \%$ of the pacing experiments and was not reproducible. The common response to pacing was a shortening in cycle length of VT resulting in R-R intervals of $300 \pm 50 \mathrm{~ms}$ ( $\mathrm{p} \leq 0.001$ ). Acceleration was dependent on duration of stimulation. A decrease in the interstimulus Interval resulted in shortening of both the first postpacing interval and the cycle length of $\mathrm{VT}$ postpacing. These concordant relattlons were independent of the pacing modes.

In conclusion, pacing of ouabain-Induced VT in the intact heart rarely results in termination of the arrhythmla. Acceleration of VT is the rule. This finding may be of help in differentlating triggered activity resulting from delayed afterdepolarizations from other arrhythmogenic mechanisms.
\end{abstract}

Presented at the American Heart Association, Cinculation 1988; $78: 157$.

Submitted for publication. 


\section{INTRODUCTION}

In vitro, triggered activity resulting from delayed afterdepolarizations (DAD's) has been investigated extensively (1-2). It remains difflcult, however, to identify this arrhythmogenic mechanism in clinical arrhythmtas (3). Several diagnostic methods have been used, including: 1) programmed electrical stimulation (4-5), 2) antiarrhythmic drugs (6-7), and 3) monophasic action potentials using suction electrodes (8-9). Unfortunately, no clinical diagnostic method has emerged to identify with certainly the tachycardias resulting from triggered activity based on DAD's.

During programmed electrical stimulation, differentiation is not possible because arrhythmias resulting both from reentry and triggered activity induced by DAD's can reproducibly be initiated and terminated by extrastimuli and/or overdrive stimulation $(5,10)$. The evidence that DAD's-induced arrhythmias can be terminated is based upon observations in isolated tissues exposed to ouabain (11) or catecholamines (12-13). Quantification of this response in vitro (14-15) showed that termination is dependent on the duration and rate of stimulation: the longer and faster the pacing trains, the greater the chance that the tachycardias will stop.

Recently, we noticed in conscious dogs having AV-block that ouabain-induced ventricular tachycardias (VT) could hardly be terminated by a pacing protocol using 20 stimuli and interstimulus intervals slightly shorter than the cycle length of the tachycardia (16). Ouabain-induced arrhythmias are likely based on triggered activity resulting from DAD's (17-20). Because this protocol differed markedly from the one succesfully used in vitro, we considered this a possible reason for the observed difference. Especially, because long and fast stimulation-trains were not used previously, we decided to perform a new study, in which we compared the response of ouabain-induced VT to the pacing protocols applied in vitro.

\section{METHODS}

Through a right thoracotomy chronic atrio-ventricular block was produced in all animals by injecting formalin $37 \%$ in the region of the bundle of His (21). Anaesthesia was achieved by administration of premedication followed by sodium pentobarbital ( $20 \mathrm{mg} / \mathrm{kg}$ iv). Two unipolar electrodes were sutured on the epicardium: one upon the basal part of the right ventricle and the other on the left ventricular apex. The electrodes were exteriorized through the neck, allowing recording and stimulation from two different sites. The ani- 
mals were investigated at least two weeks after the creation of atrio-ventricular block. This period of rest was considered necessary to avoid episodes of spontaneous VT, which often occur during the early postoperative period after creating AV-block $(6,22)$.

Twenty-four experiments were performed in conscious, non-sedated dogs. During these experiments, six electrocardiographic leads and one epicardial lead were registered simultaneously. The dogs had a body weight between 16 and $37 \mathrm{~kg}$ (mean $\pm \mathrm{SD}: 26 \pm 5 \mathrm{~kg}$ ). Electrical stimulation was done using a programmable stimulator having a synchronizing circuit. A computerized QRS-complex detecting system was used enabling a continuous display of the $R-R$ intervals on a monitor (23). This allowed instantaneous observation of changes in heart rate.

\section{Induction of ventricular tachycardia}

Ventricular tachycardia was induced by a combination of ventricular pacing and ouabain. Unipolar pacing stimuli of $2 \mathrm{~ms}$ duration were given at twice diastolic threshold. Stimulation was started 15 minutes after ouabain administration using trains of 10 and 50 stimuli with interstimulus intervals of 200 . 400,600 , or $800 \mathrm{~ms}$. Ouabain was administered as a bolus $(40 \mu \mathrm{g} / \mathrm{kg})$, followed ten minutes later by a continuous infusion $[0.072 \mu \mathrm{g} / \mathrm{kg} / \mathrm{min}]$ throughout the whole experiment (24).

The pacing protocol was performed within 15 minutes and repeated up to 10 times. When this protocol failed to induce VT, the experiment was ended. At least one week later, a higher bolus of ouabain (increment of $5-10 \mu \mathrm{g} / \mathrm{kg}$ ) was given. The rate of the infusion was dependent on the amount of the bolus (24). This increment in bolus and infusion was repeated until VT was induced.

\section{Termination of ventricular tachycardia}

Pacing was started after VT had persisted for at least 20 minutes. Four pacing modes were applied: 1-2) one extrastimulus and 2 consecutive extrastimuli which were not preceded by a basic train, 3) 20 consecutive stimuli, and 4) continuous stimulation during 15,60, and $120 \mathrm{~s}$. Between stimulations we waited for at least 30 and up to $180 \mathrm{~s}$ enabling us to study the behavior of the VT postpacing.

The single extrastimulus was given $40 \mathrm{~ms}$ shorter than the cycle length of the tachycardia. Then the extrastimulus was repeated with increasing prematurity (in steps of $20 \mathrm{~ms}$ ) until ventricular refractoriness was reached. During the double extrastimulus protocol, the coupling interval of the first extrastimulus was always $20 \mathrm{~ms}$ longer than the refractory period of the ventricle. The second stimulus was $40 \mathrm{~ms}$ shorter than the VT cycle length and was advanced similarly as the single extrastimulus. When pacing with 20 stimuli, interstimulus intervals slightly shorter than the cycle length of the VT 
were used initially. Pacing intervals were reduced in steps of $20 \mathrm{~ms}$ to a minimum of $250 \mathrm{~ms}$. For overdrive stimulation with longer trains onlly interstimulus intervals between 200 and $300 \mathrm{~ms}$ were used.

Following termination, the VT was reinduced to study reproducibility. Then the pacing protocol was continued starting with the stimulation-train which had resulted in termination.

To quantify the effect of programmed electrical stimulation on ouabain-induced VT, the following measurements were made:

1) the cycle length of the VT before and after pacing as assessed by the mean of $10 \mathrm{R}-\mathrm{R}$ intervals,

2) the interval to the first postpacing QRS-complex,

3) the GRS-configuration of the tachycardia before and after stimulation, and

4) the $\mathrm{QRS}$-configuration of the first beat postpacing.

\section{Statistical Analysis}

When appropriate (paired) Student's t-test and simple linear regression analysis were performed. All data are expressed as mean \pm standard deviation.

\section{RESULTS}

In the 24 experiments, induction of VT occurred $84 \pm 46$ min after the start of ouabain administration $(45 \pm 5 \mu \mathrm{g} / \mathrm{kg})$. In figure 1 , an example of initiation of VT is presented. After initiation the mean cycle length of the arrhythmias was $380 \pm 80 \mathrm{~ms}$.

The effects of attempting to terminate the arrhythmias with pacing are summarized in table 1. A total of 331 stimulations were performed using the four pacing modes. Cessation was observed in only $3 \%$ of the different stimulations and was not related to a specific pacing mode (column 7].

Different patterns of termination were observed. The arrhythmia either stopped immediately or continued for several beats (from 2 to 33 , mean $13 \pm 12$ ) following stimulation. Also the rate of the VT just before termination behaved differently: both acceleration and slowing were observed. Importantly, termination could not be reproduced following reinduction. Reinitiation never occurred spontaneously, but always required a pacing train.

In contrast to termination, shortening in cycle length of the tachycardia following pacing was commonly seen. Overdrive acceleration especially occurred after longer stimulation-trains (figure $2, \mathrm{p} \leq 0.001$ ). Moreover, acceleration persisted until the next stimulation was given. Subsequently, the next stimulation-train could again shorten the cycle length of the VT. This resulted 


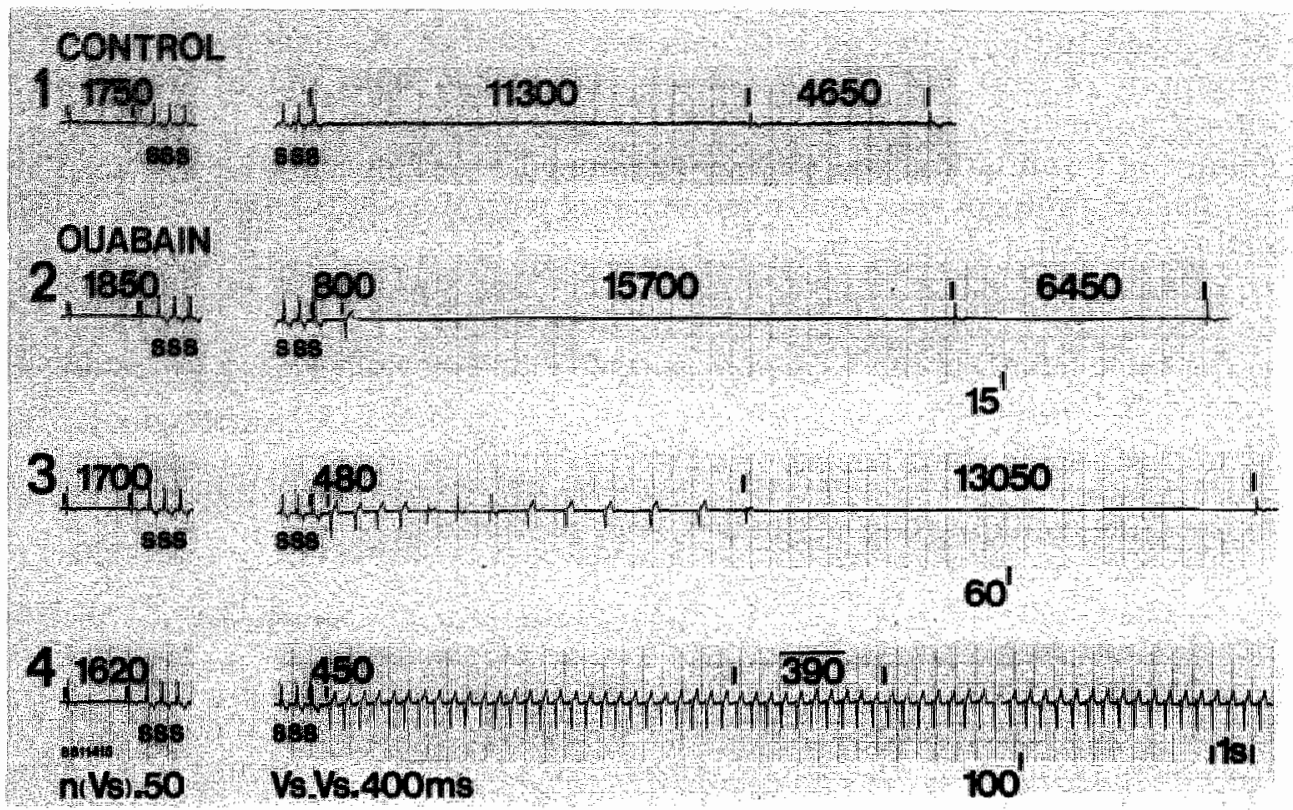

Figure 1. Induction of ventricular tachycardia by oubain and electrical stimulation.

In all 4 panels, pacing (S) was performed from the basal part of the right ventricle using 50 stimuli and an interstimulus interval of $400 \mathrm{~ms}$. Without ouabain, stimulation of the idioventricular rhythm resulted in marked overdrive suppression lasting more then $11 \mathrm{~s}$ (panel 1). Following ouabain administration, pacing induced one ectopic beat with a first postpacing interval of $800 \mathrm{~ms}$ (panel 2). In time, the number of induced beats increased, while the coupling interval shortened (panel 3) until ventricular tachycardia was induced after 100 minutes (panel 4).

Table 1. Effects of pacing on ouabain-induced ventricular tachycardilas.

\begin{tabular}{lllllll}
\hline $\begin{array}{l}\text { number } \\
\text { of stimuli }\end{array}$ & $\begin{array}{l}\text { duration } \\
(\mathrm{s})\end{array}$ & $\begin{array}{l}\text { VT pre } \\
(\mathrm{ms})\end{array}$ & $\begin{array}{l}\text { Vs-Vs } \\
(\mathrm{ms})\end{array}$ & $\begin{array}{l}\text { Vs-Vs } \\
\text { VT pre }\end{array}$ & $\begin{array}{l}\text { number of } \\
\text { stimulations }\end{array}$ & $\begin{array}{l}\text { number of } \\
\text { terminations }\end{array}$ \\
\hline 1 & & $360 \pm 50$ & $225 \pm 55$ & $0.63 \pm .15$ & 110 & 5 \\
2 & $325 \pm 30$ & $200 \pm 60$ & $0.62 \pm .17$ & 75 & 2 \\
20 & $365 \pm 60$ & $330 \pm 65$ & $0.90 \pm .10$ & 85 & 1 \\
& $15,60.120$ & $315 \pm 60$ & $255 \pm 40$ & $0.79 \pm .10$ & 61 & 3 \\
\hline
\end{tabular}

VT pre = cycle length of tachycardia before pacing;" Vs-Vs = Interstimulus interval; Vs-Vs / VT pre $=$ corrected interstimulus interval 


\section{\% stimulation - trains}

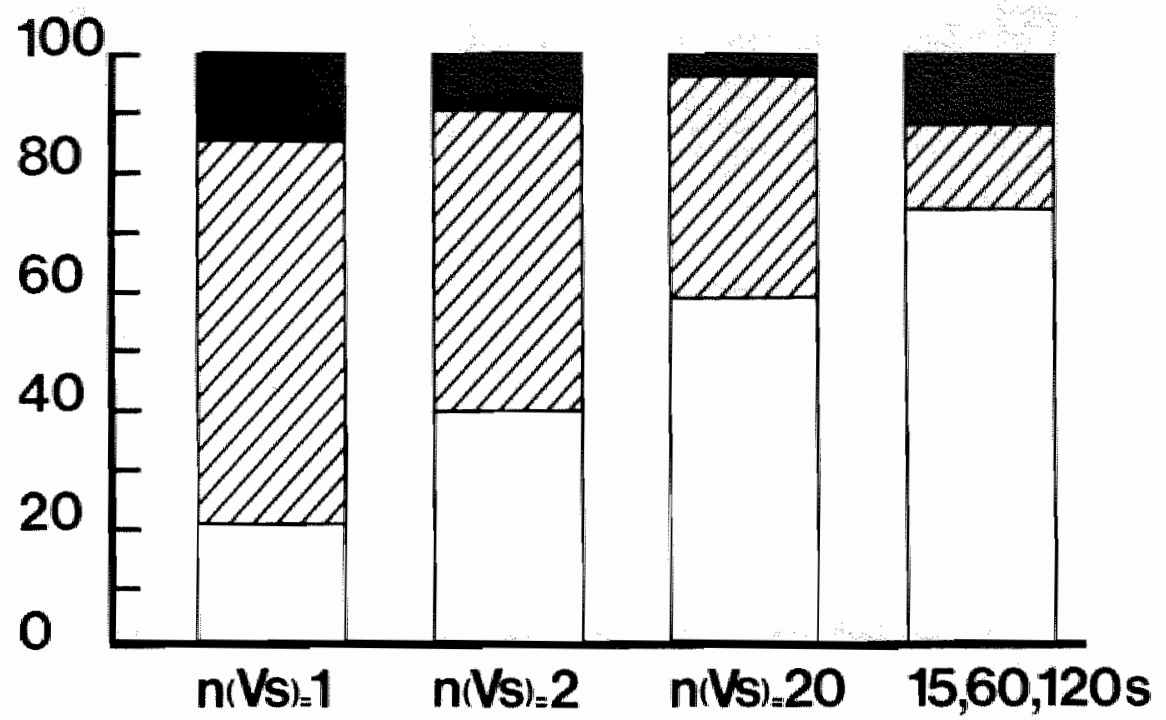

Figure 2. The response of the cycle length of the tachycardia postpacing to the different pacing modes.

On the horizontal axis, the different pacing modes are plotted. Vertically, the percentage of stimulation-trains which showed acceleration ( $\square$ ), no change ( 8 ) or the combination of deceleration or termination ( $\mathbf{D}_{\text {) }}$ are lllustrated. This diagram shows that longer pacing trains resulted in a higher incidence of acceleration of the tachycardia postpacing.

Table 2. Results of pacing on oulabain-Induced ventricular tachycardias.

\begin{tabular}{|c|c|c|c|c|c|c|c|}
\hline \multirow[b]{2}{*}{$\begin{array}{l}\text { number } \\
\text { of stimulil }\end{array}$} & \multirow[b]{2}{*}{$\begin{array}{l}\text { duration } \\
\text { (s) }\end{array}$} & \multicolumn{4}{|c|}{ After each Stimulation } & \multicolumn{2}{|c|}{ After total Protocol } \\
\hline & & $\begin{array}{l}\mathrm{Vs}-\mathrm{Vs} \\
(\mathrm{ms})\end{array}$ & $\begin{array}{l}\mathrm{Vs}-\mathrm{V} \\
\text { (ms) }\end{array}$ & $\begin{array}{l}\text { VT pre } \\
\text { (ms) }\end{array}$ & $\begin{array}{l}\text { VT post } \\
\text { (ms) }\end{array}$ & $\begin{array}{l}\text { VT pre } \\
\text { (ms) }\end{array}$ & $\begin{array}{l}\text { VT post } \\
\text { (ms) }\end{array}$ \\
\hline 1 & & $225 \pm 55$ & $425 \pm 70^{*}$ & $360 \pm 50$ & $360 \pm 50$ & $360 \pm 55$ & $355 \pm 75$ \\
\hline 2 & & $200 \pm 60$ & $370 \pm 50^{*+}$ & $325 \pm 30$ & $320 \pm 25^{*}$ & $330 \pm 30$ & $315 \pm 30^{*}$ \\
\hline \multirow[t]{2}{*}{20} & & $330 \pm 65$ & $405 \pm 70^{*}$ & $365 \pm 60$ & $355 \pm 55^{*}$ & $405 \pm 80$ & $335 \pm 55$ \\
\hline & $15,60,120$ & $255 \pm 40$ & $355 \pm 35^{*}$ & $315 \pm 60$ & $285 \pm 75^{*}$ & $340 \pm 70$ & $280 \pm 25$ \\
\hline
\end{tabular}

$\mathrm{VS}_{\mathrm{S}} \mathrm{VS}_{\mathrm{S}}=$ interstimulus interval; $\mathrm{Vs}_{\mathrm{s}} \mathrm{V}=$ first postpacing interval; $\mathrm{VT}$ pre $=$ cycle length of the tachycardia prepacing: $\mathrm{VT}^{\mathrm{T}}$ post $=$ cycle length of the tachycardla postpacing $+=50.001 \mathrm{in}$ comparison to $\mathrm{Vs}_{\mathrm{s}} \mathrm{VS}_{\mathrm{i}} *=\leq 0.001$ in comparison to respective $\mathrm{VT}$ pre 


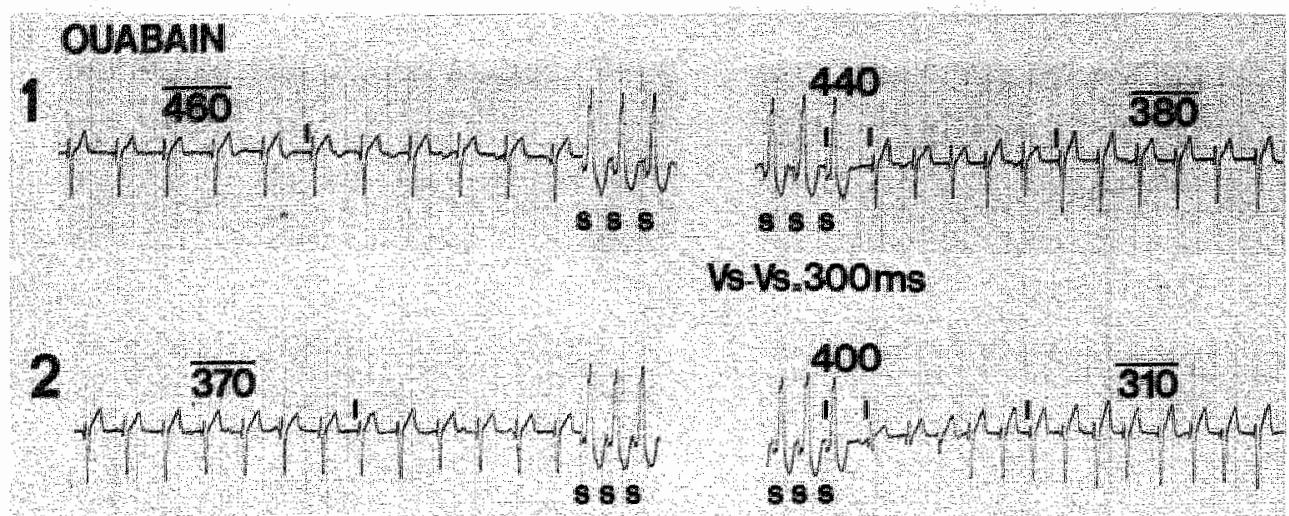

Vs.Vs.250ms

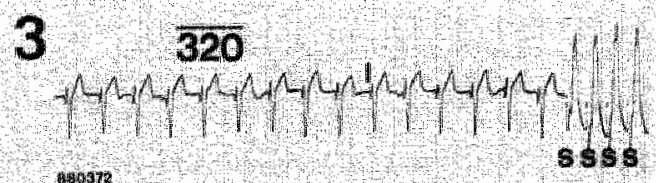

pacing duration. 15 s

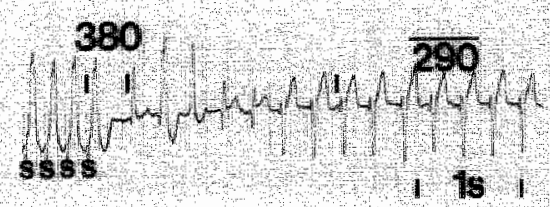

$V_{s}-V_{s} 200 \mathrm{~ms}$

Figure 3. Acceleration of ventricular tachycardia following pacing.

Ouabain-induced ventricular tachycardia was overdriven for $15 \mathrm{~s}$ using interstimulus intervals or 300,250 , and $200 \mathrm{~ms}$ (panels 1-3 respectively). Pacing was performed from the basal part of the right ventricle. Note the acceleration in rate of the tachycardia, which persisted as seen from the cycle length of the tachycardia measured before the next stimulation train. Secondly. the first postpacing interval had a concordant relation with the interstimulus interval. Finally, note the (temporary》 change of the GRS-complex following pacing at the shorter interstimulus intervals.

in continuous acceleration in VT rate following intermittent pacing at increasing rates (figure 3). To demonstrate this continuous acceleration, table 2 shows the change in cycle length of the tachycardias in two ways: 1) by comparing VT cycle length before and after the individual stimulation-trains, and 2) by comparing VT cycle lengths before and after completion of the four stimulation protocols consisting of several pacing trains.

With the exception of the protocol using a single extrastimulus, the cycle length of the tachycardia postpacing was significantly reduced after each stimulation-train (table 2, columns 5 and 6) and after each stimulation protocol (columns 7 and 8 ). Secondly, it was observed that the R-R interval of the VT postpacing was always longer than the interstimulus interval (colomn 3). Thirdly, it was found that the first postpacing interval (column 4) was significantly longer than both the cycle length of the tachycardia before pacing (column 5) and the interstimulus interval (column 3). 


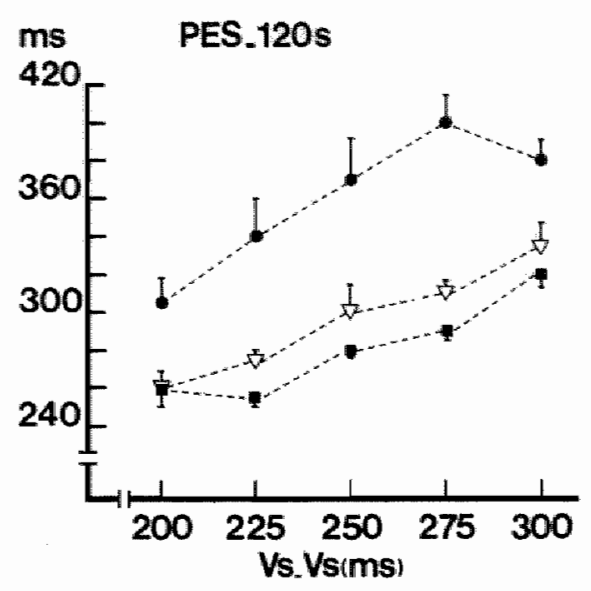

Figure 4. The behavior of the first R-R Interval and subsequent VT cycle lengths after pacing during $120 \mathrm{~s}$.

At each interstimulus interval (horizontal axis), overdrive pacing resulted in a significant increase in rate of VT: the cycle length prepacing $(\nabla)$ being longer than the cycle length postpacing ( $\mathbf{a}$ ). Decreasing the interstimulus interval resulted in shortening of the first postpacing interval (O) and the cycle length of the tachycardia. Values are expressed as the mean $\pm \operatorname{sem}(\mathrm{ms})$.

Decreasing the pacing interval in each pacing mode resulted in shortening of the first postpacing interval (figure 4). Also the cycle length of the VT after pacing showed a similar concordant relation. The correlation coefficients of all stimulation protocols for the respective parameters are shown in table 3 . It is seen that the correlation coefficients of the first postpacing interval and the cycle length of the VT postpacing do not differ markedly. This suggests that the behaviour of the first postpacing interval is representative of the changes in rate of the tachycardia postpacing.

The mean R-R interval of the arrhythmlas at the end of the pacing protocols was $300 \pm 50 \mathrm{~ms}$, a significant shortening compared to the value prepacing: $380 \pm 80 \mathrm{~ms}(\mathrm{p} \leq 0.001)$. With regard to the gRS-configuration, a different GRS-complex was induced immediately following pacing, which was dependent on the site of stimulation. When the electrode most distant from the site of origin of the ventricular tachycardia was used. pacing induced a tachycardia with QRS-complexes suggesting an origin close to the stimulation site. Usually the original tachycardia resumed after a few seconds. 
Table 3. Correlation coefficients of the first postpacing interval, mean cycle length of the tachycardia pre and postpacing in relation to interstimulus interval.

\begin{tabular}{lllll}
$\begin{array}{l}\text { Number } \\
\text { of stimuli }\end{array}$ & $\begin{array}{l}\text { duration } \\
\text { (s) }\end{array}$ & $\begin{array}{l}\mathrm{Vs}-\mathrm{V} \\
\text { (ms) }\end{array}$ & $\begin{array}{l}\text { VT pre } \\
\text { (ms) }\end{array}$ & $\begin{array}{l}\text { VT post } \\
\text { (mis) }\end{array}$ \\
\hline 1 & & 0.49 & 0.67 & 0.64 \\
2 & & 0.75 & 0.80 & 0.77 \\
20 & & 0.88 & 0.91 & 0.93 \\
& $15,60,120$ & 0.92 & 0.92 & 0.87 \\
\hline
\end{tabular}

$\mathrm{Vs}-\mathrm{V}=$ first postpacing interval; Vt pre = cycle length of the tachycardia prepacing:

VT post $=$ cycie length of the tachycardia postpacing

\section{DIscussION}

\section{Termination}

This study demonstrates that ouabain-induced VT cannot reproducibly be terminated by programmed electrical stimulation. This is in contrast to results obtained in vitro studies, which usually show termination of VT. In these studies, termination was observed independent of the cardiac tissue, (Purkinje fibers, mitral valve or coronary sinus) and the method of induction of DAD's (ouabain, catecholamines or a solution containing sodium free and high calcium concentrations (11-13,25)). Two studies have quantified pacing induced termination of arrhythmias resulting from DAD's (14-15). Occaslonally termination was seen following single extrastimull. More frequently, however termination was observed following (prolonged) overdrive pacing. Short stimulation intervals $(\leq 300 \mathrm{~ms}$ and/or $\leq 50 \%$ cycle length of the tachycardia) were succesful in up to $89 \%$.

Although similar pacing protocols were used in our experiments (table 1), we could not reproduce these findings in the intact heart. Several mechanisms may have been involved to explain this different outcome. First, the cycle length of the tachycardia in our experiments $(380 \pm 80 \mathrm{~ms})$ was shorter than the cycle length of the tachycardias studied in vitro (e.g. $670 \pm 295$ in reference 14). This may be due to the involvement of the sympathetic nervous system in the intact heart or to a higher degree of ouabain intoxication. As a consequence, we could only rarely use interstimulus intervals less than $50 \%$ of the cycle length of the tachycardia. However, pacing intervals less than 300 ms were frequently applied.

Secondly, we have used a model of triggered activity using systemic ouabain intoxication. In this study, we frequently observed pacing induced impulse formation at different sites in the heart, especially when pacing was per- 
formed distal to the site of origin of the arrhythmia. Following stimulation, temporary competition between the spontaneous tachycardia and the induced foci originating close to the site of pacing was observed (26), until the original tachycardia regained dominance of the ventricles. It is possible that the induced tachycardia led to reinduction of the original one. Against this explanation speaks the fact that we also frequently observed uninterrupted perpetuation of the original tachycardia. These considerations stress the fact that our findings may not apply to triggered rhythms originating from a single site of impulse formation (focal triggered activity) and that further investigations are needed to study the response of focal triggered activity to pacing in the intact heart.

\section{Overdrive acceleration}

Instead of termination of ouabain-induced $\mathrm{VT}_{\text {, }}$ we usually noticed pacing induced acceleration. This increase in rate of the VT especially appeared after longer stimulation-trains: 1) 20 stimuli, or 2) continuous pacing for 15,60 , or $120 \mathrm{~s}$. In these pacing modes more sodium and calcium ions will enter the myocardial cell during stimulation. Therefore, an (further) increase in intercellular calcium concentration may be responsible for the overdrive acceleration seen. In contrast to similar observations in vitro $(13,15)$ and the intact human heart (27), this reduction in cycle length persisted until the next stimulation-train. The time between subsequent stimulations was much longer than the period described in vitro as necessary to return to the cycle length observed before pacing $(12,14)$.

Typical for triggered activity resulting from DAD's is the timing of the first postpacing QRS-complex. Decreasing the interstimulus interval results in shortening of this first postpacing interval $(7,15)$. This relation is largely independent of the mode of stimulation (17). New is the finding that this concordant relation can also be observed in the subsequent cycle length of the tachycardia following pacing (figure 3). A comparison of the correlation coefficients reveals that the first postpacing interval predicts the behavior of the cycle length of the tachycardia postpacing.

\section{Implications for differentiation among arrhythmogenic mechanisms:}

\section{a) Reentry}

In (clinical) reentrant tachycardias, an inverse relation often exists between the tachycardia initiating extrastimulus interval and the interval to the first beat of the tachycardia (10).

Although overdrive acceleration may occur in the same circuit, it is the exception (10). Usually overdrive acceleration is the result of the induction of another faster tachycardia occurring in another reentry circuit. This is sup- 
ported by the observation that acceleration is frequently accompanied by changes in GRS-configuration. In our experiments we observed overdrive acceleration of the original tachycardia.

A second observation which could differentiate triggered activity induced by DAD's from reentry, was the inability to terminate DAD's dependent arrhythmias reproducibly. This is in contrast to reentrant tachycardias with an excitable gap which are reproducibly terminated by a critically timed stimulus during electrical stimulation $(4,5,10)$.

\section{b) Abnormal automaticity}

In abnormal automaticity, only the behavior of the first postpacing interval has been studied quantitatively $(7,28)$. Dependent on the level of diastolic membrane potential, arrhythmias caused by this mechanism respond to pacing by shortening, no change or prolongation of the coupling interval in respect to the cycle length of the tachycardia. Dangman et al. (28) reported that independent of enhancement or suppression of the first postpacing interval, basal rates of the tachycardia were reestablished within two to five cycles. This is in contrast to our findings, in which permanent overdrive acceleration was observed. Persistent termination of arrhythmias resulting from abnormal automaticity cannot be accomplished by pacing. So, acceleration of the VT by pacing is suggestive of DAD's dependent arrhythmias.

In conclusion, ouabain-induced ventricular arrhythmias respond to overdrive pacing in a particular way characterized by: 1) absence of termination, 2) a typical behaviour of the first postpacing interval, and 3) long lasting acceleration. Because ouabain-induced ventricular tachycardia is based on DAD's, these findings may be of help to differentiate triggered activity resulting from DAD's from other mechanisms of cardiac arrhythmias. 


\section{REFERENCES}

1. Ferrier GR: Digitalis arrhythmias: role of osclllatory afterpotenttals. Prog. Cardiovasc. Dis. 1977: 19: 459-474.

2. Cranefield PF, and Aronson RS: Cardiac arrhythmias: the role of triggered activity and other mechanisms. Futura Publishing Company Inc.. Mount Kisco, New York, 1988.

3. Gorgels APM, Vos MA, Brugadia $\mathrm{P}$ and Wellens HUJ: The clinical relevance of abnormal automaticity and triggered activity. In "Cardiac Arrhythmias: Where to go from here?", eds: Brugada P, and Wellens HJJ, Futura Publishing Company Inc., Mount Kisco, New York $1987 ; 147-169$.

4. Wellens HJJ: Value and limitations of programmed electrical stimulation of the heart in the study and treatment of arrhythmias. Circulation $1978 ; 57: 845-853$.

5. Rosen MR: Is the response to programmed electrical stimulation diagnostic of mechanisms for arrhythmias? Circulation 1986; 73 (II): 19-27.

6. Ilvento JP, Provet J, Danllo P, and Rosen MR: Fast and slow idioventricular rhythms in the canine heart; a study of their mechanism using antlarrhythmic drugs and electrophyslologic testing. Am J. Cardiol. 1982; 49:1909 1916.

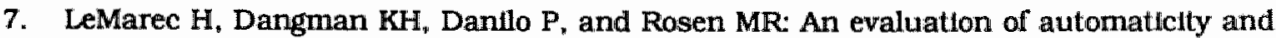
triggered activity in the canine heart one to 4 days after myocardial infarction. Circulation 1985; $71: 1224-1236$.

8. Franz MR: Long-term recording of monophasic action potentials from human endocardlum. Am. J. Cardllol. 1983; 51: 1629-1634.

9. Pritor SG, Mantica M, and Schwartz PJ: Delayed afterdepolarizations elicited in vivo by left stellate ganglion stimulation. Circulation 1988; 78: 178-185.

10. Brugada $P$, and Wellens $H J J$ : The role of triggered activity in clintical ventricular arrhythmias. In "Frontlers of Cardiac Electrophysiology", eds: Rosenbaum MB, and Elizart MV. Martinus Nithoff Publishers. The Hague, 1983; 195-216.

11. Fernier GR, Saunders $\mathrm{JH}_{\mathrm{v}}$ and Mendez $\mathrm{C}$ : A cellular mechanism for the generation of ventricular arrhythmias by acetyl-strophantidin. Circ. Res. 1973; 32: 600-609.

12. Wit AL, and Cranefleld PF: Thiggered activity in cardlac muscle fibers of the simian mitrall valve. Circ. Res. 1976; 38: 85-98.

13. Wit AL, Cranefield PF, and Gadsby DG: Electrogenic sodium extrusion can stop triggered activity in the canine coronary sinus. Circ. Res. 1981; 49: 1029-1042. 
14. Moak JP, and Rosen MR: Induction and termination of triggered activity by pacing in isolated canine Purkinje fbers. Circulation 1984; 69: 149-162.

15. Johnson $N$, Dantlo $P$, WIt $A L$, and Rosen MR: Characteristics of intiation and termination of catecholamine-induced triggered activity in atrial fibers of the coronary sinus. CirculaUon 1986; $74: 1168-1179$.

16. Vos MA, Gorgels APM, Leunissen HDM, Brugadla P, and HJJ Wellens: The effect of an entralnment protocol on ouabain-Induced ventricular tachycardia. PACE 1989; 12: 14851493.

17. Gorgels APM, Beekman HDM, Brugada P, Dassen WRM, Richards DAB, and Wellens HuJ: Extrastimulus related shortening of the first postpacing interval in digitalis induced ventricular tachycardia. J. Am. Coll. Cardiol. 1984; 1: 840-857.

18. Gorgels APM, de Wit B, Beekman HDM, Dassen WRM, and Wellens HJJ: Triggered acttvity Induced by pacing during digitalis intoxication: observations during programmed electrical stimulatian in the conscious dogs with chronic complete atrioventricular block. PACE 1987; 10: 1309-1321.

19. LeMarec $H$, Spinelli $W$, and Rosen MR: The effects of doxorubicine on ventricular tachycardia. Circulation 1986; 74: 881-889.

20. Malfatto $G$, Rosen TS, and Rosen MR: The response to overdrive pacing of triggered atrial and ventricular arrhythmias in the canine heart. Circulation 1988; 77: 1139-1148.

21. Steiner C, and Kovalik TW: A simple technique for production of chronic complete heart block in dogs. J. Appl. Phystol. 1968; 25: 631-632.

22. Vassalle $M$, Knob $\mathbb{R E}$, Cummins M, Lara GA, Castro C, and Stuckey JH: An analysis of fast Idioventricular rhythm in the dog. Circ. Res. 1977; 41: 218-226.

23. Van der Steld A, Dassen W, Gorgels A, Beekman H, and Wellens HJJ: Flexdble mult1processor system to support electrophysiological investugation in animals. Computers in Cardiology: 1984: $525-528$.

24. Rhee HM, Dutta $S$, and Marks $\mathrm{BH}$ : Cardlac $\mathrm{Na}^{+} / \mathrm{K}^{+}$ATP-ase activity during positive inotroplc and toxic actions of ouabain. Eur. J. Pharmacol. 1976: 37: 141-153.

25. Cranefield PF, and Aronson RS: Inttation of sustained rhythmic activity by single propagated action potentials in canine cardlac Purkdnje fibers exposed to sodium-free solution or ouabain. Circ. Res. 1974: 34: 477-481. 
26. Gorgels APM, de Wit B, Beekman HDM, Dassen WRM, and Wellens HWJ: Effects of different modies of stimulation on the morphology of the first GRS-complex following pacing during digitalis-induced ventucular tachycardia: observations in the conscious dog with chronic complete atrioventricular block. PACE 1986: 9: 842-859.

27. Van Agt EJ, and Wellens HJJ: The electrocardiogram in digitalis intoxication in "What's new in electrocardiography*, eds: Wellens HJJ, and Kulbertus HE, Martinus Nijhof Publishers, The Hague, 1981; 315-343

28. Dangman $\mathrm{KM}$, and Hoffman $\mathrm{BF}$ : Studies on overdrive stimulation of canine cardlac Purkinje flbers: Maximal diastolic potentlal as a determinant of the response. J. Am. Coll. Cardiol. 1983; 2: 1183-1190. 
Premature escape beats:

a model for triggered activity in the intact heart ?

\author{
Marc A Vos \\ Anton PM Gorgels \\ Bram de Wit \\ Joost PH Drenth \\ Ronald TAM van Deursen \\ Jet DM Leunissen \\ Hein JJ Wellens
}




\title{
Premature escape beats: \\ a model for triggered activity \\ in the intact heart?
}

\begin{abstract}
In consclous dogs with complete AV-block, overdrlve pacing of the Idloventricular rhythm normally results in overdrive suppression (OS). Frequently ${ }_{*}$ however ${ }_{\text {w }}$ we observed an other response to overdrive: QRS-complex(es) with an unexpectedly short first postpacing interval followed by normal $O S$. We have named such a $Q R S$-complex a "premature escape beat" (PEB). Based on the response of PEB's to electrical stimulation, we postulate that PEB's are based on triggered activity resulting from delayed afterdepolarizations.

This hypothesis was tested in 86 experiments by: 1) stimulation under control conditions and in combination with 2) subtoxic and toxic amounts of ouabain (20-50 $\mathrm{gg} / \mathrm{kg})$. 3) lidocaline (3 $\mathrm{mg} / \mathrm{kg})$, and 4) doxorubicin $\left(16-24 \mathrm{mg} / \mathrm{m}^{3}\right)$. The stimulation protocol, which was repeated at random 5 to 10 times, consisted of 10 and 50 stimull using interstimulus intervals of 200 . 400.600 , and $800 \mathrm{~ms}$. This protocol was not only performed during spontaneous idioventricular rhythm but also during a continuously paced rhythm with interstimulus intervals or $800 \mathrm{mns}$.

It was found that: 1) the chance to induce PEB(s) increased and 2) their first postpacing. Interval significantly decreased using short and/or fast drtves. Ouabain increased significantly and in a dose-dependent manner: 1) the ability to induce PEB's, 2) the number of PEB"s per stimulation, and 3) shortened their first postpacing interval. Opposite effects were seen after lldocalne, doxorublcin and continuous pacing: 1] a lower incidence of PEB's, and 2) lengthening of their first postpacing interval.

In conclusion, these results support our hypothesis that PEB's are based on triggered actlvity resulting from delayed afterdepolarkations.
\end{abstract}

Presented in part at the American Heart Association, Ciculation 1987: 76: 429

Submitted for publication 


\section{INTRODUCTION}

While studying the response of ouabain-induced ventricular tachycardia (VT) to electrical stimulation in conscious dogs (1). we noticed that initiation of "triggered" beats by pacing was possible in the absence of ouabain (figure 1). We have termed these GRS-complexes with an unexpectedly short coupling interval premature escape beats (PEB's). Their occurrence is in contrast to the phenomenon of overdrive suppression, which is normally seen when an idioventricular rhythm is overpaced (2). The amount of overdrive suppression is dependent on rate and duration of stimulation $(3,4)$ and is followed by a slow acceleration in ventricular rate until prepacing values are reached.

Based on the response of PEB's to electrical stimulation, we considered the possibility that PEB's are based on triggered activity resulting from delayed afterdepolarizations (DAD's). This arrhythmogenic mechanism has been most extensively investigated in the setting of digitalis intoxication (5-8). Other interventions inducing DAD's have also been described, like catecholamines $(9,10)$, hypokalemia $(11,12)$, the (sub)acute phase of myocardial infarction $(13,14)$, reperfusion $(15,16)$, and hypertrophy $(17)$.

DAD's have been demonstrated to result from intracellular calcium overload $(18,19)$. Resulting arrhythmlas have several characteristics in common $(1,6,20): 1)$ their induction is promoted by fast pacing rates, and 2) the first postpacing interval shows a concordant relation to the interstimulus interval. In the present study, we have tested our hypothesis by using different protocols: 1) programmed electrical stimulation under control conditions and in combination with 2) subtoxic and toxic amounts of ouabain, 3) lidocaine. and 4) doxorubicin. We expected that under control conditions faster pacing rates will: 1) increase the incidence of PEB's, and 2) shorten their first postpacing interval. Ouabain administration was expected to increase the inducibility, to increase the number and to shorten in a dose related way the first postpacing interval of the PEB's. Lidocaine and doxorubicin were chosen for their ability to suppress triggered activity $(21,22)$. Particularly, doxorubicin is of interest because of its specificity to terminate triggered arrhythmias resulting from DAD's $(22,23)$.

Finally, we performed continuous pacing at a basic cycle length of $800 \mathrm{~ms}$ before the specific pacing protocol to increase overdrive suppression probably by activation of the $\mathrm{Na}^{+} / \mathrm{K}^{+}$ATP-ase. This was also expected to: 1) decrease the ability to induce PEB's, and 2) lengthen their first postpacing interval. Especially when combined with lidocaine, which inhibits sodium influx in a use dependent way [24). 


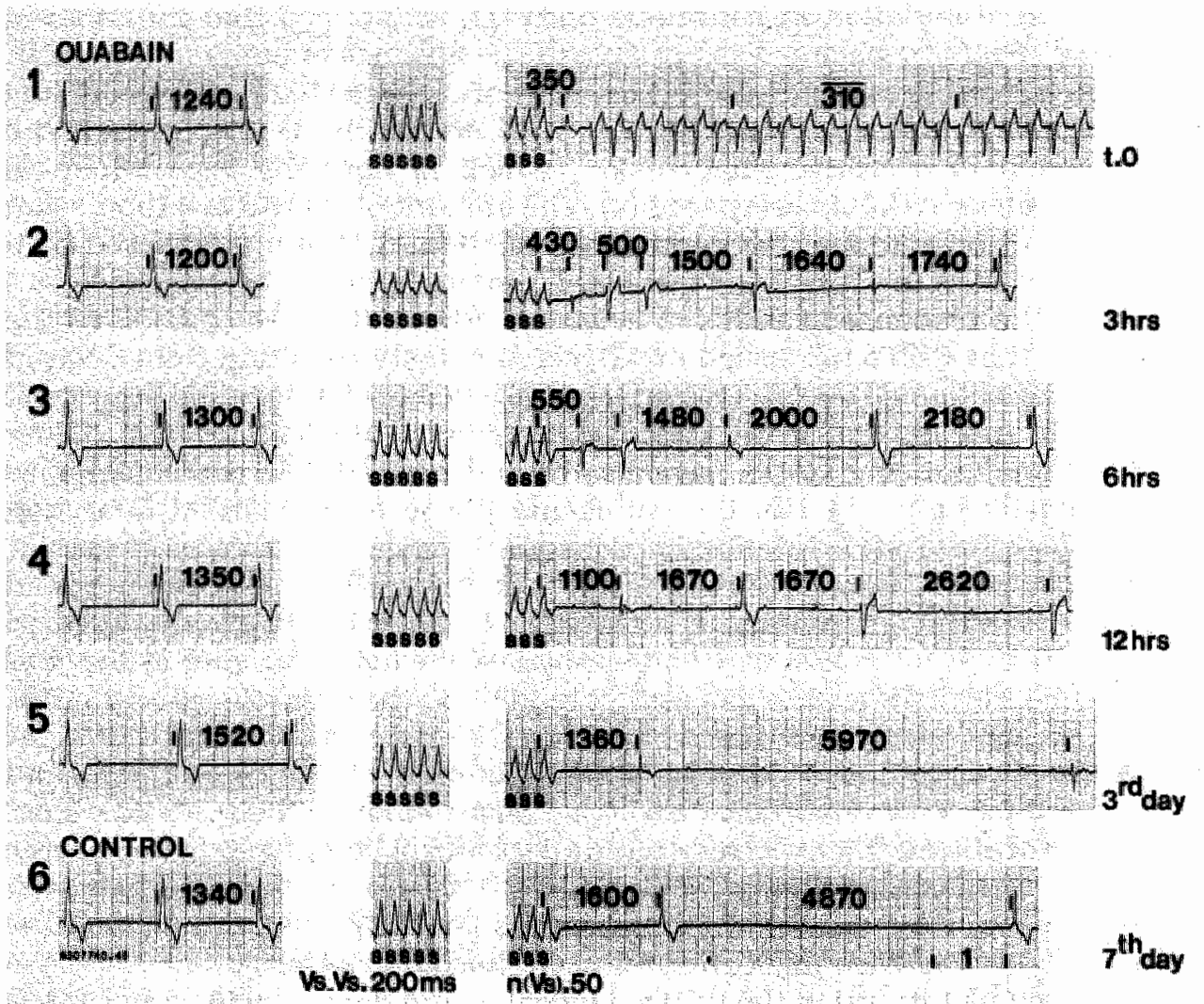

Figure 1. The effect of overdrive stimulation on the ventricular rhythm on dissipation of ourabain.

The panels are arranged from high levels of ouabain toxdicity (panel 1) to control (panel 6). Left part of all panels show the last two R-R intervals before pacing. The middle panels show part of the stimulation-train consisting of 50 stimull (S) and interstimulus intervals of $200 \mathrm{~ms}$. Right parts show end of stimulation and postpacing eplsodes. Pacing Is performed from the basal part of the right ventricle.

This figure presents the following findings: 1) pacing induces a ventricular tachycardia (panel 1). On dissipation of ouabain 2) the number of premature escape beats decreases, and 3) their first postpacing interval increases (panel 2-5). Under control conditions (panel 6), it is still possible to induce a similar beat with a first postpacing interval of $1600 \mathrm{~ms}$. 


\section{METHODS}

\section{Preparation of study animals}

A total of 86 experiments was performed in 21 mongrel dogs of either sex having a body weight between $20-35 \mathrm{~kg}$. All animals had a right thoracotomy followed by induction of AV-block by injecting Formalin $37 \%$ in the region of the bundle of His (25). Unipolar electrodes were fixed intramurally into the myocardium of the basal part of the right and the apex of the left ventricle. The electrode catheters were exteriorized through the skin of the neck. Proper care was taken postoperatively according to the instructions of the American Physiological Society.

\section{Experiments}

Experiments were performed at least two weeks after the operation to avoid episodes of spontaneous VT, which are known to occur in the early postoperative period $(26,27)$. Six surface ECG-leads and one electrogram were simultaneously registered on an ink jet recorder (Siemens Elema) and stored on tape (Ampex). Stimulation was done with a programmable stimulator having a symchronizing circuit (28). Unipolar stimuli from the right ventricle were given using a pulse width of $2 \mathrm{~ms}$ and a stimulus strength of twice the diastolic threshold.

\section{The stimulation protocol}

The idioventricular rhythm was overdriven using trains of 10 or 50 stimuli and interstimulus intervals of $200,400,600$, and occasionally $800 \mathrm{~ms}$. These stimulation-trains were repeated 5 to 10 times during each experiment in a randomized sequence. Thereafter, drugs were administered or continuous pacing started. Fifteen minutes later the pacing protocol was repeated. Between consecutive stimulation-trains enough time was allowed for the ventricular rhythm to regain its prepacing rate and QRS-configuration. The $\mathrm{R}-\mathrm{R}$ intervals were continuously displayed on a monitor screen using a computerized GRS-complex detecting system (28). The last interval before pacing and the first and second interval following pacing were measured automatically and stored on disk. Because of the regularity of the spontaneous rhythm, we considered the last interval before pacing as representative for the rate of the ventricular escape rhythm. 


\section{Ouabain}

A total of 32 experiments was performed in 4 dogs: 16 controls followed by 16 experiments in which the pacing protocol was repeated in combination with subtoxic and toxic amounts of ouabain. This drug was given as a bolus intravenously over a one minute period, followed 10 minutes later by a continuous infusion (29). At random a bolus of 20,30 or $40 \mu \mathrm{g} / \mathrm{kg}$ was administered followed by an infusion of respectively $0.036,0.054$, and 0.072 $\mu \mathrm{g} / \mathrm{kg} / \mathrm{min}$ throughout the experiment. The end point was the completion of the stimulation protocol or induction of VT. If no sustained VT was induced even after the highest dose of $40 \mu \mathrm{g} / \mathrm{kg}$, an additional experiment using a bolus of $50 \mu \mathrm{g} / \mathrm{kg}$ and infusion of $0.090 \mu \mathrm{g} / \mathrm{kg} / \mathrm{min}$ of ouabain was performed. In between experiments, a rest period of at least one week allowed for complete washout of ouabain. This period of time was based on a serum half life of 21 hours (30).

\section{Lidocaine and doxorubicin}

In 6 dogs $3 \mathrm{mg} / \mathrm{kg}$ lidocaine was given intravenously in $2 \mathrm{~min}$, directly followed by a continuous infusion of $100 \mu \mathrm{g} / \mathrm{kg} / \mathrm{min}$. The stimulation protocol was repeated 15 minutes later. In another 4 dogs doxorubicin was administered intravenously in a dose of $16 \mathrm{mg} / \mathrm{m}^{3}$ in two minutes (22). Thereafter the pacing protocol consisting of 120 stimulations was repeated. Subsequently a second injection of $24 \mathrm{mg} / \mathrm{m}^{3}$ was given after which the stimulation protocol was repeated again.

\section{Continuous pacing}

The ventricular rate was increased to 75 beats $/ \mathrm{min}(=800 \mathrm{~ms})$ in 12 dogs. During this rhythm, the pacing protocol was repeated. Following stimulation 10 spontaneous beats were registered after which regular pacing was started again. This rhythm was continued for at least one minute before the next stimulation was given.

In 4 dogs, the pacing protocol was repeated once more after administration of lidocaine. Also. in 2 animals doxorubicin was given in combination with continuous pacing. Both drugs were administered in the same dosage as above.

The following abbreviationg are used (see tables):

Va-Va : The last $R-R$ interval before pacing

$\mathrm{n}(\mathrm{Vs})$ : Number of stimuli 
Vs-Vs : Interstimulus interval

Vs-V : First postpacing interval

V-V2 : The interval between the first and second postpacing QRS-complex

\section{Analysis of data}

The data were analyzed according to the relation between the last prepacing, and the first and second postpacing $R-R$ intervals. Overdrive suppression was defined as the occurrence of a QRS-complex with a first postpacing interval longer than the second (and subsequent) ones. A PEB was characterized by a QRS-complex with a coupling interval which is shorter than the second postpacing interval. All data are presented as the mean \pm standard deviation. Analysis of variance, student's $\mathrm{t}$-test for non-paired events and $\mathrm{x}^{2}$-test were performed.

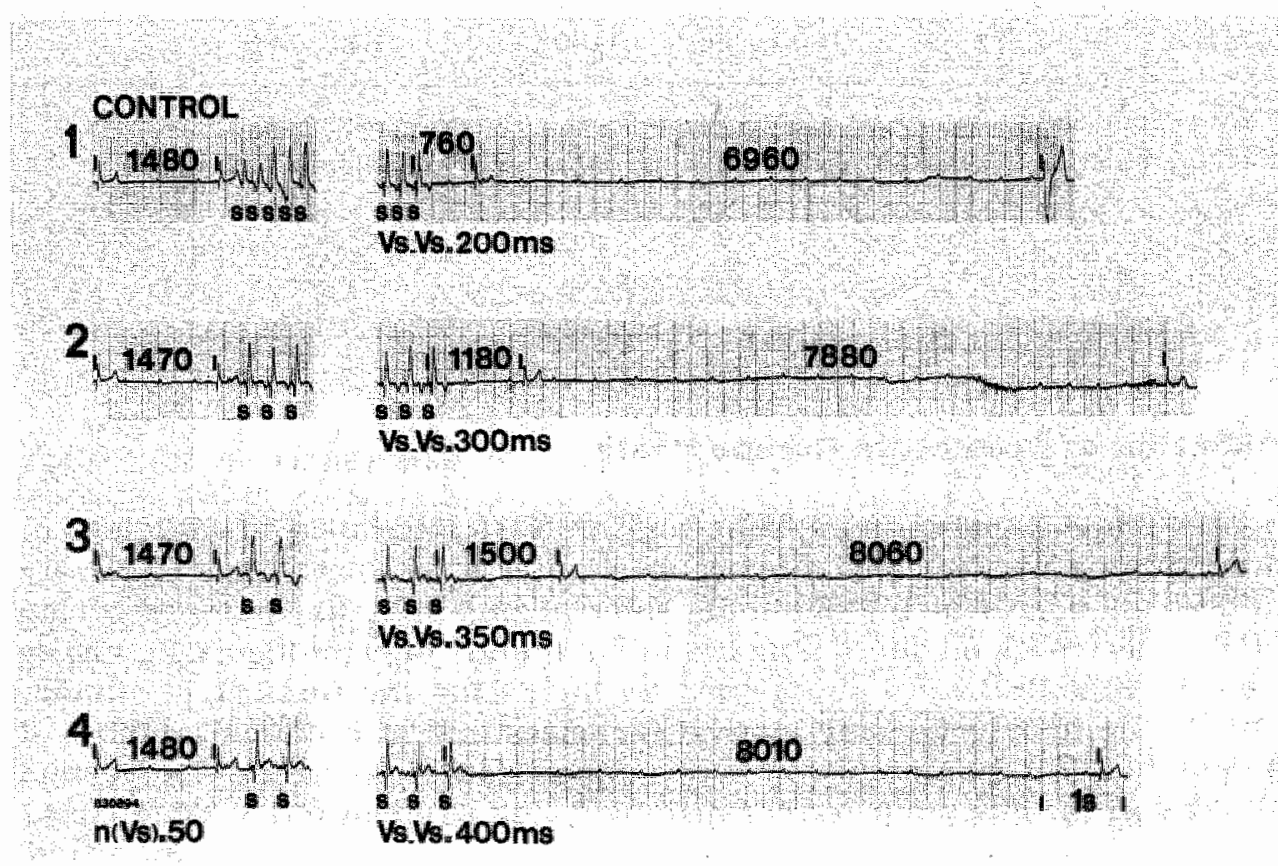

Figure 2. The effect of prolanging the interstimulus interval on the response observed following pacing.

In all panels, the idioventricular rhythm is overdriven using 50 stimull. Pacing is performed varying the interstimulus interval between 200 and $400 \mathrm{~ms}$. In panels 1-3, premature escape beats are induced: the flrst postpacing interval is shorter than the second interval. Note also that the first postpacing interval increases on prolonging the interstimulus interval. Further lengthening of this interval to $400 \mathrm{~ms}$ (panel 4) results in overdrive suppression. 
Table 1. The effect of pacing on incidence and duration of the first postpacing interval of premature escape beats.

\begin{tabular}{|c|c|c|c|c|}
\hline & \multicolumn{4}{|c|}{ number of stimulı } \\
\hline & 10 & 50 & & \\
\hline \multirow{2}{*}{ OPEB"S } & $517 / 1090$ & $224 / 1080$ & & \\
\hline & $47 \%$ & $21 \%$ & $\leq 0.001$ & \\
\hline \multirow[t]{3}{*}{$\mathrm{Vs}-\mathrm{V}$ (ms) } & $1380 \pm 290$ & $1720 \pm 600$ & $\leq 0.001$ & \\
\hline & \multicolumn{4}{|c|}{ Interstimulus interval (ms) } \\
\hline & 200 & 400 & 600 & 800 \\
\hline \multirow[t]{2}{*}{ \%PEB's } & $453 / 650$ & $174 / 620$ & $76 / 460$ & $38 / 440$ \\
\hline & $70 \%$ & $28 \%$ & $17 \%$ & $9 \%$ \\
\hline $\mathrm{Vs}-\mathrm{V}$ (ms) & $1360 \pm 360^{*}$ & $1600 \pm 390^{*}$ & $1750 \pm 600$ & $1820 \pm 500$ \\
\hline
\end{tabular}

$\% \mathrm{PEB}=$ Induclbllity Premature Escape Beats; Vs-V = The first postpacing Interval; Mean \pm standard deviation; ${ }^{*}=\mathrm{p} \leq 0.01$ compared to the subsequent interstimulus interval.

\section{RESULTS}

\section{Induction of Premature Escape Beats}

Figures 2 and 3 illustrate the behaviour of PEB"s in relation to variations in interstimulus interval and number of stimull. It is shown that PEB's are induced at a critical interstimulus interval and that its first postpacing interval decreases on shortening the interstimulus interval (figure 2). Figure 3 shows that PEB's are suppressed by increasing the number of stimuli. Initially the first postpacing interval increases and at a critical number of stimuli no PEB but only overdrive suppression is induced. The results obtained in the different control experiments are summarized in table 1.

\section{Ouabain}

The results of pacing in the presence of ouabain are divided in two groups: 1) therapeutic level: 12 experiments not leading to VT (960 stimulations), and 2) toxic level: 4 experiments in which VT was induced (136 stimulations). 


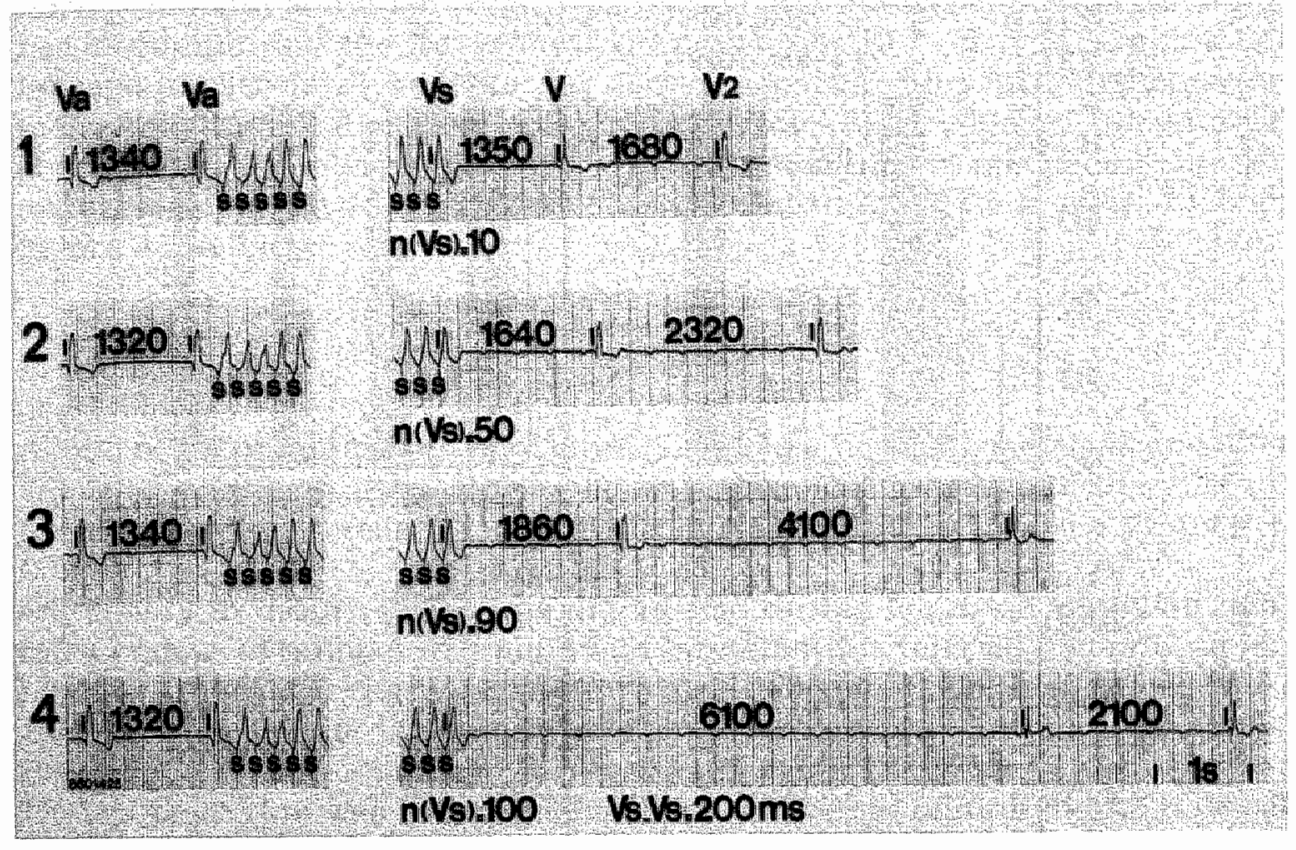

Figure 3. The effect of increasing the number of stimull on the response seen following pacing. The idloventricular thythm is overdriven with a constant interstumulus interval of $200 \mathrm{~ms}$. In panels 1-3, pacing results in the induction of premature escape beats (PEB's), which are defined as a first postpacing interval shorter than the second interval. Increasing the number of stimull from 10 to 90 also results in a lengthening of the first postpacing interval of these PEB's. A further increase to 100 stimuli, however, induces overdrive suppresslon.

The R-R interval of the idioventricular rhythm increased from $1360 \pm 490$ to $1430 \pm 320 \mathrm{~ms}(\mathrm{p} \leq 0.001)$ in a dose dependent way (figure 4, panel 3). A maximum was reached at $20 \mu \mathrm{g}$ of ouabain (1520 $\pm 390 \mathrm{~ms})$ and a gradual decrease was observed at larger amounts of ouabain. Following administration of the toxic dose the mean R-R interval was $1390 \pm 380 \mathrm{~ms}$.

Ouabain administration resulted in a dose dependent increase in the ability to induce PEB's. For example, for 10 stimuli, the incidence increased significantly from $41 \%$ to $70 \%$ at therapeutic and to $93 \%$ at toxic levels (figure 4 , panel 1). Similar results were obtained for the other pacing variables (figure 1, upper panels). Similar to the results shown in figure 1 higher dosages of ouabain induced more PEB's per stimulation-train, finally resulting in sus- 


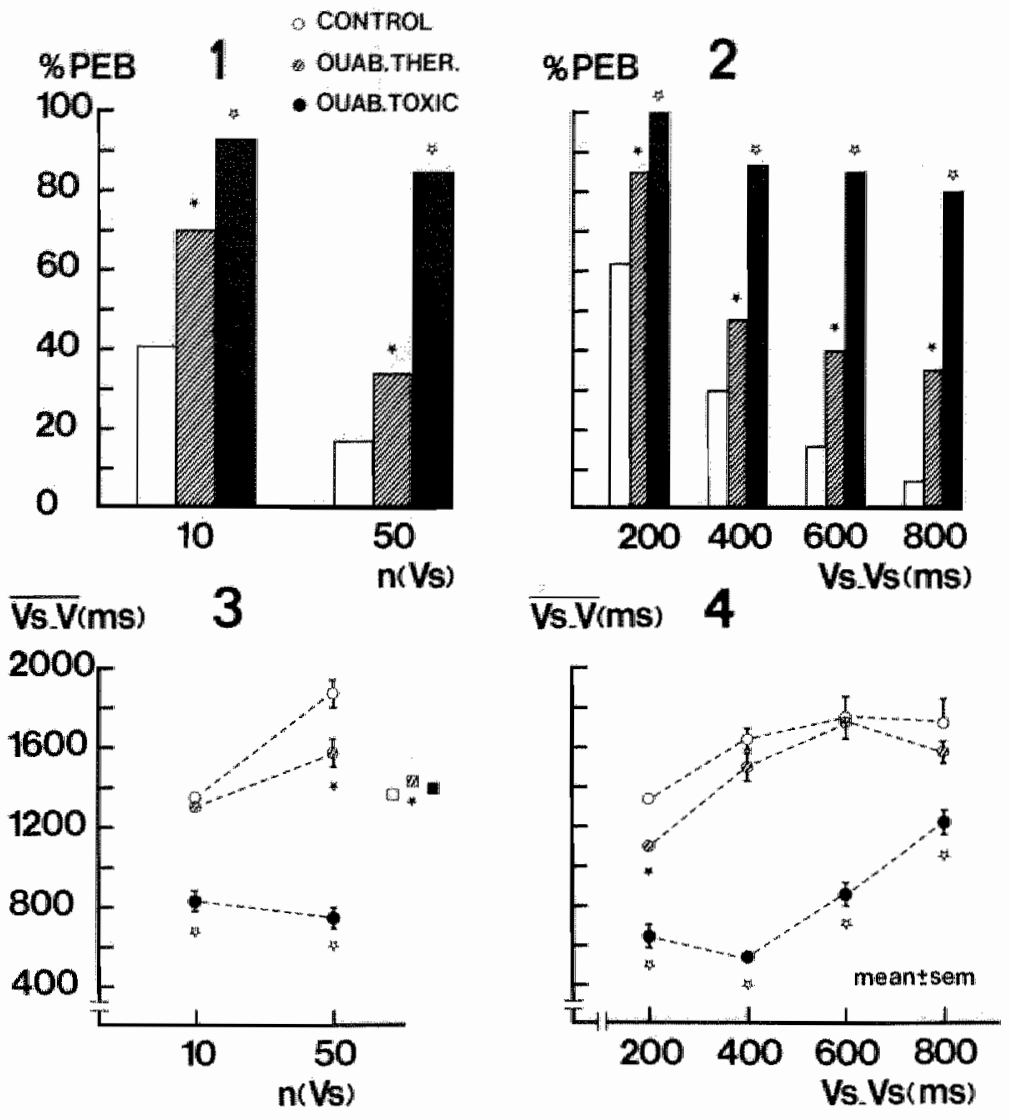

Figure 4. The effect of different dosages of ouabain on premature escape beats (PEB's).

In the upper panels, the ablity to induce PEB's (vertical axis) is presented in relation to vartations in number of stimull (panel 1) and interstimulus interval (panel 2). The same representation is used for the length of the first postpacing interval in the lower panels. Control data are llustrated as open symbols, while the therapeutic dosage of ouabaln is in grey and the toxic dosage in black. The squares in panel 3 represent the mean of the spontaneous RR intervals under the three conditions.

Ouabain administration results in: 1) a dose dependent increase in the ability to induce PEB's (panels 1-2), and 2) a dose dependent decrease of the first postpacing interval (panels 3-4). Note that the observed relations under control conditions: l.e. higher incidence and reduced coupling interval when pacing is performed for fast and/or short stimulations trains remain present under the different dasages of ouabain. $\star=p \leq 0.01$ versus control, while $t=p \leq 0.01$ versus therapeutic dosage of ouabain. 
tained VT. The observed relations seen in control conditions persisted: i.e. inducibility of $\mathrm{PEB}$ 's decreased on increasing the number of stimuli (figure 4 , panel 1). Also inducibility decreased at longer interstimulus intervals, although differences became small at toxic levels of ouabain (figure 4, panel 2). The first postpacing interval of PEB's showed a dose dependent reduction during ouabain administration. This reduction was independent of the number of stimuli and the interstimulus interval (figure 4, panels 3 and 4). At therapeutic levels of ouabain the first postpacing interval lengthened on increasing the number of stimuli (figure 4, panel 3). In contrast this interval shortened at toxic levels. The observed reduction in first postpacing interval on decreasing the interstimulus interval remained present after ouabain (figure 4, panel 4).

\section{Lidocaine}

A total of 400 stimulations were given both under control conditions and after lidocaine administration. During lidocaine the $R-R$ intervals of the tdioventricular rhythm increased markedly from $1350 \pm 150$ to $1550 \pm 240 \mathrm{~ms}$ (p s 0.001 ).

The ability to induce PEB's was diminished during lidocaine administration independent of number of stimuli and interstimulus interval (figure 5, upper panels). This decrease occurred in a use-dependent fashion: it was most outspoken following 50 stimuli and an interstimulus interval of $200 \mathrm{~ms}$. Secondly, lidocaine significantly increased the first postpacing intervals of the PEB's. Again this was independent of the number of stimuli (figure 5, lower left panel) and the interstimulus intervals (figure 5, lower right panel).

\section{Dororubicin}

The pacing protocol consisted of 120 stimulations under control conditions and 240 after doxorubicin administration. This drug caused a slight but significant increase of the last prepacing interval from $1160 \pm 260$ to $1250 \pm$ $310 \mathrm{~ms}(\mathrm{p} \leq 0.01)$.

The effect of doxorubicin on the ability to initiate PEB's and their coupling interval is summarized in table 2 . There was a decrease seen in inducibility of PEB's, which was significant $(\mathrm{p} \leq 0.01)$ for 50 stimuli and interstimulus intervals 200 and 600 ms. In figure 6, an example of suppressing a PEB using doxorubicin is presented. Also, the first postpacing interval of the remalning PEB's lengthened, although this was not significant for any of the pacing variables. 

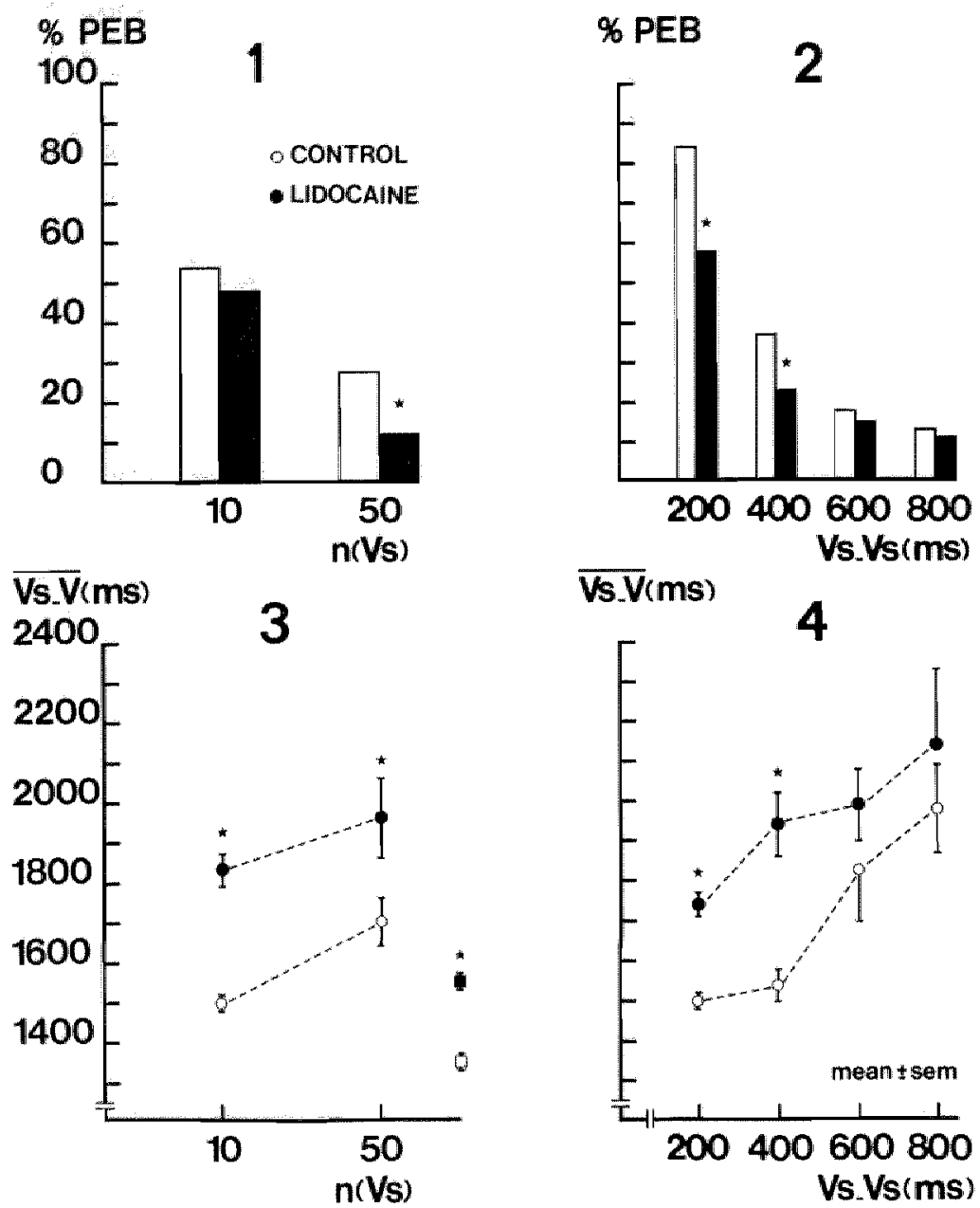

Figure 5. The effect of lidocalne on premature escape beats (PEB's).

In the upper panels, the ability to induce PEB"s (vertical axis) is presented in relation to varlations in number of stimuli (panel 1) and interstimulus interval (panel 2). Similar representation is used for the first postpacing interval in the lower panels. The squares in panel 3 represent the mean of the spontaneous RR intervals.

Lidocaine administration results in: 1) a diminished inctdence of PEB's (panels 1-2), 2) a lengthening of their first postpacing interval (panels 3-4), and 3) Increase in the mean spontaneous RR intervals (panel 3). Note that the behaviour of PEB's to variations in pacing persist after lidocaine adminilstration (panels $1-4$ ]. $\star=p \leq 0.05$ versus control. 
Table 2. The effect of doxorubicin on incidence and duration of the first postpacing interval of premature escape beats.

\begin{tabular}{lllllll}
\hline & \multicolumn{2}{l}{ Number of stmuli } & & \multicolumn{2}{l}{ Interstimulus interval } \\
\cline { 2 - 3 } \cline { 6 - 7 } & 10 & 50 & & 200 & 400 & 600 \\
\hline \%PEB C & $53 \%$ & $18 \%$ & & $78 \%$ & $20 \%$ & $10 \%$ \\
\%PEB D & $43 \%$ & $5 \%$ & & $56 \% *^{*}$ & $15 \%$ & $0 \%$ \\
Vs-V C & $1280 \pm 240$ & $1570 \pm 470$ & $1310 \pm 350$ & $1620 \pm 160$ & $1710 \pm 0$ \\
Vs-V D & $1350 \pm 240$ & $1810 \pm 430$ & $1330 \pm 250$ & $1700 \pm 260$ & - \\
\hline
\end{tabular}

Mean \pm standard deviatian; \% PEB = Induclbility Premature Escape Beat ${ }_{*}^{*}$ Vs-V $=$ The Arst postpacing interval; $\mathrm{C}=$ Control; $\mathrm{D}=$ Doxorubicin; * $=\mathrm{p} \leq 0.01$ versus control

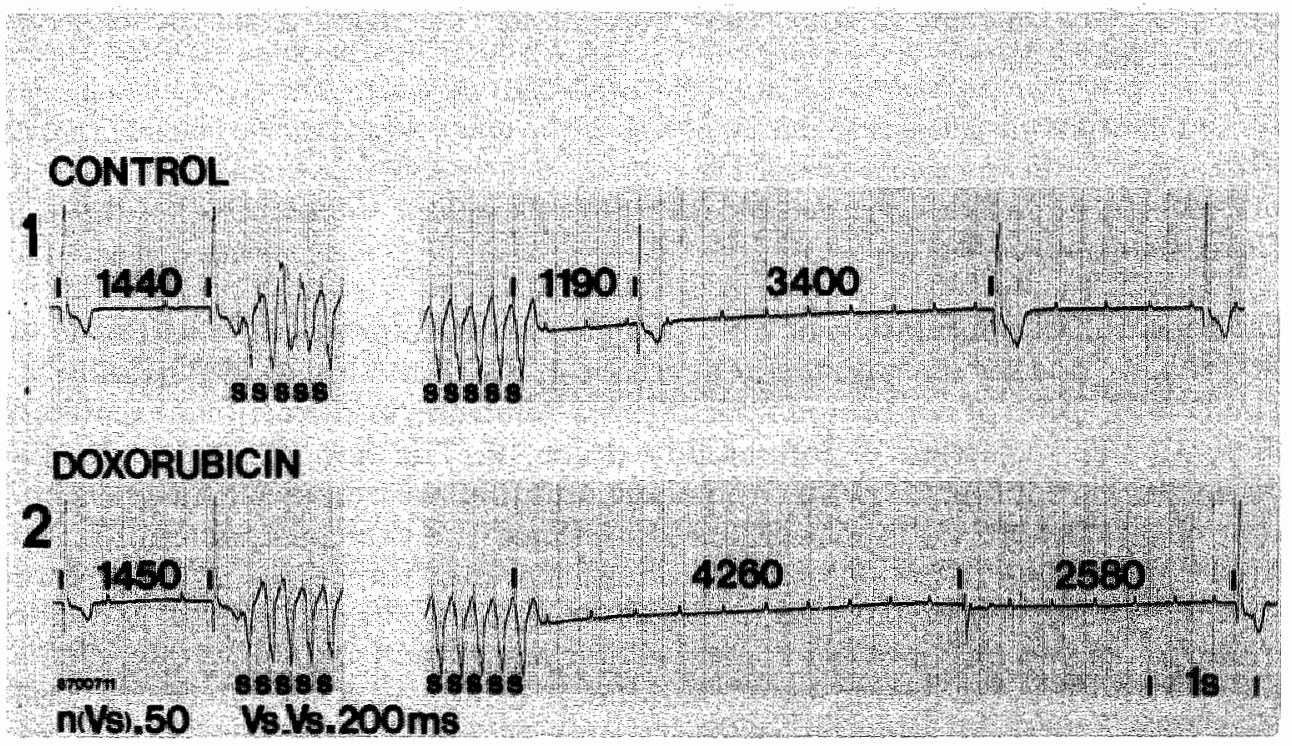

Flgure 6. Suppression of a premature escape beat using doxorubicin.

In both panels, stimulation is performed from the left ventricle using 50 stimull and an interstimulus interval of $200 \mathrm{~ms}$. Under control conditions, a PEB is induced: the first postpacing interval is shorter than the second (panel 1). After administration of doxorubicln. the same stimulation-train results in overdrtve suppression (panel 2). 
Table 3. The effect of continuous pacing on incidence and duration of the first postpacing tnterval of premature escape beats.

\begin{tabular}{|c|c|c|c|c|c|}
\hline & \multicolumn{2}{|c|}{ Number of stimull } & \multicolumn{3}{|c|}{ Interstimulus interval } \\
\hline & 10 & 50 & 200 & 400 & 600 \\
\hline \multicolumn{6}{|l|}{$\%$ PEB } \\
\hline $\mathrm{C}$ & $59 \%$ & $25 \%$ & $73 \%$ & $23 \%$ & $18 \%$ \\
\hline CP 800 & $33 \%$ & $7 \%$ & $41 \%$ & $2 \%$ & $3 \%$ \\
\hline $\mathrm{CP}+\mathrm{L}$ & $15 \%$ & $0 \%+$ & $23 \%{ }^{*}+$ & $0 \%$ & $0 \%$ \\
\hline$C P+D$ & $20 \%+$ & $0 \% "+$ & $30 \%$ & $0 \%$ & $0 \%$ \\
\hline \multicolumn{6}{|l|}{$\mathbf{V g - V}$} \\
\hline C & $1360 \pm 280$ & $1430 \pm 400$ & $1300 \pm 300$ & $1560 \pm 270$ & $1710 \pm 270$ \\
\hline CP800 & $1590 \pm 310$ & $1410 \pm 290$ & $1540 \pm 300$ & $1770 \pm 290$ & $1850 \pm 630$ \\
\hline $\mathrm{CP}+\mathrm{L}$ & $1630 \pm 340$ & - & $1630 \pm 340$ & - & - \\
\hline$C P^{\prime}+D$ & $1880 \pm 100$ & - & $1880 \pm 100$ & - & - \\
\hline
\end{tabular}

Mean \pm standard deviation; \% PEB = Inductbillty Premature Escape Beats: Vs-V = The first postpacing interval: $\mathrm{C}=$ Control; $\mathrm{CP} 800=$ Continuous Pacing using a cycle length of $800 \mathrm{~ms}$; $\mathrm{CP}+\mathrm{L}=\mathrm{CP} 800+$ Lidocaine; $\mathrm{CP}+\mathrm{D}=\mathrm{CP} 800+$ Doxorubicin; $* \mathrm{p} \leq 0.001$ versus control $;+=\mathrm{p}$ $\leq 0.05$ versus $C P 800$

\section{Continuous pacing}

On continuous stimulation of the ventricles using interstimulus intervals of $800 \mathrm{~ms}$, we observed a significant decrease in the induction of PEB's (table 3). The combination of continuous pacing with lidocaine or doxorubicin resulted In a further reduction of inducibility (table 3). The few PEB's which still occurred were Induced by fast and short stimulation-trains. With the exception of 50 stimuli, all interventions lengthened the first postpacing interval (table 3). This increase was most pronounced after the combination of continuous pacing and medication. In figure 7 , an example is presented. Note the induction of two PEB's under control conditions, which are followed by a long pause. Continuous pacing led to induction of one PEB and both the first postpacing interval and the overdrive suppressed second interval are increased. Finally, the combination of continuous pacing and lidocaine completely suppressed the induction of the PEB, while increasing overdrive suppression. 


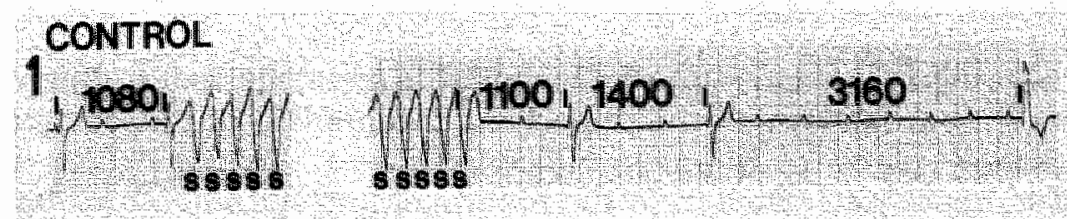

\section{CONTINUOUS PACING}
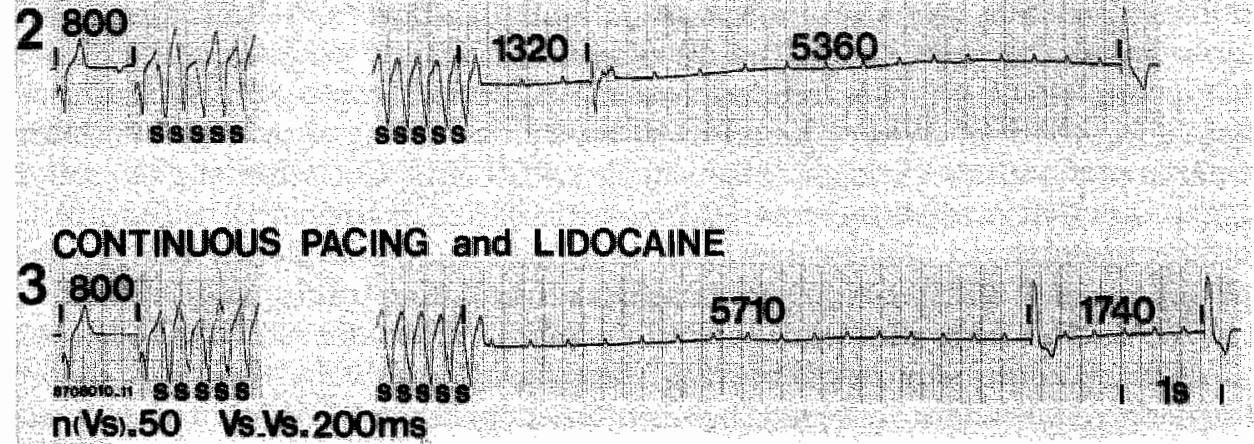

Figure 7. The effect of continuous pacing with and without lidocaine on premature escape beats (PEB's).

The idtoventricular rhythm is overdriven using 50 stimull and an interstimulus interval of 200 ms. Pacing is perfiormed from the apical part of the left ventricle. In panel 1, two premature escape beats are induced: both RR Intervals are shorter than the subsequent ones. Decreasing the spontaneous R-R interval from $1080 \mathrm{~ms}$ to $800 \mathrm{~ms}$ by continuous pacing (panel 2) results In the induction of only one PEB with an increase in the first postpacing interval from 1100 to $1320 \mathrm{~ms}$. The combination of continuous pacing and lidocalne induces overdive suppresstion (panel 3). Note also that the amount of overdrive suppression increases from 3160 (panel 1) to $5710 \mathrm{~ms}$ in panel 3.

\section{DISCUSSION}

The results of this study show that in conscious dogs with surgically induced AV-block, overdrive stimulation of the idioventricular rhythm not only results in suppression of the spontaneous pacemaker focus but also in the induction of QRS-complexes with an unexpectedly short interval. The latter gRS-complexes were termed PEB'S, which were defined as having a first postpacing interval shorter than the second. This definition was chosen because in classical overdrive suppression, the first postpacing interval is the longest one $[3,4)$. Thereafter gradual acceleration occurs until prepacing values are attained.

It was found that: 1) the chance to induce a PEB increased, and 2) their first postpacing interval decreased using short and/or fast drives. Especially the concordant relations observed between both inducibility and first postpacing 
interval of PEB's with the interstimulus interval suggested that triggered activity resulting from DAD's was the underlying mechanism of this ectopic impulse formation.

Support for this hypothesis came from the results of pacing in combination with (different dosages of ouabain, lidocaine and doxorubicin. Ouabain increased in a dose dependent way: 1) the ability to induce PEB's, 2) the number of PEB's per stimulation-train, and 3) shortened their first postpacing interval (figure 4). On the other hand, lidocaine and doxorubicin had an opposite effect: 1) lower incidence of PEB"s, and 2) lengthening of their first postpacing interval. While the effect of lidocaine still leaves several arrhythmogenic mechanisms possible, the effect of doxorubicin clearly suggests that triggered activity resulting from DAD's is the cause of these PEB's $(22,23)$.

Both drugs showed a use-dependent behavior: they completely suppressed the induction of PEB's when using longer stimulation-trains, while the effect of short and/or fast stimulation-trains was only partially effective. This is a well-known action for lidocaine (24) but for doxorubicin this has to our knowledge not been reported before. Nelther lidocaine, doxorubicin nor ouabain changed the relations in regard to variations in pacing rate and duration as observed during control conditions. There was one exception: increasing the number of stimuli from 10 to 50 at toxic dosages of ouabain (figure 4, panel 3) did not result in a lengthening of the first postpacing interval but in a reduction. This may be explained by the possible ionic events underlying the appearance of PEB's (see below).

We have introduced the term "Premature Escape Beats", although we are aware that other names like "Accelerated Ventricular Escape Beat" (31). "Repetitive Ventricular Response" (32), or "Overdrive Excitation" (4) already exist to describe similar responses. Our definition of PEB"s, however, is different from previous terms: we relate the first postpacing interval to the subsequent $\mathrm{R}-\mathrm{R}$ interval. We avoided the term "acceleration" because this suggests a relation to the spontaneous $\mathrm{R}-\mathrm{R}$ interval prepacing. And although "true acceleration" can also be observed in PEB"s, they may have a first postpacing interval which is longer than the spontaneous prepacing interval. Secondly, PEB's do not need an additional condition besides stimulation: like ouabain $(31,32)$ or (elevated) catecholamines (4).

Because our dogs had artificial AV-block, it is conceivable that the occurrence of PEB's was related to this procedure. Support for such a relation would be the finding that the site of enhanced impulse formation was located close to the site of injection. Analysis of the timing of a local electrogram recorded from the site of AV-block and the onset of the GRS-complex postpacing revealed that PEB's frequently originate distant to the site of block. 


\section{Possible ionic mechanism of peb's}

Overdrive pacing results in sodium (and to a lesser extent in calcium) accumulation in the myocardial cells. Due to the AV-block our experimental dogs have a low ventricular rate (40-50 beats per minute). This implies that the activity of the $\mathrm{Na}^{+} / \mathrm{K}^{+}$ATP-ase will be low too (4). Because of the $\mathrm{Na}^{+} / \mathrm{K}^{+}$ ATP-ase operates with a time delay in respect to the onset of drive (4), it will not be able to adapt to a sudden increase of electrolytes. The resulting sodium accumulation is exchanged by calcium through the $\mathrm{Na}^{+} / \mathrm{Ca}^{2+}$ exchange leading to calcium overload. Calcium is released in an oscillatory way from the sarcoplasmic reticulum (19). It is in this setting that DAD's can arise (18). Concomitantly, the $\mathrm{Na}^{+} / \mathrm{K}^{+}$ATP-ase resumes control resulting in suppression of triggered activity and in overdrive suppression of the subsequent Idioventricular rhythm. A longer period of pacing either by increasing the number of stimuli and/or increasing the interstimulus interval enables the $\mathrm{Na}^{+} / \mathrm{K}^{+}$ATP-ase to become fully active. By this the appearance of DAD's are prevented or the height of their amplitude diminished resulting in no PEB's but only overdrive suppression. This may explain why PEB's are less easily induced at a higher number of stimuli and after longer interstimulus intervals.

Increasing the rate of the ventricles results in activation of the $\mathrm{Na}^{+} / \mathrm{K}^{+}$ ATP-ase. In our experiments, this was achieved by continuous pacing with $800 \mathrm{~ms}$ intervals. This procedure resulted in responses according to the mechanism described above. It was found that (table 3): 1) the inducibility of PEB's decreased, and 2) their first postpacing interval lengthened. The PEB"s which could still be induced were seen especially after fast and short stimulation-trains.

Also the effect of ouabain is in agreement with our hypothesis. It diminishes the ability of the pump to become activated. Because of this property this drug is expected to increase induction of PEB's after longer stimulationtrains. Apparently, stimulation with 50 stimuli did not result in an adequate adaptation of $\mathrm{Na}^{+} / \mathrm{K}^{+}$ATP-ase leading to suppression but to a further increase in the intracellular sodium concentration inducing (more) PEB's with shorter first postpacing intervals. The observed increase in first postpacing interval on increasing the number of stimuli under control conditions is less pronounced following therapeutic dosages of ouabain and is even reversed after toxic dosages of ouabain (figure 4, left panel).

Combining the effect of continuous pacing with either lidocaine or doxorubicin further suppressed the ability to induce PEB's.

As shown in figure 7 , overdrive pacing of the idioventricular rhythm could induce more than one PEB followed by overdrive suppression. This is in agreement with in vitro experiments, in which more DAD's reaching threshold could be induced $[5,6,21)$ following fast pacing trains. Against this explanation speaks the fact that application of this stimulation protocol in isolated tissue did not result in induction of PEB"s nor in DAD's (unpublished observations by Molina Viamonte $V$, and Rosen MRJ. However, a number of 
differences exists between the experimental conditions in vitro and in the intact heart. The spontaneous rate in isolated Purkinje fibers is markedly slower than in the intact heart. Isolated tissue lacks innervation of the autonomic nervous system. Sympathetic contribution is an important factor in the induction of triggered activity. The number of potential pacemakers in vitro is much smaller than in the intact heart. Therefore, we are not convinced that this negative observation exclude the possibility of triggered activity as an explanation for the results of our experiments, but we think that other additional factors must contribute to the heart in situ. This is supported by studies from Vassalle et al. (4), who showed that the induction of similar beats by pacing was only possible in the presence of elevated levels of catecholamines.

\section{Other arrythmogenic mechanisms}

Abnormal automaticity, enhanced normal automaticity, or reentry have also be considered as possible underlying mechanisms of PEB's.

Abnormal automaticity is unlikely because PEB's frequently had the same QRS-configuration as the markedly suppressed second QRS-complex (figures 2 and 3), which indicate that PEB's orlginate from focl with a high diastolic membrane potential (33).

Reentry cannot explain the suppression of PEB's on increasing the number of stimuli. Moreover, 1) the induction of PEB's was not restricted to a specific range of interstimulus intervals, and 2) the frequency of induction of PEB"s increased when the interstimulus interval was shortened.

The third possible mechanism is enhanced normal automaticity. It was suggested (34) that electrical stimulation results in catecholamine release at the site of stimulation. This mechanism seems unlikely because then PEB"s are expected to have a similar QRS-configuration as the paced beats, which was not the case. A second observation argueing against involvement of catecholamines is the disappearance of PEB's at higher number of stimuli, an intervention expected to increase the induction of PEB's. In addition, continuous pacing often induced marked overdrive suppression of the second interval, while the PEB was still inducible.

Triggered activity resulting from DAD's as the cause for PEB's is suggested by several observations: 1) the incidence and length of the first postpacing interval in relation to variations in pacing, 2) promotion of induction by ouabain, 3) suppression by lidocaine, doxorubicin and continuous pacing, and 4) shortening of the first postpacing interval of the PEB's by ouabain, and lengthening by lidocaine, doxorubicin and continuous pacing.

In conclusion, the results obtained in these experiments support our hypothesis that PEB's are based upon triggered activity. 


\section{Clinical Implications}

Triggered activity has been demonstrated in vitro under many different pathophysiological conditions. This suggests a more frequent occurrence of arrhythmias based on this mechanism than is presently thought. Systematic study of triggered activity in the human heart is still not feasible because of lack of sufficiently specific tools to identify this mechanism clinically. Therefore, an intact heart model is urgently needed. When triggered activity is indeed the underlying mechanism for the PEB's, our model may allow systematic investigation of this mechanism in the intact heart under different pathophysiological circumstances and/or pharmacological interventions. 


\section{REFERENCES}

1. Corgels APM. Ventricular impulse formation and the induenice of digitalis intoxication. Thesis, University of Limburg. The Netherlands, Schrijen-Luppertz, Voenendaal, 1985.

2. Lange 6 : Action of driving stimuli from intrinsic and extrinsic sources on in situ cardiac pacemaker tissues. Circ. Res. 1965; 17:449-459.

3. Vassalle M. Electrogentc suppressiton of automaticity in sheep and dog Purkinje flbers. Circ. Res. 1970; 27: 361-377.

4. Vassalle $M$, Cummins $M$, Castro $C_{\text {" }}$ and Stuckey $J H$. The relationship between overdrtve suppression and overdrive excitation in ventricular pacemakers in dogs. Circ. Res. 1976; 38: $367-374$.

5. Ferrler GR. Digitalis arrhythmias: Role of oscillatory afterpotentials. Progress Cardiovasc. Dis. 1977; 19: 459-473.

6. Rosen M, and Danilo P. Digitalis induced delayed after depolarzations. In: "The slow Inward current and cardiac arrhythmias", eds: Zipes $D_{n}$ Balley J, and Elharrar V, Martinus Ny hof, The Hague 1980; 417-435.

7. Gorgels APM, de Wit B, Beekman HDM, Dassen WRM, and Wellens HJJ. Triggered activity Induced by pacing during digitalts intoxdcation. PACE 1987: 10: 1309-1321.

8. Cranefield PF, and Aronson RS. Cardlac Arrhythmlas: the role of triggered activity and other mechanisms. Futura Publlshing Company Inc., Mount KIsco, New York, 1988.

9. Wit $\mathrm{AL}_{\text {, }}$ and Cranefield PF. Triggered activity in cardiac muscle fibers of the simian mitral valve. Circ. Res. 1976; 38: 85-98.

10. Johnson N, Danilo P. Wit AL, and Rosen MR Characteristics of initiation and termination of catecholamine induced triggered activity in atrial fibers of the coronary sinus. Circulathon 1986; 74: 1168-1179.

11. Elsner DA, and Lederer WJ. Inotropic and arrhythmogenic effects of potassium-depleted solutions on mammalian cardiac muscle. J. Physiol. 1979; 294: 255-277.

12. Hiraoka $M$, Okamoto $Y$, and Sano $T$, Oscillatory after-depolarkations in dog ventricular muscle fiber. Circ. Res. 1981; $48: 510-518$.

13. El-Sherif N, Gough WB, Zeller RH, and Mehra R. Triggered ventricular rhythms in 1-day-old myocardlial infarction in the dog. Circ. Res. 1983; 52: 566-579. 
14. LeMarec H, Dangman KH. Danillo $P$, and Rosen MR. An evaluation of autornaticity and triggered activity in the canine heart one to 4 days after myocardial infarction. Circulation. 1985; 71 : 1224-1236.

15. Fernler GR, Moffat MP. and Lukas A. Possible mechanisms of wentricular anthythmas elicited by ischemia followed by reperfusion. Circ. Res. 1985; 56:184-194.

16. Thandroyen FT. McCarthy J, Burton KP, and Ople LF. Ryanodine and caffeline prevent ventricular arrhythmias during acute myocardial ishemla and reperfusion in rat heart. Circ. Res. 1988; 62: 306-314.

17. Aronson RS. Afterpotentials and triggered activity in hypertrofled myocardium from rat with renal hypertenston. Circ. Res. 1981; 48: 720-727.

18. Kass RS, Lederer W.J. Tsien RW, and Weingart R. Role of calclum tons in transient Inward currents and aftercontractions induced by strophanthidin in cardlac Purkdnje nbers. J. Physiol. 1978; 281: 187-208.

19. Orchard $\mathrm{CH}$. Eisner DA, and Allen DG. Osctllations of intracellular $\mathrm{Ca}^{2+}$ in mammalian cardiac muscle. Nature 1983; 304: 735-738.

20. Malfatto G, Rosen TS, and Rosen MR. The response of overdrive pacing of triggered atrlal and ventricular arrhythmias in the canine heart, Circulation 1988: 77: 1139-1148.

21. Rosen MR, and Danilo P. Effects of tetrodoxin, lidocaine, verapamil and AHR-2666 on ouabain-induced delayed afterdepolarizations in canine Purkinje fibers. Circ. Res. 1980; 46: $117-124$.

22. LeMarec $H$, Spinelli $W$, and Rosen MR. The effects of doxorubicin on ventricular tachycardia. Circulation 1986:74:881-889.

23. Binah $O$, Cohen IS, and Rosen MR. The effects of adriarnycin on normal and ouabaln-toxic canine Purkinje and ventricular muscle fiber. Circ. Res. $1983 ; 53: 655-662$.

24. Bean $\mathrm{BP}$ " Cohen $\mathrm{CJ}$, and Tsien RW. Lidocalne block of cardiac sodium channels. J. Gen. Physiol. 1983; 8: 613-742.

25. Steiner $\mathrm{CH}$, and Kovalik ATHW. A simple technique for production of chronic complete heart block in dogs. J. Appl. Physiol. 1968;25: 631-632.

26. Vassalle $M$, Knob RE, Cummins M, Lara GA, Castro $C$, and Stuckey JH. An analysis of fast idioventricular rhythm in the dog. Circ. Res. 1977: 41: 218-227.

27. Ilvento JP, Provet J, Danllo P. and Rosen MR. Fast and slow Idloventricular rhythms in the canine heart: A study of their mechanism using antlarrhythmic drugs and electrophysiologic testing. Am. J. Cardiol. 1982: 49: 1909-1916. 
28. Steld A v.d., Dassen W, Gorgels APM, Beekman HDM, and Wellens HuJ. Flexible multprocessor system to support electro-physiological investigation in animals. Computers Cardiol. 1984; $525-528$.

29. Fhee HM, Dutta $\mathbf{S}$, and Marks BH. Cardiac $\mathrm{Na}^{+} / \mathrm{K}^{+}$ATP ase activity during positive inotrople and toxic actions of ouabain. Eur. J. Pharmacol. 1976, 37: 141-153.

30. Seldlen $\mathrm{R}$, and Smith TW. Ouabain pharmacokinetics in man and dog: determinations by radio-Iminunoassay. Circulation 1972; 45: 1176-1182.

31. Zipes DP, Arbel E, Knope RF, and Moe GK. Accelerated cardiac escape rhythms caused by ouabaitn intoxication. Am. J. Cardiol, 1974: 33: 248-253.

32. Lown B, Cannon RL, and Rossi M. Electrical stimulation and digitalis drugs: repetitive responses in diastole. Proc. Soc. Exp. Blol. Med. 1967; 126: 698-701.

33. Dangman $\mathrm{KH}$, and Hofmann $\mathrm{BF}$. Studies on overdrive st mulation canine cardiac Purkinje fibers: Maximal diastolic potential as a determinant of the response. $\mathrm{J}$. Am. Call. Cardiol. 1983; 2 : 1183-1190.

34. Vincenz FF, and West ThC. Release of autonomic mediators in cardiac tissue by direct subthreshold electrical stimulation. J. Pharmacol. Exp. Ther. 1963; 141: 185-194. 
Value of programmed electrical stimulation to identify arrhythmias caused by abnormal automaticity in vivo

\author{
Marc A Vos \\ Anton PM Gorgels \\ Jet DM Leunissen \\ Hein JJ Wellens
}




\title{
Value of programmed electrical stimulation to identify arrhythmias caused by abnormal automaticity in vivo
}

\begin{abstract}
Ventricular tachycardia (VT) occurring 16-24 hours following LAD-occlusion has been used as a model for abnormal automaticity (AA) in the intact heart. It has been described that in witro overdrive pacing of rhythms based on AA results in marked, slight, or no suppression depending on the dlastollic membrane potential.

In 12 conscious dogss with AV-block, we investigated the response of these VT to overdrive pacing using stimulation-trains lasting 15,60 , and $120 \mathrm{~s}$ with interstimulus intervals of 400 . 300 , and $200 \mathrm{~ms}$. The GRS-confguration, the mean cycle length of VT before (VT pre) and after pacing (VT post), and the first postpacing interval (Vs-V) were measured.

Twenty-two different QRS-configurations were identified during sustained VT. In 13, terminathon of VT occurred (group T). VT pre was $420 \pm 60 \mathrm{~ms}$ in group $\mathrm{T}$ and $360 \pm 30 \mathrm{~ms}$ (p $\leq 0.01$ ) In the non-suppresstble group (group NT). Termination was also dependent on rate and duration of pacing: the longer and the faster the stimulation-train the higher the chance to terminate VT. Stimulation did not accelerate VT post.

In group $T$, a significant Increase in $V_{s-V}$ was observed on shortening the interstimulus Interval, while a decrease was seen in NT. Secondly, increasing the duration of pacing resulted in a signiflcant lengthenimg of $\mathrm{Vs}-\mathrm{V}$ in group $\mathrm{T}$, but in no change in NT. However, when the stimulation-trains terminating VT were excluded from group $T$, Identical behavior of Vs-V was noticed as in NT.

In conclusilon, overdrive termination of VT based on AA depends on the cycle length of the tachycardia and the stimulation mode. suggesting that these arrhythmias originate from different diastolic membrane potentials. Untll termination. the behavior of Vs-V during pacing did not predict suppressiblity of VT.
\end{abstract}

Submitted for publication 


\section{INTRODUCTION}

Over the years, the existence of several mechanisms of cardiac arrhythmias has been demonstrated (1). The most important arrhythmogenic mechanisms are reentry, abnormal automaticity, and triggered activity based on early or delayed afterdepolarizations. The clinical relevance of abnormal automaticity and triggered activity is not well known. The main reason for this is the lack of specific tools for differentiating between the different mechanisms of arrhythmias. Increasing our knowledge of the underlying mechanism is important, because it may lead to more rational treatment. Therefore, we have studied the effect of programmed electrical stimulation on abnormal automaticity in the intact heart.

For this purpose, ventricular tachycardias (VT) occurring spontaneously 16-24 hours after occlusion of the left anterior descending artery (LAD) were studied. These arrhythmias are a well known model for abnormal automaticity (2-4), which is defined as spontaneous impulse generation originating from a reduced maximal diastolic potential in cardiac fibers, normally showing a high diastolic membrane potential of -80 to $-90 \mathrm{mV}$ (1). The rate of these arrhythmias and their response to overdrive stimulation in vitro is dependent on the amount of reduction of the diastolic membrane potential (5). When the reduction is minimal (high diastolic potential), the rate will be slow and the tachycardia will be markedly suppressed following pacing. Arrhythmias originating from a more reduced potential (intermediate or low) are fast, and no or only slight overdrive suppression is seen postpacing.

In the intact heart, after coronary artery occlusion VT with different QRS-configurations can be observed (6-8), which likely represent different ectopic foci. Because VT with different configurations may also vary in rate, they possibly originate from different diastolic membrane potentials. It was the purpose of this study to identify automatic arrhythmias having different $Q R S$-configurations and investigate their response to overdrive stimulation. To eliminate interference of conducted sinus beats, we used dogs with artificially induced chronic AV-block. 


\section{METHODS}

\section{Preparation of study dogs}

The experiments were performed in 12 mongrel dogs of either sex with a body weight between $20-35 \mathrm{~kg}$. The animals underwent two operations: 1) to induce AV-block, and 2) to occlude the left anterior descending artery. At least 3 weeks passed between operations to allow full recovery of the animal and stabilize the idioventricular rhythm.

During the first (right) thoracotomy formalin 37\% was injected into the region of the bundle of His (9) to induce AV-block and two electrodes were sutured to the heart: one at the basal part of the right and the other at the apex of the left ventricle. The electrodes were exteriorized through the skin of the dorsal surface of the neck.

During the second (left) thoracotomy, a slightly adjusted Harris protocol (10) was used in the first 8 animals. The second diagonal branch of the LAD was ligated. In the last 4 dogs the original Harris protocol was used: occlusion of the $\mathrm{LAD} 1 \mathrm{~cm}$ below the left auricle just below or above the first diagonal. In both procedures, lidocaine was administered before ligation to prevent (lethall) arrhythmias. This drug was given as a bolus $(3 \mathrm{mg} / \mathrm{kg})$ in 2 minutes followed by a continuous infusion throughout the operation $(100 \mu \mathrm{g} / \mathrm{kg} / \mathrm{min})$. Proper care was taken postoperatively according to the statement of the American Physiological Society.

\section{Experiments}

Six external electrocardiographic (I, II, III, aVR, aVL, and aVF) and one epicardial lead were simultaneously registered on an ink jet recorder (Siemens Elema) and stored on tape. Pacing was performed with a programmable stimulator having a synchronizing circuit. Unipolar stimuli were given with a stimulus strength of twice diastolic threshold. Using a computerized QRScomplex detecting system, values of $R-R$ intervals were continuously displayed on a monitor screen allowing instantaneous evaluation of the ventricular rate (11).

The spontaneous VT occurring 16-24 hours following LAD-occlusion were registered for 20 minutes. During that period the (different) QRS-configuration(s) of the arrhythmia[s] were noticed. Overdrive pacing was started after a particular QRS-configuration had been dominant for at least one minute. Sttmulation during 15,60 , and 120 seconds was performed using interstimulus intervals of 400,300 , and $200 \mathrm{~ms}$. Pacing was done at random from both the right and the left ventricular electrode. 


\section{Data analysis}

The QRS-configuration and the mean of $10 \mathrm{R}-\mathrm{R}$ intervals before (VT pre) and after pacing (VT post) was determined. Also, the configuration and the interval from the last paced beat to the first spontaneous QRS-complex was measured. When the VT could be terminated by pacing, we waited at least two minutes after reoccurrence of VT before the stimulation protocol was continued.

Analysis of variance (ANOVA) and student's t-test for unpaired events were used to determine statistical significance. All data are presented as mean \pm standard deviation.

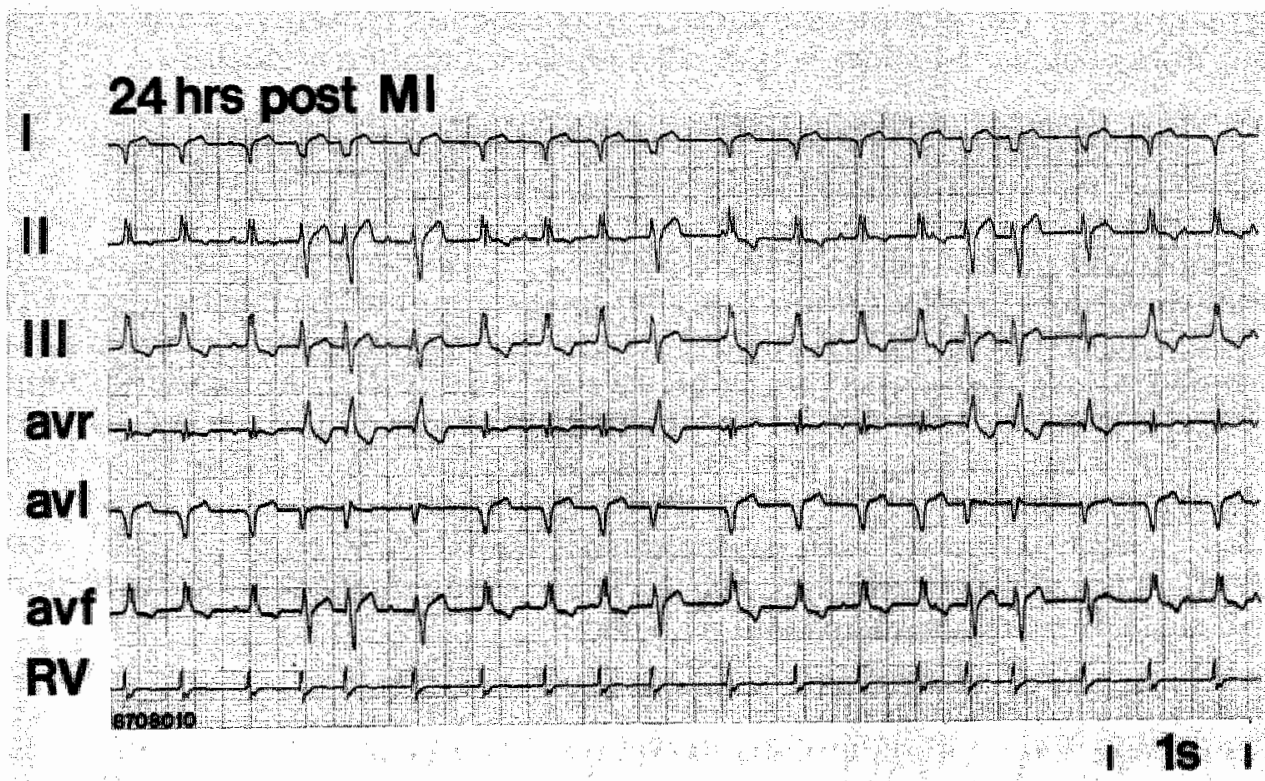

Figure 1. Spontaneous arrhythma(s) occurring 16-24 hours post myocardial infaunction. Note the competition between two different QRS-configurations, resulting in continuous QRS-changes because of varying degrees of fusion. 


\section{RESULTS}

\section{Termination}

Longlasting sustained VT was observed in all animals 16-24 hours after LAD-occlusion. A total of 22 different gRS-configurations were seen: only 1 QRS-configuration was present in 4 animals, 2 were seen in 6 animals, while 3 gRS-configurations were observed in the remaining 2 dogs. Usually, one focus was manifest during a certain period of time but competition between different foci could also be present resulting in continuous QRS-changes because of varying degrees of fusion (figure 1).

Overdrive pacing terminated 13 of 22 QRS-configurations $(60 \%)$. The cycle length of the VT which could reproducibly be terminated was significantly longer ( $420 \pm 60 \mathrm{~ms}$ ) than the cycle length in the non-suppressible group (360 $\pm 30 \mathrm{~ms}, \mathrm{p} \leq 0.01$ ). Both terminable and non-terminable VT could be observed within the same experiment. Termination was also dependent on rate and duration of stimulation (table 1). Pacing using interstimulus intervals of 300 ms was able to terminate the VT in $37 \%$, while pacing with interstimulus intervals of $200 \mathrm{~ms}$ achieved termination in $67 \%(\mathrm{p} \leq 0.001)$. Similar results were obtained on increasing the duration of pacing from 15 to $120 \mathrm{~s}$ (table 1). An example of the latter is presented in figure 2. Termination was not dependent on the site of stimulation. Spontaneous reoccurrence of the VT was always observed starting $30 \pm 55 \mathrm{~s}$ after termination of pacing.

\section{Behavior of first postpacing interval and VT post}

We looked at possible differences in behaviour of the first postpacing interval and/or VT post in relation to the ability to terminate VT by pacing (group T) versus those whom VT could not be terminated (group NT). Moreover, in group $\mathbf{T}$ we compared the stimulation-trains resulting in termination (group TT) versus those which did not (group TNT). This was done to detect possible parameters to differentlate between QRS-configurations which were or were not suppressible.

After pacing, we never observed a spontaneous QRS-complex which was identical to the paced complex. When tachycardia reappeared after pacing it had the same QRS-configuration as before.

\section{Interstimulus Interval}

Shortening of the interstimulus interval resulted in a significant reduction ( $p$ $\leq 0.05$ ) of the first postpacing interval in group NT, while the opposite was observed in group T (table 2). In group TNT, however, a similar concordant behaviour of the first postpacing interval was seen as in group NT. The only 
Table 1. The ability to terminate automatic arrhythmias in relation to variations in stimulus interval and duration of pacing.

\section{$\%$ Termination ANOVA}

\section{Stimulus interval}

$400 \mathrm{~ms}$

$300 \mathrm{~ms}$

$0 / 13=0 \%$

$200 \mathrm{~ms}$

$15 / 41=37 \% \quad \mathrm{p} \leq 0.001$

Duration of pacing

$\begin{array}{rrr}15 \mathrm{~s} & 7 / 30=23 \% & \\ 60 \mathrm{~s} & 13 / 28=46 \% & \mathrm{p} \leq 0.05 \\ 120 \mathrm{~s} & 13 / 23=57 \% & \end{array}$
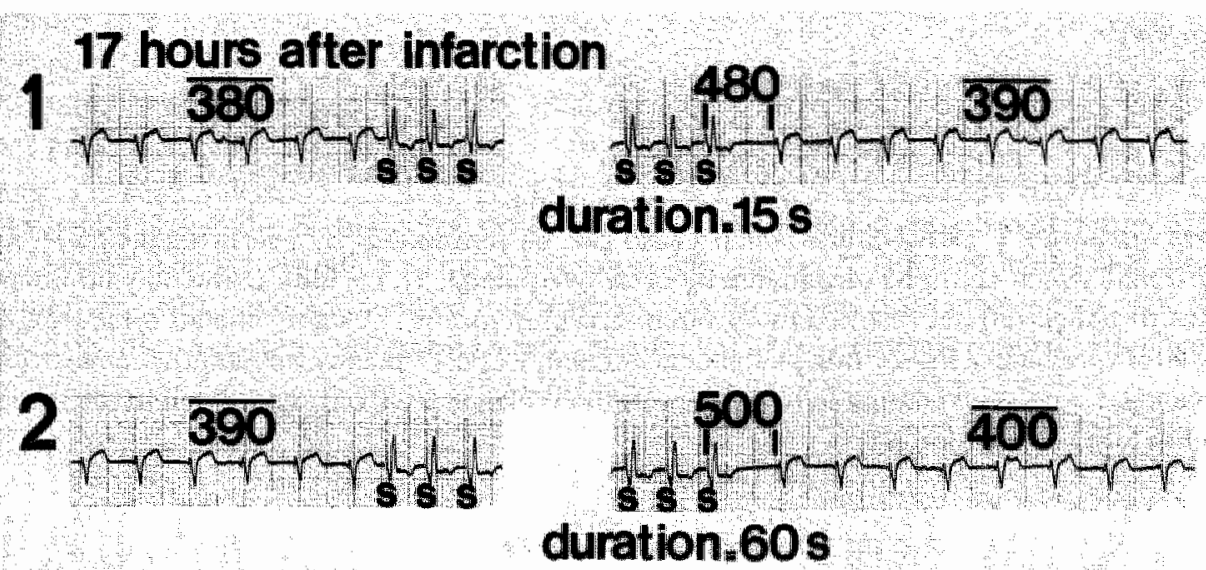

3

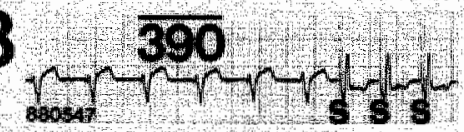

Vs-Vs.300ms

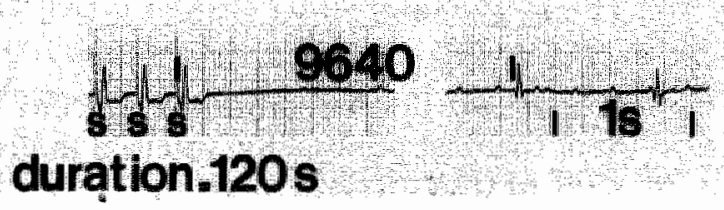

Figure 2. Termination of ventricular tachycardla occurring 16-24 hours post myocardial Infarction by overdrive pacing.

In the 3 panels, the spontaneous arrhythmia is overdriven (S) with an interstimulus interval of $300 \mathrm{~ms}$ using three different durations of pacing. In the first 2 panels, overdrive pacing using 15 (panel 1) or $60 \mathrm{~s}$ (panel 2) does not result in termination. Only a slight increase in first postpacing interval from $480 \mathrm{~ms}$ to $500 \mathrm{~ms}$ can be noticed. The cycle length of the tachycardia is not changed by pacing. After $120 \mathrm{~s}$ of overdrive pacing results in termination of VT. 
Table 2. The effects of changes in the interstimulus interval.

\begin{tabular}{|c|c|c|c|}
\hline & \multicolumn{3}{|c|}{ Interstimulus interval (ms) } \\
\hline & 200 & 300 & 400 \\
\hline \multicolumn{4}{|c|}{ Group NT } \\
\hline VT pre & $350 \pm 20$ & $370 \pm 30$ & - \\
\hline$V_{s-V}$ & $370 \pm 70$ & $430 \pm 90$ & - \\
\hline VT post & $340 \pm 20$ & $380 \pm 60$ & - \\
\hline \multicolumn{4}{|l|}{ Group $\mathrm{T}$} \\
\hline VT pre & $400 \pm 70$ & $420 \pm 50$ & $460 \pm 30$ \\
\hline $\mathrm{Vs}-\mathrm{V}$ & $1480 \pm 2070$ & $930 \pm 1600$ & $570 \pm 40$ \\
\hline VT post & - & - & $450 \pm 30$ \\
\hline \multicolumn{4}{|c|}{ Group TNT } \\
\hline VT pre & $410 \pm 80$ & $420 \pm 50$ & $460 \pm 30$ \\
\hline $\mathrm{Vs}-\mathrm{V}$ & $450 \pm 60^{+}$ & $530 \pm 50^{*+}$ & $570 \pm 40^{\circ}$ \\
\hline VT post & $420 \pm 80$ & $410 \pm 50$ & $450 \pm 30$ \\
\hline
\end{tabular}

Abbreviations: $\mathrm{NT}=$ arrhythmias which could not be terminated by overdrive pacing. $\mathrm{T}=$ arrhythmias which could be terminated by overdrtve pacing. TNT = data using only stimulation-trains which did not resulted in termination within group T. VT pre $=$ mean cycle length tachycardia prepacing, $V_{s-V}=$ first postpacing interval, $V T$ post $=$ mean cycle length tachycardia postpacing. $"=p \leq 0.05$ compared to the shorter interval(s),$+=p \leq 0.01$ compared to the same stumulus interval in group NT.

difference between these two groups was the length of the first postpacing interval, being significantly longer in TNT than in NT ( $p \leq 0.01$ ). VT post was not different from VT pre in any of the groups studied (table 2).

\section{Duration of pacing}

Increasing the duration of stimulation from 15 to $120 \mathrm{~s}$ did not influence the duration of the first postpacing interval in group NT (table 3), while there was an increase of this interval in group $T$. Again, considering the subgroup TNT within group T, a different behaviour was observed. Then no change in the first postpacing interval was seen, a response similar to the one seen in group NT. The length of this interval was significantly longer in group TNT than in NT ( $p \leq 0.001)$. Variations in duration of pacing did not result in changes in rate of VT post (table 3 ). 
Table 3. The effect of changes in the duration of pacing.

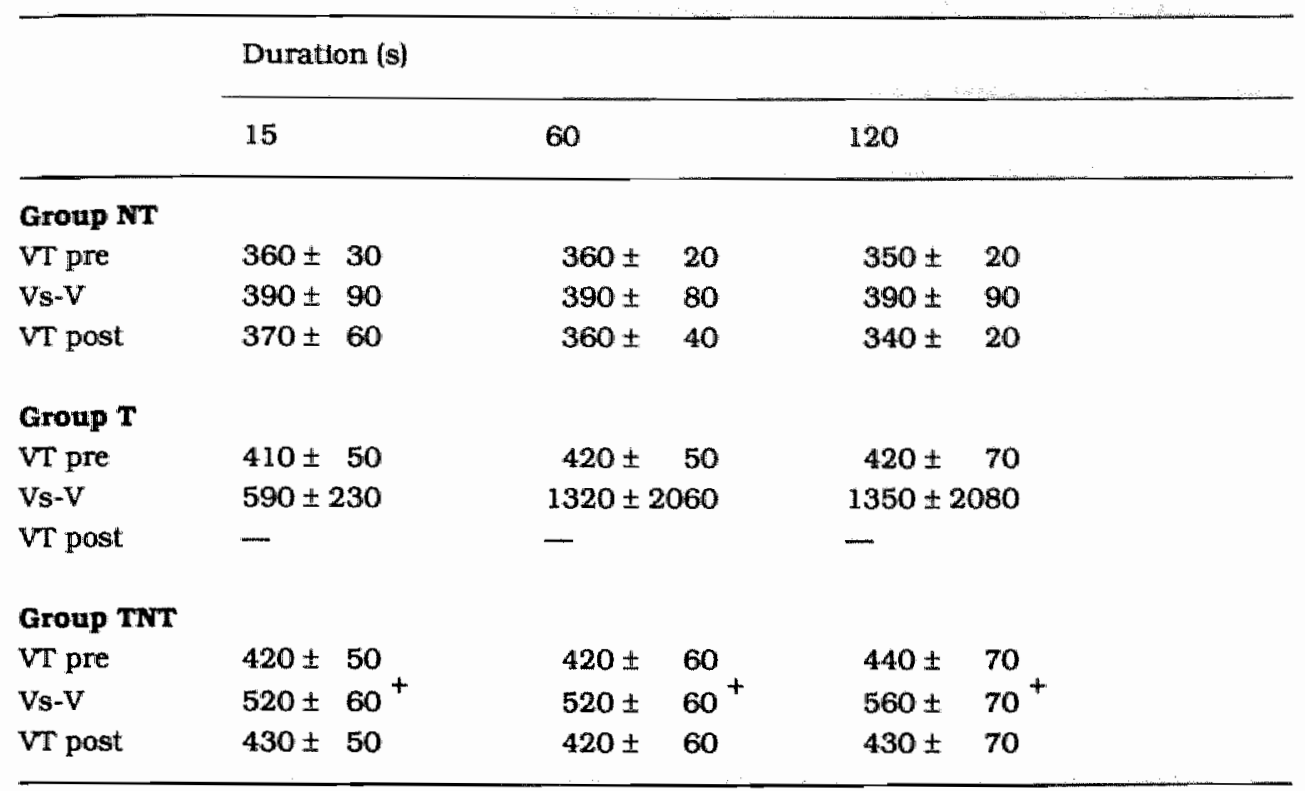

Abbreviations: $\mathrm{NT}=$ arrhythmtas which could not be terminated by overdrtve pacing. $\mathrm{T}=$ arrhythmias which could be terminated by overdrtve pacing, TNT = data using only stimulatIon-trains which did not resulted in termination within group $T$. VT pre = mean cycle length tachycardia prepacing ${ }_{n}$ Vs-V = first postpacing interval ${ }_{\text {. }}$ T post = mean cycle length tachycardia postpacing, $+=p \leq 0.001$ compared to the same duration in group NT.

\section{DISCUSSION}

In this study, we found that overdrive termination of VT occurring $16-24$ hours after LAD-occlusion in the intact canine heart depends on: 1) rate of the tachycardia, and 2) stimulation mode. The slower the arrhythmia and/or the faster and longer the stimulation-train, the greater the chance that the automatic VT is terminated.

These VT are most likely resulting from the arrhythmogenic mechanlsm abnormal automaticity (3), although triggered activity resulting from delayed afterdepolarizations has also been suggested as the cause (12). The inability of doxorubicin (4) and flunarizine (13) to terminate these spontaneous arrhythmias occurring 16-24 hours after LAD-occlusion makes the involvement of triggered activity unlikely.

In vitro, three types of abnormal automaticity have been recognized, according to the value of the diastolic membrane potential: high potential automaticity $(>-70 \mathrm{mV}$ ), intermediate potential automaticity (between -61 and -70 
$\mathrm{mV})$, and low potential automaticity $(<-60 \mathrm{mV})$. Both the rate of the arrhythmia and the ability to suppress these tachycardias depend on the type of automaticity: 1) the more negative the diastolic potential the slower the rate, and 2) short overdrive pacing (15 s) results in marked supression of high potential, slight suppression of intermediate and little or no suppression of low potential automaticity (5). The extent of overdrive suppression of intermediate potential automaticity was related to rate and duration of the overdrive train: the longer and faster the stimulation-train the greater the chance of suppression of the tachycardia. Low potential automaticity was not overdrive suppressible, even after periods of pacing of up to 5 minutes (5).

The different responses to pacing seen in the two groups in our study suggest that these arrhythmias are originating from Purkinje fibers with different diastolic membrane potentials. VT which can be terminated most likely belong to a less reduced diastolic membrane potential (i.e. high or intermediate) than non-suppressible VT. Also the faster rate of the non-suppressible VT supports this hypothesis. Both types of VT could be present in the same animal. This means that arrhythmias can originate from surviving Purkinje fibers having different diastolic membrane potentials.

When VT could be not terminated by pacing (group NT and group TNT), we noticed a similar response to variations in pacing: 1) a shortening of the first postpacing interval on decreasing the interstimulus interval, and 2) no change in this interval when the duration of pacing was increased. Therefore, during programmed electrical stimulation no prediction can be made concerning which tachycardia will be terminated and which will not.

In this study, we found a similar concordant relation between the interstimulus interval and the first postpacing interval as in VT resulting from triggered activity based on delayed afterdepolarizations $(4,14-17)$. Therefore, the behavior of the first postpacing interval is not specific for either mechanism of arrhythmias.

We do believe, however, that the response of tachycardias to pacing can be of help elucidating the arrhythmogenic mechanism involved. In ouabain-induced VT, we have recently reported $(14,15,17)$ that: 1 ) the cycle length of the VT postpacing could be accelerated as a result of pacing, 2) VT post demonstrated a concordant relation with the interstimulus interval, 3 ) the QRS-configuration of the first postpacing interval in triggered arrhythmias is dependent on the site of stimulation, 4) pacing can virtually never terminate ouabain-induced VT, and 5) ouabain-induced VT never started spontaneously but always had to be induced by pacing. These findings are different from the observations made in VT based on abnormal automaticity as described in this study.

Therefore, we consider programmed electrical stimulation of the heart a useful tool to differentiate different forms of abnormal impulse formation in the intact heart. These findings may be of importance to study the relevance and incidence of abnormal automaticity in arrhythmias occurring in the human heart. 


\section{REFERENCES}

1. Hoffman BF, and Rosen MR. Cellular mechanisms for cardlac arrhythmias. Circ Res 1981 ; 49: 1-15.

2. Davis J. Glassman R, and wit AL. Method for evaluating the effects of antiarthythmic drugs on ventricular tachycardias with different electrophysiologic characteristics and different mechanisms in the infarcted canine heart. Am J Cardiol 1982; 49: 1177-1185.

3. LeMarec $\mathrm{H}_{*}$ Dangman $\mathrm{KH}$, Dantlo $\mathrm{P}$, and Rosen MR. An evaluation of automaticity and triggered activity in the canine heart one to 4 days after myocardial infarction. Circulation 1985: $71: 1224-1236$.

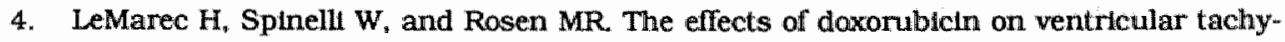
cardia. Cinculation 1986; 74: $881-889$.

5. Dangman $\mathrm{KH}$, and Hoffman $\mathrm{BF}$. Studies on overdrive stimulation of cantne cardiac Purkinje fibers: Maxdmal diastolic potential as a determinant of the response. J Am Coll Cardiol 1983; 2: 1183-1190.

6. Lazzara R, El-Sherlf $\mathrm{N}$, and Scherlag $\mathrm{BJ}$. Electrophysio-logical properties of canine Purkinje cells in one-day-old myocardial infarction. Circ Res 1973; 23: 722-734.

7. Frledman PL. Stewart JR, and Wit AL. Spontaneous and induced cardiac arrhythmias in subendocardial Purkinje fibers surviving extensive myocardial infarction in dogs. Circ Res $1973 ; 23: 612-626$.

8. Horowitz LN, Spear JF, and Moore EN. Subendocardial origin of ventricular arrhythmias in 24-hour-old experimental myocardial infarction. Circulation 1976: 53: 56-63.

9. Steiner $\mathrm{CH}$, and Kovalik ATHW. A stmple technique for production of chronic complete heart block in dogs. J Appl Physiol 1968; 25: 631-632.

10. Harris AS. Delayed development of ventricular ectoplc rhythms following experimental coronary occhusion. Circulation 1950; 1 : 1318-1324.

11. v.d. Steld A, Dassen W, Gorgels APM, Beekman HDM, and Wellens HJJ. Flexible multiprocessor system to support electrophyslological investigation in animals. Computers in Cardlol. 1984; 525-528.

12. El-Sherif N, Gough WB, Zeller RH, and Mehra $R$. Triggered ventricular rhythms in 1-day-old myocardial infarction in the dog. Circ Res 1983; 52: 566-579.

13. Vos MA, Gorgels APM, Leunissen HDM, and Wellens HJJ. Flunarizine allows differentiation between mechanisms of arrhythmias in the intact heart. Submitted for publication. 
14. Gorgels APM, de W1t B, Beekman HDM, Dassen WRM, and Wellens HJJ. Triggered activity induced by pacing during digttalis intoxtcation. Pace 1987; 10: 1309-1321.

15. Gorgels APM, Vos MA, Brugada $P$, and Wellens $H J J$. The value of programmed electrical stmulation in triggered activity-induced arrhythmias in Lethal arrhythmias resulting. from myocardlal ischemla and infarction", eds Rosen MR, and Palti J. Kluwer Academic Publ. Dordrecht, 1989; 269-278.

16. Rosen $M$, and Danilo P. Digitalis Induced delayed afterdepolarizations in The slow inward current and cardiac arrhythmias", edls. Zlpes D, Bailey J, and EIharrar V, Martinus Nifhoff, The Hague, 1989; 417-435.

17. Vos MA, Gorgels APM, Leunissen HDM, and Wellens HJJ. The in vtwo response of ouabain-induced arrhythmias to pacing: Acceleration instead of termination. Submitted for publication. 


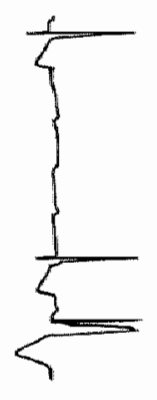

Termination of ouabain-induced ventricular tachycardias by flunarizine in conscious dogs

\author{
Marc A Vos \\ Anton PM Gorgels \\ Joost PH Drenth \\ Jet DM Leunissen \\ Hein JJ Wellens
}




\title{
Termination of ouabain-induced ventricular tachycardias by flunarizine in conscious dogs
}

\begin{abstract}
The ability of flunarizine to terminate ouabain-induced ventricular tachycardia (VT) was Investigated in consclous dogs. These arrhythmias are resulting from triggered activity based on delayed afterdepolarizations.

In 13 animals with surglcally induced complete atrio-ventricular block, sustained VT was induced by ouabain $(48 \pm 6 \mu \mathrm{g} / \mathrm{kg}$ ) and pacing. When arrhythmla had persisted for at least $20 \mathrm{~min}$, flunarizine was administered intravenously.

In all dogs, flunartzine induced an increase of the R-R interval from $300 \pm 30$ to $410 \pm 50 \mathrm{~ms}$ (p $\leq 0.001)$. Flunarlzine $(2 \mathrm{mg} / \mathrm{kg}$ ) terminated VT with long R-R intervals (330 $\pm 20 \mathrm{~ms})$ in 7 dogs. An additional dose of $1 \mathrm{mg} / \mathrm{kg}$ flunarizine resulted also in termination of faster tachycardias $(280 \pm 15 \mathrm{~ms})$. The arrhythmlas were not relnducible by pacing during $27 \pm 18$ min. Following reinitiation VT could again be suppressed by flunariztne.

In conclusion, flunarizine: 1) slows and terminates arrhythmias resulting from delayed afterdepolarizations, and 2) prevents their reinduction.
\end{abstract}

Presented at European Soclety of Cardiology at Vienna, Eur H J 1988; 9: 168. Accepted for publication in Eur J Pharmacol, 1989: 165: 139-145. 


\section{INTRODUCTION}

Until recently, clinical cardiac arrhythmias were thought to be based on automaticity or reentry. During the last decade, additional mechanisms have been described in cellular electrophysiological studies (1). One of these mechanisms is triggered activity resulting from delayed afterdepolarizations (DAD's). Its clinical relevance is yet unknown, because of the lack of specific tools to identify arrhythmias based upon this mechanism (2). Methods like programmed electrical stimulation, monophasic action potentials, and drugs which specifically suppressing arrhythmogenic mechanisms have been used for this purpose (3). Especially drugs seem useful because they can be easily administered, inform the clinician about the arrhythmogenic mechanism and terminate the arrhythmia. Such drugs are not avallable at the moment as most antiarrhythmic drugs affect more than one mechanism (4).

The occurrence of DAD's is promoted by the presence of an increased intracellular calcium concentration (5). Suppression of these arrhythmias is possible using calcium antagonists, like nifedipine and verapamil (6-8). However, inhibition of the movement of calcium through the slow calcium channel is also effective in other mechanisms of tachycardias, like (ab)normal automaticity (9-11) and reentry, e.g. tachycardias incorporating an accessory pathway and the AV-node $(12,13)$.

Because of its interesting electropharmacological profile, our attention was directed to flunarizine as a possible drug to specifically terminate DAD-dependent triggered activity (14). In myocardial tissue, flunarizine does not inhibit the movement of electrolytes during phase 0 and 2 of the action potential (15). This finding suggests no effect of flunarizine on rhythms due to normal automaticity (e.g. sinus node or ventricular escape rhythms) nor on tachycardias based on abnormal automaticity. In contrast, flunarizine has been shown to markedly delay the occurrence of ouabain-induced arrhythmias in anaesthetized guinea pigs (16). In vitro, these tachycardias are dependent on DAD's $(8,17)$. Also in the intact heart evidence has been put forward supporting the same underlying mechanism (18-20).

Because of these properties of flunarizine, we were interested to study whether this drug could terminate DAD-dependent arrhythmlas. Also we studied: 1) the effect of flunarizine on normal ventricular automaticity in the absence of ouabain, and 2) the possible action of the solvent cyclodextrine. 


\section{METHODS}

The experiments were performed in 13 mongrel dogs of either sex (20-35 kg). Through a right thoracotomy complete atrio-ventricular block was produced by formalin 37\% [21]. During this procedure an electrode was sutured at the basal part of the right and the other to the apex of the left ventricle. The electrodes were exteriorized through the skin of the neck. At least one week was permitted before the animals were investigated. This one week of rest is necessary because spontaneous tachycardias occur after induction of atrioventricular block $(4,22)$.

Six electrocardlographic leads and one epicardial lead were simultaneously registered. All experiments were performed in the conscious state without any premedication.

Ventricular tachycardia (VT) was induced by ventricular pacing after ouabain administration. Electrical stimulation was done using a programmable stimulator having a synchronizing circuit. Using a computerized QRS-complex detecting system values of $R-R$ intervals were continuously displayed on a monitor screen allowing instanteneous evaluation of the ventricular rate (23).

Unipolar stimuli were given with a stimulus strength of twice the diastolic threshold. Trains of 10 and 50 stimuli were given on the electrode at the right ventricle. The idioventricular rhythm was overdriven using interstimulus intervals of $800,600,400$ and 200 ms respectively. Each set of 8 stimulationtrains was performed within $15 \mathrm{~min}$.

Ouabain was administered as a bolus (mean: $48 \pm 6 \mu \mathrm{g} / \mathrm{kg}$ ) followed by a continuous infusion throughout the whole experiment (24).

Twenty minutes after the induction of VT, flunarizine (dissolved in cyclodextrine) was administered intravenously as a bolus of $2 \mathrm{mg} / \mathrm{kg}$ over a two minutes period. In four animals with a faster tachycardia, the dosage of flunarizine was increased by $1 \mathrm{mg} / \mathrm{kg}$. The cycle length of the tachycardia was determined by the average of ten consecutive intervals. Measurements every 30 seconds were taken during 5 minutes preceding flunarizine and thereafter up to 15 minutes. In case the arrhythmia did not terminate partial efficacy was determined by using the longest cycle length measured. If VT was suppressed the last 10 intervals before termination were used to determine longest mean cycle length.

Following termination the pacing protocol was repeated starting with the stimulation-train which induced the tachycardia. After reinitation of the arrhythmia flunarizine was again given in a dosage of $1 \mathrm{mg} / \mathrm{kg}$. In the animals In which we falled to suppress the arrhythmia, a second dosage of flunarizine was administered after 30 minutes.

In three experiments, the effect of the solvent cyclodextrine was tested in combination with flunarizine. In one experiment, cyclodextrine was administered following reinitiation of the tachycardia which was previously suppres- 
sed by flunarizine. This sequence was reversed in the other two experiments. The volume of cyclodextrine was equal to the amount needed to dissolve 2 $\mathrm{mg} / \mathrm{kg}$ flunarizine in two experiments and, in one, to dissolve $3 \mathrm{mg} / \mathrm{kg}$. Finally, six experiments were performed to evaluate the effect of flunarizine on normal ventricular automaticity in the absence of ouabain.

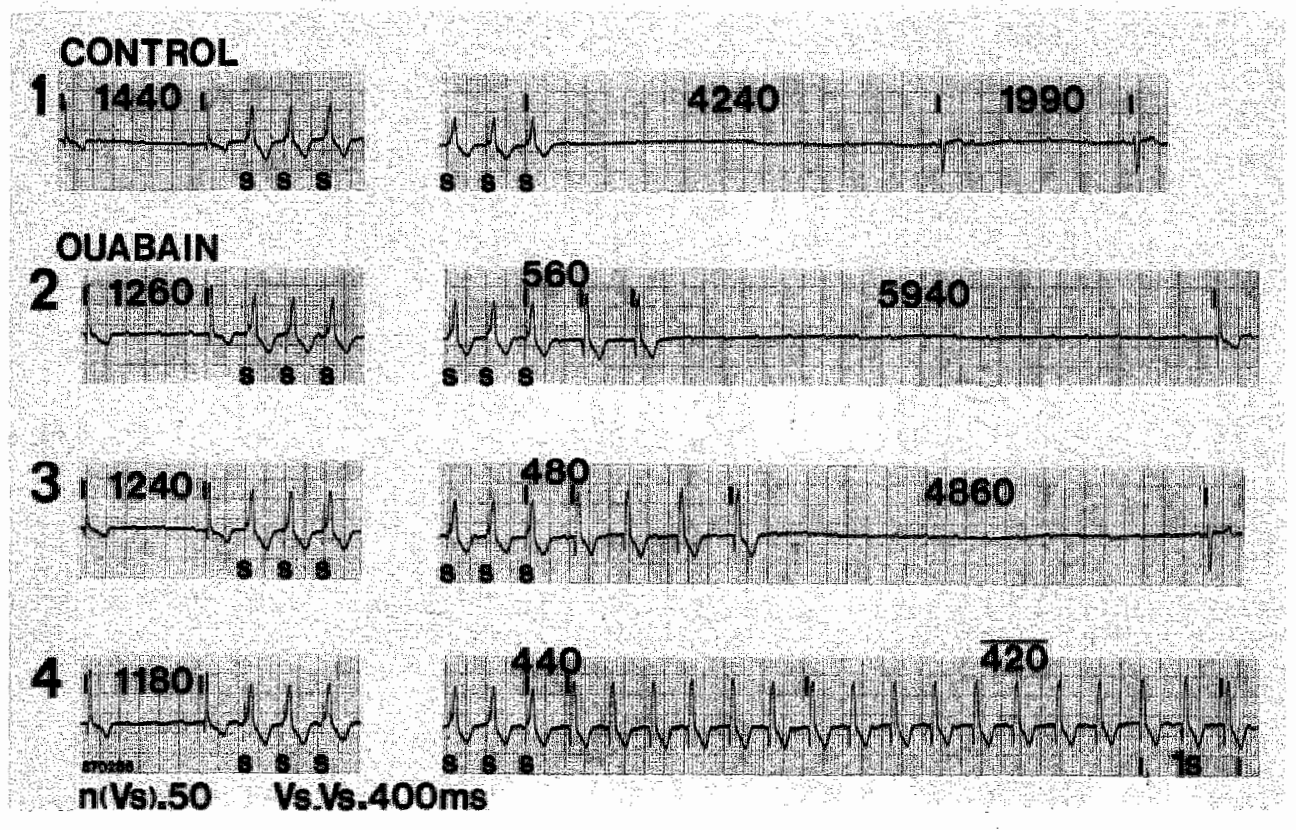

Figure 1. Induction of a ventricular tachycardia by ouabain and pacing.

The idloventricular rhythm was overdriven from the right ventricle using 50 stimull and an interstimulus interval of $400 \mathrm{~ms}$. In panel 1 under control conditions. stimulation resulted in overdrive suppression. Shortly after ouabain $(15 \mathrm{~min})$ two premature escape beats were induced having a first postpacing interval of $560 \mathrm{~ms}$ (panel 2). During subsequent minutes (panels 3-4). the number of induced ectopic beats increased and their first postpacing interval decreased untill a sustained monomorphic tachycardia was induced (panel 4). 


\section{RESULTS.}

\section{The effect of flunarizine on ouabain-induced VT}

Figure 1 is a representative example of the effect of ventricular pacing and ouabain administration on idioventricular rhythm. Panel 1 shows that under control conditions a stimulation-train of 50 stimuli and interstimulus intervals of $400 \mathrm{~ms}$ resulted in suppression of the idioventricular rhythm. Shortly after ouabain administration (15 minutes) the same stimulation-train induced two premature escape beats having a first postpacing interval of 560 ms (panel 2). During the subsequent minutes (panels 3-4), the number of

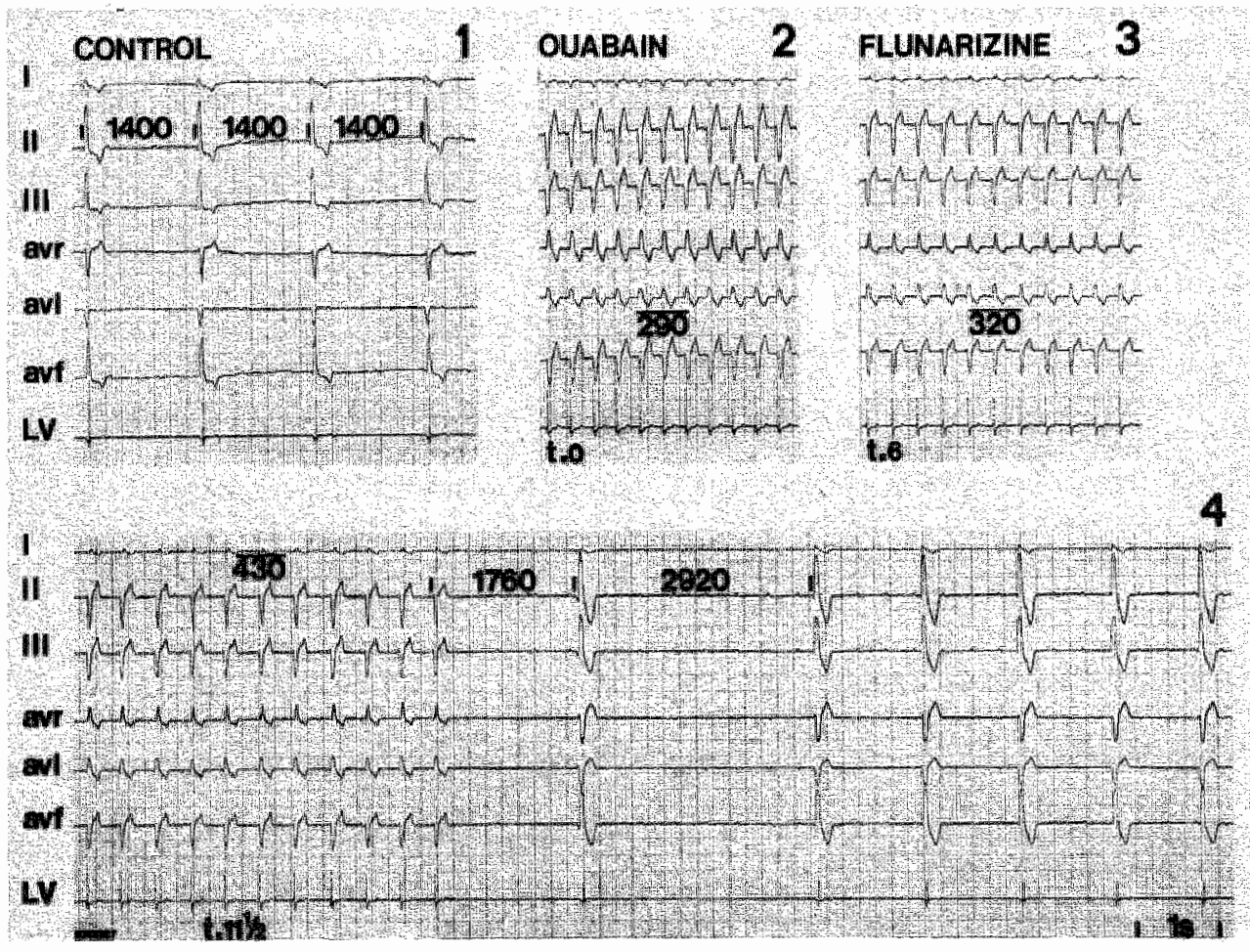

Figure 2. Slowing and termination of ouabain-induced ventricular tachycardia by flunarizine. SIx surface ECG-leads and a local electrogram at the left ventricular apex were recorded simultaneously using a paper speed of $25 \mathrm{~mm} / \mathrm{s}$. In panel 1 the spontaneous idiloventricular thythm is seen. The comblination of ventricular pacing and ouabain administration induced a tachycardia with a mean $R-R$ interval of $290 \mathrm{~ms}$ (panel 2). Flunarizine ( $2 \mathrm{mg} / \mathrm{kg}$ ) 1 ncreased the R-R interval to $320 \mathrm{~ms}$ after 6 minutes (panel 3). An additional dosage of $1 \mathrm{mg} / \mathrm{kg} F \mathrm{increased}$ the cycle length further to $430 \mathrm{~ms}$ followed by termination (panel 4 ). 
induced ectopic beats increased and their first postpacing interval decreased until VT became sustained (panel 4). The time needed to induce a tachycardia in all experiments was $78 \pm 50 \mathrm{~min}$.

The effect of flunarizine on the arrhythmias is shown in table 1. In all animals the cycle length of the VT increased significantly from $300 \pm 30$ to $410 \pm 50$ ms (columns 2 and 3). Termination of the tachycardias was dependent on the rate of the arrhythmia. Using a dose of $2 \mathrm{mg} / \mathrm{kg}$, flunarizine terminated the VT above $305 \mathrm{~ms}$ (mean: $330 \pm 20 \mathrm{~ms} ; 7$ animals). An additional dose of 1 $\mathrm{mg} / \mathrm{kg}$ flunarizine resulted also in termination of the faster VT (mean: $280 \pm$ $15 \mathrm{~ms}$ ) in the four experiments in which this was tested. Flunarizine terminated the arrhythmias after $5.5 \pm 4.0$ minutes. An example of termination of a fast tachycardia is presented in figure 2 . In panel 1 , the spontaneous idioventricular rhythm is shown. The induced VT had a cycle length of 290 $\mathrm{ms}$ (panel 2). Flunarizine increased the R-R interval to $320 \mathrm{~ms}$ after 6 minutes (panel 3). An additional bolus of flunarizine further increased the cycle length of the tachycardia further to $430 \mathrm{~ms}$ followed by termination (panel 4).

Table 1. Effect of flunarizine on ouabain-Induced ventricular tachycardia.

\begin{tabular}{|c|c|c|c|c|}
\hline \multirow[t]{2}{*}{ DOG } & \multicolumn{2}{|c|}{ VT (ms) } & \multirow{2}{*}{$\begin{array}{l}\text { Term. } \\
\text { (min) }\end{array}$} & \multirow{2}{*}{$\begin{array}{l}\text { Reind. } \\
\text { (min) }\end{array}$} \\
\hline & pre $F$ & post $F$ & & \\
\hline 1 & 335 & 370 & 2.0 & 1 \\
\hline 2 & 305 & 365 & $\mathrm{NT}$ & - \\
\hline 3 & 285 & 500 & NT & - \\
\hline 4 & 305 & 335 & 4.5 & 37 \\
\hline 5 & 305 & 390 & 2.5 & 33 \\
\hline 6 & 320 & 435 & 1.0 & 20 \\
\hline 7 & 315 & 390 & 3.5 & 19 \\
\hline 8 & 290 & $430^{*}$ & 11.5 & 50 \\
\hline 9 & 345 & 500 & 6.5 & 24 \\
\hline 10 & 265 & $380^{\circ}$ & 12.0 & 54 \\
\hline 11 & 270 & $420^{\circ}$ & 4.5 & 6 \\
\hline 12 & 360 & 410 & 1.0 & - \\
\hline 13 & 260 & $350^{*}$ & 10.0 & - \\
\hline $\mathrm{x}$ & 300 & 410 & 5.5 & 27 \\
\hline \multirow[t]{2}{*}{$\mathrm{SD}$} & 30 & 50 & 4.0 & 18 \\
\hline & \multicolumn{2}{|c|}{$\mathrm{p} \leq 0.001$} & & \\
\hline
\end{tabular}

VT = Ventricular Tachycardia; Term.. = Termination; Relnd. = Reinduction; $\mathrm{F}=$ Flunarizine; * $=3 \mathrm{mg} / \mathrm{kg}$ flunarlaine; $\mathrm{X}=$ Mean; SD = Standard devlation. 


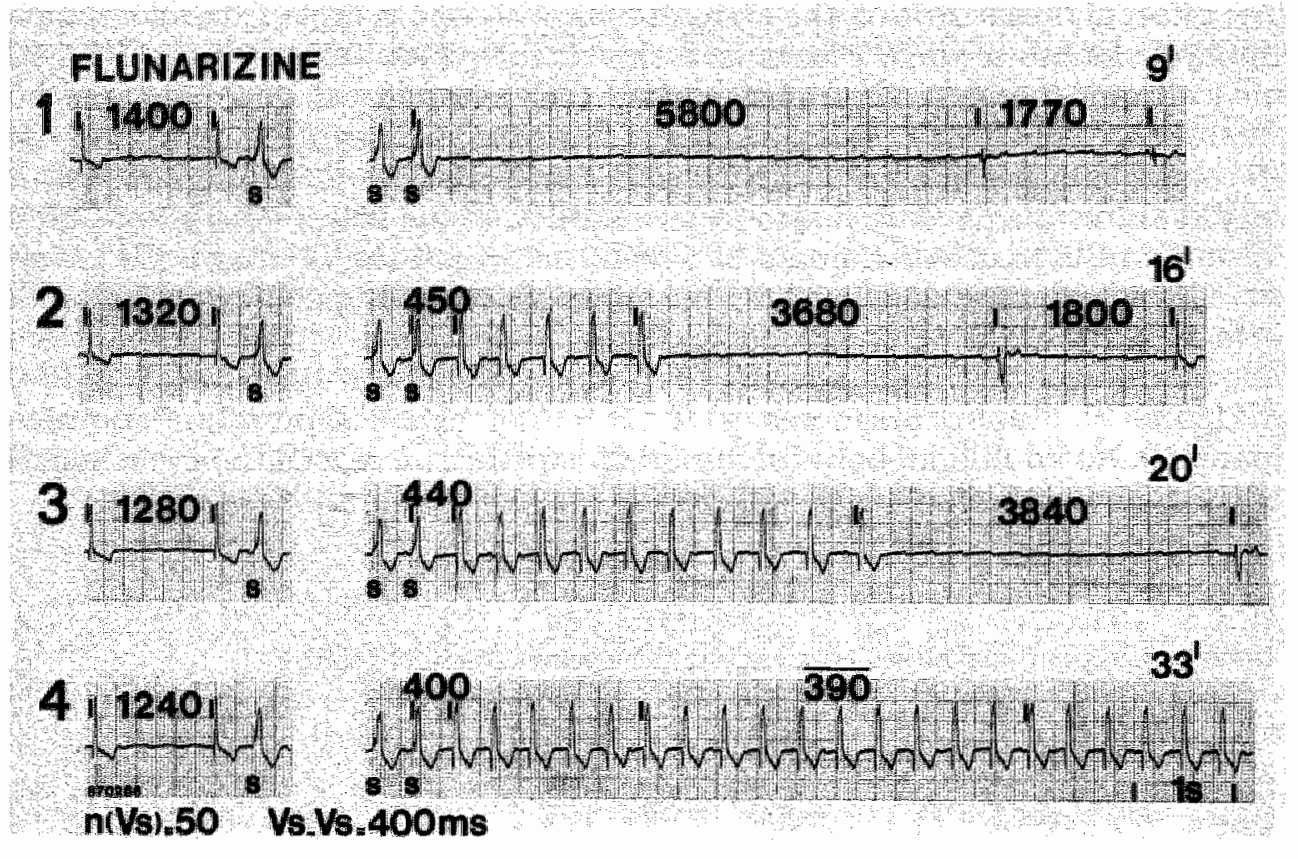

Figure 3. The effect of ventricular pacing immediately following termination of the ventricular tachycardia.

Same animal as in figure 1 . In panel 1 a simllar response to overdrive stimulation is seen when pacing was performed directly after termination of the arrhythmia by flunarizine compared to control conditions. In time the number of ectopic beats increases and the first postpacing Interval decreases (panels 2-4) until a sustained monomorphic ventricular tachycardia is reinduced after 33 minutes (panel 4 ).

In some experiments the slowing in tachycardia rate was accompanied by changes in QRS-configuration.

Following cessation of the arrhythmia normal P-waves persisted and the idioventricular rhythm quickly returned with hardly any change in cycle length compared to control conditions $(1450 \pm 260$ versus $1390 \pm 370 \mathrm{~ms}$ respectively). These findings suggest no influence of flunarizine on normal automaticity.

An example of reinduction of tachycardia is shown in figure 3. Data from the same animal are presented in figure 1. In panel 1, overdrive stimulation immediately after termination resulted again in overdrive suppression. Following this first stimulation-train, a gradual increase in number of ectopic beats occurs together with a decrease of the first postpacing interval indica- 
ting weaning of the effect of flunarizine (panels 2-4). After 33 minutes, this stimulation procedure resulted in reinduction of the tachycardia (panel 4 ). In the animals in which reinitiation was studied, the tachycardia occurred after $27 \pm 18 \mathrm{~min}$ (table 1 , collumn 5 ).

Results were reproducible in those animals to whom a second dosage of flunarizine was administered. Again, flunarizine increased the R-R interval of VT from $310 \pm 40$ to $440 \pm 80 \mathrm{~ms}(\mathrm{p} \leq 0.01)$. Also, a second termination was observed in those experiments in which the first attempt had been succesful. All dogs tolerated the drug well as was assessed by: 1] the behavior of the dogs (quiet versus restless and drowsy versus alert, 2) respiration rate, and 3) idioventricular rate.

The solvent cyclodextrine resulted neither in termination nor in changes in cycle length of the tachycardias ( $300 \pm 60 \mathrm{~ms}$ versus $300 \pm 50 \mathrm{~ms}$ ).

\section{The effect of flunarizine on normal ventricular automaticity}

Administration of flunarizine in the absence of ouabain resulted in a decrease of the mean R-R interval of the idioventricular rhythm from $1400 \pm 410$ to $1070 \pm 250 \mathrm{~ms}(\mathrm{p} \leq 0.01)$. The shortest interval was measured $3.3 \pm 1.4 \mathrm{~min}$ after flunarizine administration and was followed by a gradual return to the original cycle length after $13.7 \pm 3.7 \mathrm{~min}$.

\section{DISCUSSION}

Our results demonstrate that the calcium blocker flunarizine is a very effective drug in terminating ouabain-induced VT in the conscious dog. To summarize the other results: 1) higher doses were required when the arrhythmia was faster, 2) a gradual slowing occurred before suppression, sometimes accompanied by changes in QRS-morphology, 3) idloventricular rhythm returned rapidly following cessation, 4) pacing immediately after termination showed similar results as seen under control conditions, 5) sustained arrhythmias were not relinducible during a mean of $27 \pm 18$ minutes, and 6) these results were reproducible when a second dosage was administered following reinitiation.

However, flunarizine has a different effect on normal automaticity. The rate of the idioventricular rhythm increased. This acceleration is probably due to a reflex response of the sympathetic system because of peripheral vasodilatation (12).

The question arises how flunarizine acts on arrhythmias caused by ouabain intoxication. These tachycardias are based on triggered activity resulting from delayed afterdepolarizations $(8,17,18,19)$. The latter are oscillations of the 
diastolic membrane potential occurring in the setting of an increased intracellular calcium concentration (5). Ouabain inhibits the $\mathrm{Na}^{+} / \mathrm{K}^{+}$ATP-ase. thereby increasing the sodium concentration intracellularly. Through the $\mathrm{Na}^{+} / \mathrm{Ca}^{2+}$ exchange the calclum accumulates inside the cell. It is thought that this intracellular calcium overload causes both an oscillatory release and reuptake of calcium by the sarcoplasmic reticulum. The resulting oscillatory change in free calcium concentration in the cytoplasm causes a transient inward current responsible for the DAD's $(25,26)$.

At present, it is not clear how flunarizine exerts its effect on the arrhythmias occurring as a result of ouabain intoxication. Hypothetically, flunarizine may act in a number of ways: 1) by preventing or reducing the calcium overload, 2) through inhibition of the oscillatory release from the sarcoplasmic reticulum and/or 3) by blocking the transient inward current.

Several authors have shown that these ouabain-induced arrhythmias could be prevented, delayed or terminated by sodium and calcium blockers 17,8 , 16,20). These findings indicate that either the build up of electrolytes leading to the calcium overload and/or the transient inward current is affected. Information about the effect of flunarizine on the transient inward current is not avallable. Two lines of evidence suggest that flunarizine does not affect the fast sodium nor the slow calcium channels: 1) the lack of effects seen on the action potential during normal automaticity (15), and 2) the ability to protect the myocardial cell from calcium overload induced by veratrine (27) and depolarizing concentrations of potassium (15). In these experiments other calcium antagonists, like verapamil and nifedipine were not or less effective. More recently. Tytgat et al. (28) demonstrated that flunarizine blocks both the L-type as the T-type calcium channel in ventricular myocytes, whereas verapamil only was effective blocking the L-type channel. The importance of these results for in vivo experiments is not clear due to the very high dosages which were needed to obtain these data.

Our results of flunarizine on normal automaticity fit with the findings that flunarizine does not affect movement of electrolytes through the fast sodium (quick return of the idioventricular rhythm) or the slow calcium channel (indicated by the presence of P-waves directly following termination of the arrhythmia).

This study demonstrates that flunarizine is very effective against triggered activity resulting from DAD's. An observation which is different from the effect of flunarizine on ventricular escape rhythm based on normal automaticity. Because this drug is thought not to affect slow calcium channels, flunarizine is also not likely to suppress abnormal automaticity. These specific properties could make flunarizine a diagnostic tool in differentiating triggered activity from other arrhythmogenic mechanisms. Further research is needed to confirm this hypothesis.

In conclusion, flunarizine slows, terminates and prevents the reinduction of ventricular arrhythmias resulting from triggered activity in conscious dogs. 


\section{REFERENCES}

1. Hoffman BF, and MR Rosen. Cellular mechantisms for cardiac arrhythmias, Circ. Res. 1981: 49:1-15.

2. Brugada $P_{4}$ and HJJ Wellens. The role of triggered activity in clinical ventricular arrhythmias, PACE; 1984: 7: 260-271.

3. Gorgels, APM. MA Vos, P Brugada, and HJJ Wellens. The clinical relevance of abnormal automaticity and triggered activity, in: "Cardiac arrhythmias: Where to go from here ?". eds. P Brugada and H.JJ Wellens, Mount Kisco. NY. Future Publishing Company Inc., $1987: 147 \cdot 169$.

4. Ilvento. JP. J Provet, P Danilo Jr., and MR Rosen. Fast and slow Idioventricular thythms in the canine heart: a study of their mechanism using antarrhythmic drugs and electrophystologic testing. Am. J. m m J Cardiol 1982; 49: 1909-1916.

5. Kass RS, WJ Lederer, RW Tsten, and R Weingart. Role of calcium Ions in transient inward currents and aftercontractions induced by strophantidin in cardlac Purkinje fibers. J. Physiol. 1978: 28: 187-208.

6. Gough WB, RH Zeller, and N El-Sherif. Effects of nufediptne on triggered activity in 1-day-old myocardial infarction in dogs, Am.. J. Cardiol. 1984; 53: 303-306.

7. Dangman $\mathrm{KH}$, and $\mathrm{BF}$ Hoffman. Effects of nifedipine on electrical activity of cardiac cells, Am J Cardiol 1980; 46:1059-1067.

8. Rosen MR, and P Danilo Jr. Effects of tetrodotoxdn, lidocaine, verapamill and AHR-2666 on ouabain-induced delayed afterdepolarzations in cantne Purkinje fbers, Circ Res 1980: 46: $117-124$.

9. Rosen MR, JP Ilvento, H Gelband, and C Merker. Effects of verapamil on electrophysiologic properties of canine cardlac Purkinje fibers, J. Pharmacol. Exp. Ther. 1974; 189:414-422.

10. Dersham $\mathrm{GH}$, and $\mathrm{J} H \mathrm{Han}$. Actions of verapamil on Purkinje flbers from normal and infarcted heart tissues, J. Pharmacol. Exp. Ther. 1980; 216: 261-264.

11. Kawai C. T Konish1, E Matsuyama, and H Okazakd. Comparative effects of three calclum antagonists, diltiazem, verpamil and nifedipine, on the sinoatrial and atriowentricular nodes. Experimental and clinical studies. Circulation 1981; 63; 1035-1042.

12. Singh $B N$, and $\mathrm{K}$ Nademance. Use of calcium antagonists for cardiac arrhythmias, Am. J. Cardlol. 1987; 59: 153B-162B. 
13. Wellens HUJ, Brugada and OC Penn. The management of preexcitation syndromes. JAMA $1987 ; 257: 2325-2333$.

14. Vanifoute PM. The expert committee of the World Health Organisation of caliclum antagonists": the vlewpoint of the raporteur. Am. J. Cardiol. 1987; 59: 3A -8A.

15. Borgers $M$, F de Clerck, J van Reempts, $R X$ Xhonneux, and $J$ van Nueten. Selectve blockade of cellular Ca2+-overload by Munarizine, Int. Angiology. 1984; 3: 25-31.

16. Jonkman FAM, HWCM Bedekke and PA van Zwieten. Protective activity of calcium entry blockers against ouabain intoxication in anaesthexid guinea plgs, J. Cardiovasc. Pharmeicol. 1986; 8: 1009-1013.

17. Ferrter GR, JH Saunders, and C Mendez. A cellular mechanism for the generation of ventricular arrhythmias by acetylstrophantidin, Circ. Res. 1973; 23: 600-609.

18. Gorgels APM ${ }_{n}$ HDḾ Beekman, P Brugada, WRM Dassen, DAB Richards, and HJJ Wellens. Extrastimulus related shortening of the first postpacing interval in digitalis induced ventricular tachycardia, J. Am. Coll. Card. 1984; 1: 840-857.

19. Gorgels APM, B de Wit, HDM Beekman. WRM Dassen, and HJJ Wellens. Triggered activity Induced by pacing during digitalls intoxdication. Observations during programmed electrical stimulation in the conscious dogs with chronic complete atrioventricular block, Pace 1987; 5 : $1309-1321$.

20. LeMarec $H_{\text {, }}$ KH Dangman, P Danilo, and MR Rosen. An evaluation of automaticity and triggered activity in the canine heart one to four days after myocardial infarction. Circulation 1985: 71: 12241236.

21. Steliner $C_{\text {n }}$ and TW Kovalik. A simple technique for production of chronic complete heart block in dogs, J. Appl. Physiol. 1968; 25: 631-632.

22. Vassalle M, RE Knob, M Cummins, GA Lara, C Castro, and JH Stuckey. An analysis of fast Idioventricular rhythm in the dog. Circ. Res. 1977; 41:218-226.

23. Van der Steld A, WRM Dassen, APM Gorgels, HDM Beekman, and HJJ Wellens. Flexdble multprocessor system to support electrophysiological investigation in animals, Computers in Cardiol. 1984, 525-528.

24. Rhee HM, S Dutta, and BH Marks. Cardiac Na/K ATP-ase activity during positive inotroplic and toxde actlons of ouabain, Eur. J. Pharmacol. 1976; 37: 141-153.

25. Cranefield PF. The conduction of the cardlac Impulse. Futura Publishing, Mount Kisco, New York, 1975 
26. Kass RS, and RW Tsien. Fluctuations in membrane current drven by intracellular calcium in cardiac Purkinje fibers, Biophys. J. 1982; 38: 259-269.

27. VerDonck L, PJ Pauwels, G Vandenplassche, and M Borgers, Isolated rat cardtac nyyocytes as an experimental model to study calcium overload: the effects of calcium entry blockers, Life Sciences 1985; 38: 765-772.

28. Tytgat J, J Vereecke, and E Carmeliet. Differentlal effects of verapamil and flunarizine on cardiac L-type and T-type Ca channels, Arch. Pharmacol. 1988; 337: 690-692. 


$$
\mid
$$

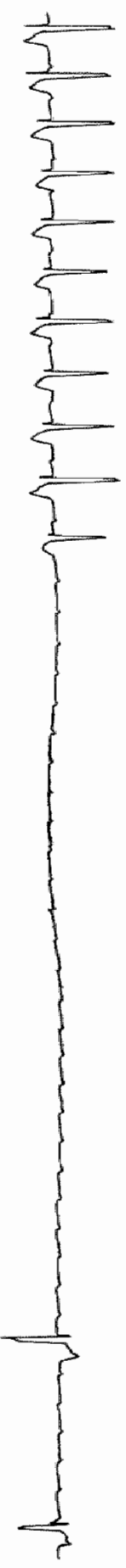

\title{
Flunarizine allows differentiation between mechanisms of arrhythmias in the intact heart
}

\author{
Marc A Vos \\ Anton PM Gorgels \\ Jet DM Leunissen \\ Hein JJ Wellens
}




\title{
Flunarizine allows differentiation between mechanisms of arrhythmias \\ in the intact heart
}

\begin{abstract}
The calctum antagonist flunarizine (F) suppresses pathological accumulation of calcium intracellularly without affecting the fast sodjum or the slow calcium channel. To establish its value in differentlating between mechanisms of arrhythmtas in the canine heart, the effect of F was investigated on venitricular tachycardia (VT) induced by ouabain intoxication or occurring 16-24 hours after occlusion of the left anterior descending coronary artery (LAD). Four groups of dogs were studiled. Group 1 consisted of 13 animals with VT induced by ouabain intoxication (triggered activity (TA) group). Group 2 included 9 dogs in whom VT developed 16-24 hours after occlusion of the LAD (abnormal automaticity (AA) group). Group 3 were 6 dogs with normally conducted stnus beats (SR), while group 4 consisted of 6 animals having a ventricular escape rhythm (VER). With the exception of group 3, all dogs had surgically induced complete AV-block. All animals were studied while consclous without premedication. In group 1 and $2, F(2-3 \mathrm{mg} / \mathrm{kg})$ was given intravenously after VT had persisted for at least $20 \mathrm{~min}$. In group 3 and 4 F $(2 \mathrm{mg} / \mathrm{kg})$ was given after the rhythm was registered for 20 minutes. The cycle lengths of the different rhythms were compared before and after $\mathrm{F}$.

In TA (group 1), F increased the cycle length of the VT from $300 \pm 30$ to $410 \pm 50 \mathrm{~ms}$ (p s $0.001)$. Termination of VT was seen in 11 out of 13 animals. In AA (group 2), F resulted in a non-significant shortening of the R-R Interval from $450 \pm 60$ to $440 \pm 60 \mathrm{~ms}$. Persistent termination was observed in only 1 out 9 dogs. A significant acceleration in rate was seen in SR (group 3) and VER (group 4).

In conclusion. flunariaine slows and terminates ventricular arrhythmias resulting from triggered activity, but accelerates rhythms based upon normal and abnormal automaticity. These findings suggest that flunarizine can be used to differentlate between mechanisms of arrhythmlas.
\end{abstract}

Presented at the Amenican Heart Association. Cinculation 1988; 78: 157. Accepted for publication in Circulation, 1989. 


\section{INTRODUCTION}

Two decades ago, clinically occurring cardiac arrhythmias were thought to result from either automaticity, reentry or a combination of these mechanisms (1). In vitro, other mechanisms have been described, like triggered activity induced by early and delayed afterdepolarizations (DAD's) and abnormal automaticity (2). While reentry has been proven to be responsible for a number of human supraventricular and ventricular arrhythmias $(3,4)$, the clinical relevance of the other mechanisms is not known. Because these arrhythmogenic mechanisms have been demonstrated to occur under different pathophysiological circumstances (for review see 5). it seems conceivable that clinical arrhythmias may be caused by mechanisms other than reentry. To differentiate among arrhythmogenic mechanisms, several methods have been studied, including programmed electrical stimulation $(1,2,5,6)$, monophasic action potentials $(7,8)$, and drugs specifically suppressing one mechanism $(5,9-12)$. Especially the latter approach is intriguing because drugs have on theoretical and practical grounds, advantages for identifying mechanisms of arrhythmias. Drugs can easily be administered either intravenously or orally, can terminate the tachycardia, and may give information about pathophysiology of the arrhythmia.

Until now only a few drugs having such a specific action have been developed. An example is doxorubicin, which specifically suppresses ouabain-induced triggered activity (9). Due to its toxicity, doxorubicine cannot be used clinically for this purpose. In general, different drugs must be used sequentially for determining the mechanism involved. A good example is the combination of lidocaine and ethmozin for differentiating between abnormal automaticity and triggered activity (10-12).

Our interest was directed to flunarizine, because of its interesting electropharmacological profle. Flunarizine, a calcium antagonist, is clinlcally used for the prophylaxis of migraine and epllepsy (13) and it does not possess unfavourable side-effects. In myocardial tissue, flunarizine does not inhibit the sodium nor the calcium channel (14). However, this drug has been shown to markedly delay the onset of ouabain-induced ventricular tachycardia in anaesthetized guinea pigs (15). These arrhythmias are most likely based on triggered activity resulting from DAD's $(9,16-19)$, occurring in the presence of intracellular calcium overload (20). The above suggest that flunarizine does not affect rhythms based on normal automaticity (sinus node or ventricular escape rhythms) and tachycardias due to abnormal automaticity. The latter originates from a reduced diastolic membrane potential. Depending on the level of depolarization, they are partly dependent on the sodium and/or calcium channel (21).

It was the purpose of this study to establish the value of flunarizine in differentiating between two mechanisms of ventricular arrhythmias in the canine heart: 1) ouabain-induced ventricular tachycardias (VT) thought to be based on DAD's, and 2) arrhythmias occurring spontanously 16-24 hours 
after occlusion of the left anterior descending coronary artery. The latter tachycardias are most likely caused by abnormal automaticity $(12,22-23)$. although triggered activity resulting from DAD's has also been described as the underlying mechanism (24). In addition, the effect of flunarizine on two types of normal automaticity was investigated: 1) sinus rhythm, and 2) ventricular escape rhythm in complete AV-block. It was hypothesized that flunarizine would affect ouabain-induced tachycardias, but not 16-24 hours Infarct arrhythmias and the two forms of normal automaticity. When correct. flunarizine could become a clinical tool to differentiate between arrhythmogenic mechanisms.

\section{METHODS}

\section{Preparation of study dogs}

The experiments were performed in mongrel dogs of either sex having a body weight between $20-35 \mathrm{~kg}$. All animals were studied in the conscious state without premedication. With the exception of the dogs in normally conducted sinus rhythm, all animals had surgically induced complete AV-block. Through a right thoracotomy block was produced by injection of formalin $37 \%$ (25). During the same procedure one electrode was sutured on the basal part of the right ventricle and an another one on the apex of the left ventricle. The electrodes were exteriorized through the skin of the dorsal surface of the neck. Proper care was taken postoperatively according to the statement of the American Physiological Society.

The animals were not investigated during two weeks following the operation. because spontaneous episodes of VT are known to occur after creation of AV-block (26-27). For the 9 dogs undergoing a second thoracotomy using the two-stage Harris protocol (28), the time period between operations was at least four weeks. We slightly adjusted this procedure by ligating the second dlagonal of the LAD in two stages. This was done to reduce infarct size in dogs which already had undergone a first thoracotomy to induce AV-block. During the operation lidocaine was administered to prevent (lethal) arrhythmias. This drug was given as a bolus ( $3 \mathrm{mg} / \mathrm{kg}$ ) followed by a continuous infusion throughout the procedure $(100 \mu \mathrm{g} / \mathrm{kg} / \mathrm{min}$.). Lidocaine administration was stopped one hour after the first occlusion. 


\section{Experiments}

Six external electrocardiographic and one epicardial lead were simultaneously registered. Pacing in the ouabain-treated animals and in the dogs with LAD-occlusion was performed using a programmable stimulator having a synchronizing circuit. Unipolar stimuli were given with a stimulus strength of twice the diastolic threshold. Using a computerized QRS-complex detecting system, values of $R-R$ intervals were continuously displayed on a monitor screen allowing instantaneous evaluation of the heart rate in the four protocols (29).

Overdrive pacing during the tachycardia was performed to confirm the underlying arrhythmogenic mechanism. On reducing the interstimulus interval, we expected shortening of the first postpacing interval for the triggered arrhythmias $(19,30)$, while no change of this interval was expected for the tachycardias resulting from abnormal automaticity $(12,21)$.

In 13 dogs, VT was induced by ventricular pacing after ouabain administration. First, ouabain was given (mean $48 \pm 6$; range $40-55 \mu \mathrm{g} / \mathrm{kg}$ ) over a two minutes period. The amount of this dosage is inversely related to the body weight [31]. Ten min later, a corresponding infusion was started of 0.072 for 40 up to $0.099 \mu \mathrm{g} / \mathrm{kg} / \mathrm{min}$ of ouabain for $55 \mu \mathrm{g} / \mathrm{kg}$ (32), which was continued throughout the whole experiment. The pacing protocol began $15 \mathrm{~min}$ after the start of the adminstration of ouabain and consisted of trains of 10 and 50 stimuli using interstimulus intervals of $800,600,400$, and $200 \mathrm{~ms}$. Each set of 8 stimulation-trains was completed in $15 \mathrm{~min}$ and randomly repeated until sustained tachycardia occurred.

After its initiation, the arrhythmia had to persist for 10-15 minutes before overdrive pacing was started. This protocol consisted of stimulation for 15 . 60 , and $120 \mathrm{~s}$ using an interstimulus interval between 300 and $200 \mathrm{~ms}$. Thereafter flunarizine was administered according to the dose regimen below. When flunarizine terminated ouabain-induced VT, the pacing train that previously initiated the arrhythmia was repeated until sustained tachycardia occurred again.

The spontaneous ventricular tachycardias occurring 16-24 hours after myocardial infarction were registered for 20 minutes. Then overdrive pacing during 15,60 , and $120 \mathrm{~s}$ was performed using interstimulus intervals of 400 . 300 , and $200 \mathrm{~ms}$. Following this stimulation protocol flunarizine was given. In dogs studied during sinus rhythm and idioventricular rhythm, the ECG was registered for 20 minutes before flunarizine was given.

Flunarizine (dissolved in cyclodextrine) was administered intravenously (2 $\mathrm{mg} / \mathrm{kg}$ ) over a two minutes period. In 4 ouabain-treated animals and in one dog included in the adjusted Harris protocol, this dosage was increased by 1 $\mathrm{mg} / \mathrm{kg}$ given in one minute for a total of $3 \mathrm{mg} / \mathrm{kg}$ flunarizine. 


\section{Measurements}

Apart from the ability of flunarizine to terminate the arrhythmia, also the rate of the different rhythms before and after administration of this drug was investigated. For this purpose the cycle length was determined every minute as the average of ten consecutive intervals beginning at least $5 \mathrm{~min}$ prior to flunarizine administratton and ending $25 \mathrm{~min}$ thereafter. If tachycardia was terminated, the mean of the last ten intervals before termination was used. When the arrhythmia did not terminate the longest or shortest mean R-R interval was used for comparison.

\section{Statistical Analysis}

The student's paired t-test was used to compare the cycle lengths before and after flunarizine administration. ANOVA was applied to determine significance of the first postpacing interval in relation to the different interstimulus intervals used. All data are presented as mean \pm standard deviation.

\section{RESULTS}

\section{Ouabain-Induced arrhythmias}

In the 13 animals investigated, ouabain intoxication combined with pacing induced sustained VT $78 \pm 50 \mathrm{~min}$ after the start of ouabain administration. Overdrive stimulation of these sustained VT resulted in a significant shortening of the first postpacing interval ( $p \leq 0.001)$ on decreasing the interstimulus interval from 300 to $200 \mathrm{~ms}$ (table 1 ).

Flunarizine Increased the cycle length of the tachycardia from $300 \pm 30$ to $410 \pm 50 \mathrm{~ms}(\mathrm{p} \leq 0.001$ ) in all dogs (table 2). Termination of the VT was related to the rate of the arrhythmla. A VT having an R-R interval greater than 305 ms (mean: $330 \pm 20 \mathrm{~ms} ; 7$ animals) was always terminated by $2 \mathrm{mg} / \mathrm{kg}$ flunarizine (figure 1). An additional dosage of $1 \mathrm{mg} / \mathrm{kg}$ flunarizine also resulted in termination of the faster tachycardias (mean: $280 \pm 15 \mathrm{~ms}$ ) in the 4 experiments in which this was tested.

Flunarizine terminated the arrhythmia after $5.5 \pm 4.1$ min. Following termination the tachycardias were not reinducible by pacing during $27 \pm 18 \mathrm{~min}$. 
Table 1. The effect of overdrive pacing on the first postpacing interval.

\begin{tabular}{|c|c|c|c|}
\hline \multicolumn{2}{|c|}{ Ouab-ind. VT } & \multicolumn{2}{|c|}{ Infarct-ind. VT } \\
\hline Vs-Vs & Vs-V & Vs-Vs & Vs-V \\
\hline 300 & $380 \pm 25$ & 400 & $580 \pm 40$ \\
\hline 275 & $395 \pm 25$ & 300 & $560 \pm 120$ \\
\hline 250 & $360 \pm 40$ & 200 & $590 \pm 270$ \\
\hline 225 & $340 \pm 20$ & & \\
\hline 200 & $310 \pm 20$ & & \\
\hline ANOVA & $p \leq 0.001$ & & NS \\
\hline
\end{tabular}

ouab-ind. VT = ouabain-Induced ventricular tachycardias; infarct-ind. $\mathrm{VT}=$ spontaneous tachycardias occurring 16-24 hours after LAD-occlussiton; Vs-Vs = interstimulus interval; Vs-V = first postpacing interval; NS = not significant

Table 2. The effect of flunarizine on the cycle length of the tachycardia.

\begin{tabular}{|c|c|c|c|c|c|c|}
\hline \multirow[t]{2}{*}{$\operatorname{dog} \#$} & \multicolumn{3}{|c|}{ Ouab.-Ind. VT } & \multicolumn{3}{|c|}{ Infarct-ind. VT } \\
\hline & VT pre & VTF & & VT pre & VT F & \\
\hline 1 & 335 & 370 & $\mathrm{~T}$ & 440 & 410 & \\
\hline 2 & 305 & 365 & & 415 & 365 & \\
\hline 3 & 285 & 500 & & 405 & 380 & \\
\hline 4 & 305 & 335 & $\mathrm{~T}$ & 475 & 420 & \\
\hline 5 & 305 & 390 & $T$ & 510 & 490 & \\
\hline 6 & 320 & 435 & $\mathrm{~T}$ & 430 & 480 & $\mathrm{~T}$ \\
\hline 7 & 315 & 390 & $\mathrm{~T}$ & 380 & 370 & $*$ \\
\hline 8 & 290 & 430 & $\mathrm{~T} *$ & 440 & 450 & \\
\hline 9 & 345 & 500 & $\mathrm{~T}$ & 570 & 560 & \\
\hline 10 & 265 & 380 & $\mathrm{~T} *$ & & & \\
\hline 11 & 270 & 420 & $\mathrm{~T} *$ & & & \\
\hline 12 & 360 & 410 & $\mathrm{~T}$ & & & \\
\hline 13 & 260 & 350 & $\mathrm{~T} *$ & & & \\
\hline $\mathrm{x}$ & 300 & 410 & & 450 & 440 & \\
\hline \multirow[t]{2}{*}{$\mathrm{SD}$} & 30 & 50 & & 60 & 60 & \\
\hline & \multicolumn{3}{|c|}{$P \leq 0.001$} & \multicolumn{3}{|c|}{ NS } \\
\hline
\end{tabular}

ouab - -ind. VT $=$ ouabain-induced ventricular tachycardias; infarct-tnd. VT = spontaneous tachycardlas occurring 16-24 hours after LAD-occlussion; VT pre = cycle length of VT before flunarizine; VT F = cycle length of VT after flunarkine; $T=$ persistent termination: ${ }^{*}=3 \mathrm{mg} / \mathrm{kg}$ flunartzine; $\mathrm{NS}=$ not signiflcant 


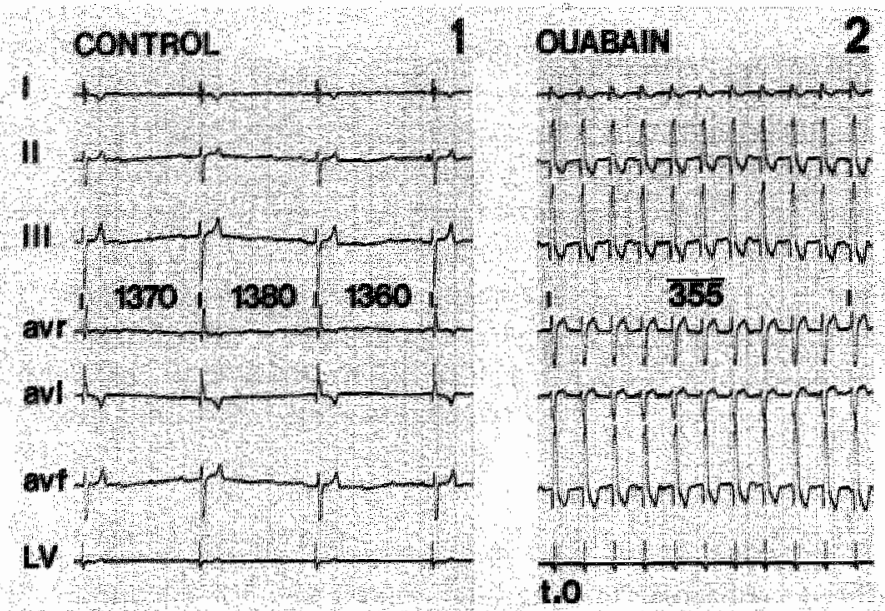

\section{FLUMARIZINE}

3

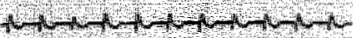

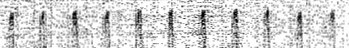

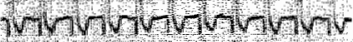
$1.111111,1$ whruvvrmhwh

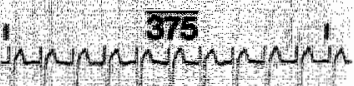

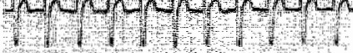
prempromerer 141,1114

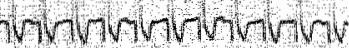
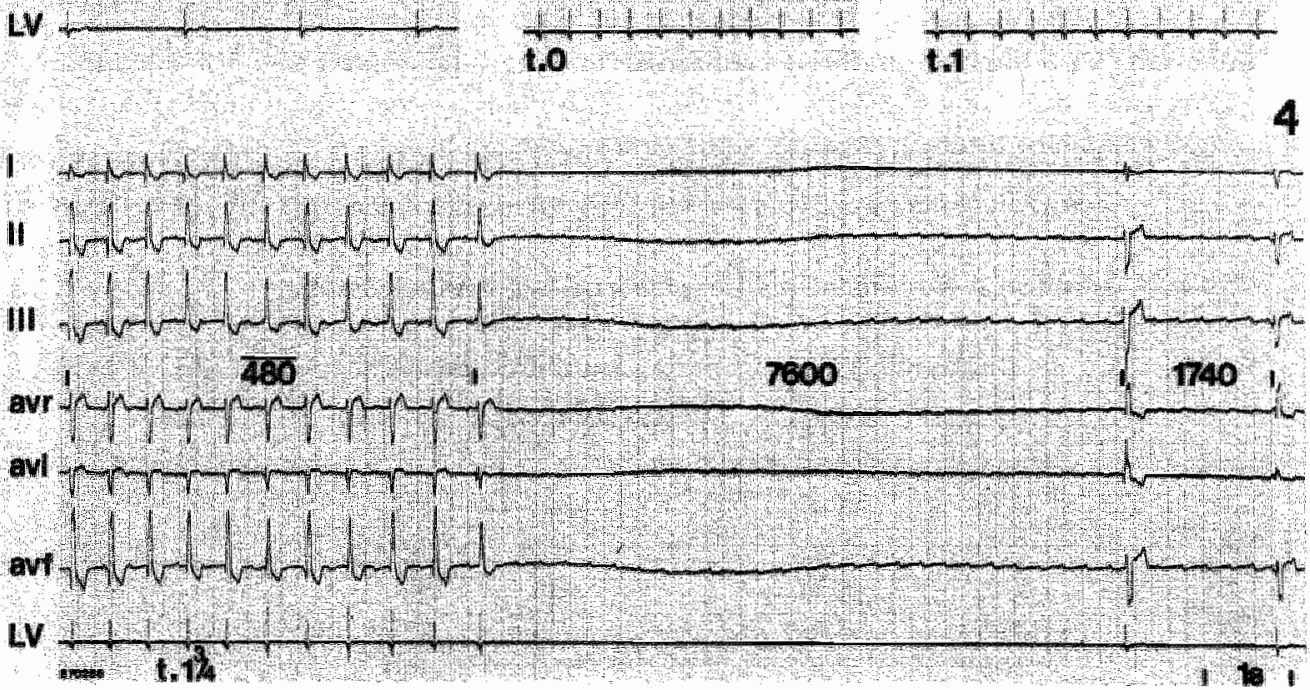

Figure 1. Slowing and termination of ouabain-Induced ventricular tachycardias by flumartzine. S1x surface ECG-leads and a local electrogram at the left ventricular apex are recorded simultaneously. Paper speed is $25 \mathrm{~mm} / \mathrm{s}$. In panel 1. the spontaneous fdioventricular rhythm is seen. The combination of ventricular pacing and ouabain administration induced an arrkythmia with a mean cycle length of $355 \mathrm{~ms}$ (panel 2). Flunarizine increased the R-R interval to $375 \mathrm{~ms}$ after 1 minute (panel 3 ) and to a maximal value of $480 \mathrm{~ms}$ after 1.75 minutes, followed by termination of the tachycardia (panel 4). Note the presence of the P-waves and the rapid return of the idioventricular rhythm following termination, suggesting no influence of this drug on nomal automaticity. 


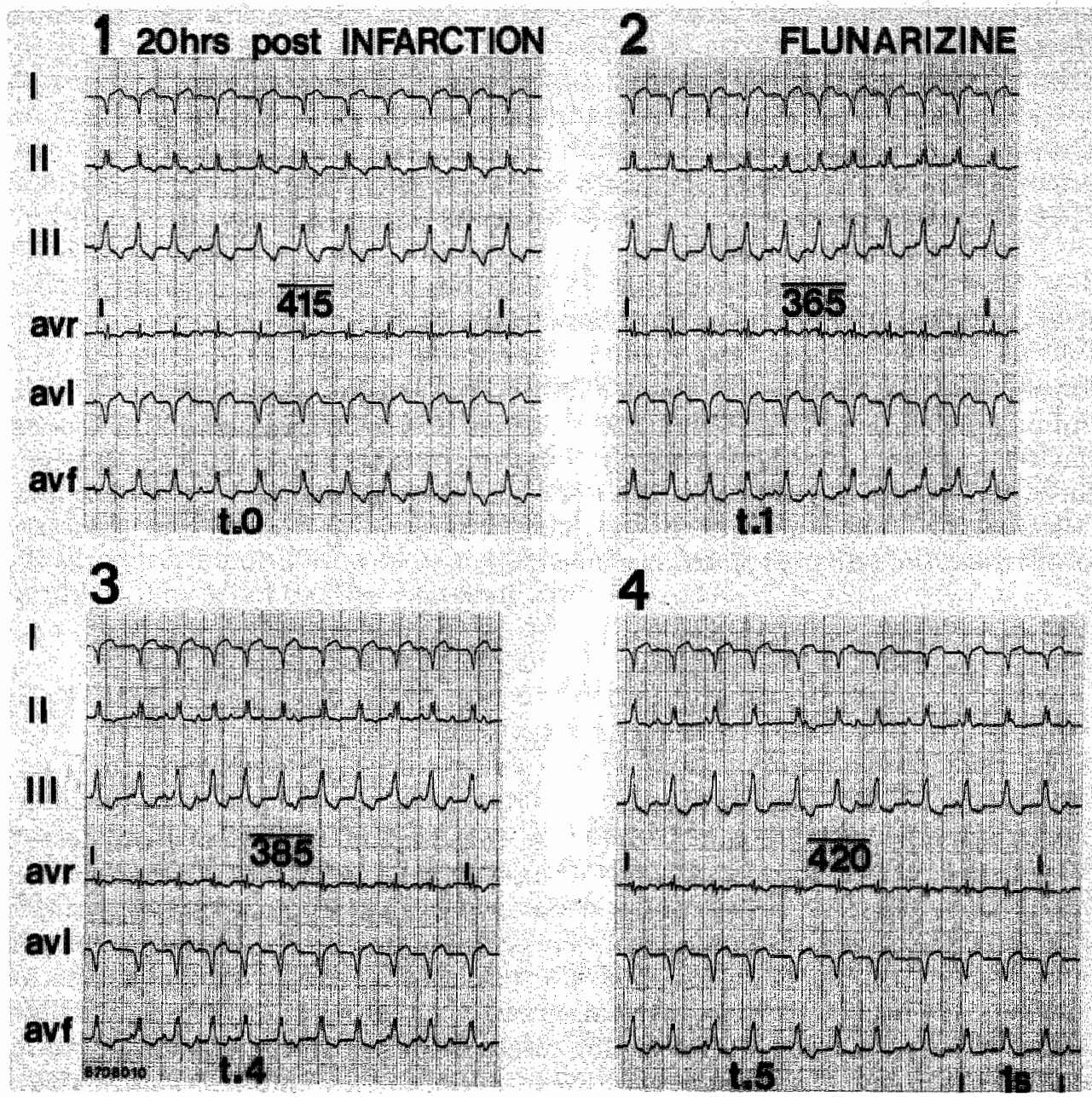

Figure 2. Acceleration in rate of the ventricular tachycardia occurring 16-24 hours after LAD-occlusion following flunarizine administration.

Six surface ECG-leads are recorded using a paper speed of $25 \mathrm{~mm} / \mathrm{s}$. In panel 1, the infarction-induced arrhythmia having a mean cycle length of $415 \mathrm{~ms}$ is seen. Flunarzine decreased the rate of the tachycardla to $365 \mathrm{~ms}$ after 1 minute (panel 2). Following acceleration, the cycle length slowly returned to $385 \mathrm{~ms}$ after 4 minutes (panel 3) and to tts basal value of $420 \mathrm{~ms}$ after 5 minutes (panel 4). 


\section{Arrhythmias occurring 16-24 hours following LAD-occlusion}

In the 9 animals studied, spontaneous VT was observed approximately one day after occlusion of the second diagonal of the LAD. Decreasing the interstimulus interval did not result in any change in the first postpacing interval (table 1). Pacing using the longest duration (120 s) and the fastest interstimulus interval $(200 \mathrm{~ms})$ frequently resulted in termination of the arrhythmia. Reinitiation however occurred always after a few spontaneous beats.

Flunarizine $(2 \mathrm{mg} / \mathrm{kg})$ decreased the cycle length of the tachycardia from 450 \pm 60 to $440 \pm 60 \mathrm{~ms}$, which is not statistically different (table 2). An example is presented in figure 2. Acceleration reached its peak after $2.3 \pm 1.2 \mathrm{~min}$. Then a slow return to the basal rate was observed, which was reached after $7.0 \pm 6.4 \mathrm{~min}$. Persistent termination was only observed once.

\section{Rhythms based on normal automaticity.}

Flunarizine decreased the cycle length significantly $(p \leq 0.01)$ in all six animals in sinus rhythm (from $550 \pm 120$ to $370 \pm 50 \mathrm{~ms}$ ) and in all 6 dogs having an idioventricular escape rhythm (from $1400 \pm 410$ to $1070 \pm 250 \mathrm{~ms}$ ). In both groups, the shortest R-R interval was reached after $3.1 \pm 1.2 \mathrm{~min}$ followed by a slow return to the basal rate taking $13.5 \pm 3.2 \mathrm{~min}$. No suppression of either rhythm was observed.

\section{DISCUSSION}

In this study, we have demonstrated that the effect of the calcium antagonist flunarzine is different in ouabain-induced ventricular tachycardias as compared to ventricular arrhythmias occurring 16-24 hours after myocardial infarction. Administration of flunarizine resulted in a increase in cycle length followed by termination of the ouabain-induced ventricular tachycardias. In contrast, an acceleration in rate was frequently observed in the ventricular arrhythmias occurring 16-24 hours after LAD-occlusion. Also, flunarizine increased the rate of rhythms resulting from normal automaticity: sinus node activity and an idioventricular escape rhythm. These results are consistent with our expectations, which were based on the following considerations: 


\section{Triggered activity resulting from delayed afterdepolarisations}

Flunarizine has been shown to protect the myocardial cell against calcium overload, induced by exposure to a depolarizing concentration of potassium (14) or veratrine administration (33) in cardiac myocytes. Also, flunarizine markedly delayed the onset of ouabain-induced arrhythmias in anaesthetized guinea-pigs (15). In these studies, flunarizine was far more effective than the selective calcium blockers, like verapamil and nifedipine. Previous studies $(9,16-19,34)$ have shown that ouabain-induced arrhythmias are most likely based on triggered activity resulting from DAD's. They occur in the setting of an increased intracellular calcium concentration (20). When the sarcoplasmic reticulum becomes overloaded with calcium, it releases this electrolyte in an oscillatory fashion (35). This increases monovalent cation conductance, and induces a transient inward current, which is thought to be responsible for DAD's.

The results of programmed electrical stimulation were in agreement with previous studies $(12,16-19,34)$ which supported the hypothesis that DAD's are responsible for the arrhythmias. Overdrive pacing resulted in a specific behavior (table 1) of the first postpacing interval which was found to have a concordant relation to the interstimulus interval $[12,18)$.

At present it is not clear how flunarizine affects triggered activity resulting from delayed afterdepolarisations. Hypothetically, flunarizine may act in a number of ways: 1) by preventing or reducing the calcium overload, 2) through inhibition of the oscillatory release from the sarcoplasmic reticulum, and/or 3) by blocking the transient inward current.

\section{Rhythms based on normal and abnormal automaticity}

As shown by Borgers (14), in myocardial cells flunarizine has no effect on: 1) phase 0 and 2 of the action potential. 2) the inotropic state, even in high concentrations, and 3) the enhanced contractility elicited by increasing concentrations of calcium in electrically stimulated cells. Recently, Tytgat et al. (36), however, demonstrated that flunarizine in high dosages blocks both types of calcium channels: i.e. Ca-T and Ca-L channels. This in contrast to verapamil or nifedipine which only affect the Ca-L type channel (37). The described effect of flunarizine on the Ca-T channel is of interest because it was suggested that this channel is involved in sinus node automaticity (38), and may contribute to abnormal automaticity [37].

In this study, we did not find a suppressing effect of flunarizine on normal automaticity. Instead, acceleration was seen. Also, our observation that following termination of the ouabain-induced arrhythmias the P-waves persisted and the idioventricular rhythm rapidly returned, supports these findings (figure 1). 
Arrhythmias occurring 16-24 hours after acute myocardial infarction are most likely based on abnormal automaticity $(12,22-24)$. They arise from a (partly) depolarized diastolic membrane (21). Depending on the level of depolarization, the sodium channel, the calcium channel or both are activated during these arrhythmias. The greater the influence of the sodium channel, the more pronounced the suppression of these rhythms following stimulation. The sodium potassium pump which is likely to be responsible for overdrive suppression ( 21 ), is sodium dependent and will not be activated when only calcium fluxes are involved. Our finding that in the infarct-induced arrhythmias no overdrive suppression could be induced (table 1) indicates that these arrhythmias arise from an intermediate or low resting membrane potential. Long stimulation trains (120 s) and short interstimulus intervals (200 ms) resulted in termination of these arrhythmias suggesting activation by the sodium channel, pointing to the intermediate resting potential as the mechanism for these tachycardias. The fact that flunarizine does not terminate these tachycardias makes it a diagnostic tool differentiating between arrhythmogenic mechanisms.

Flunarizine is specific for arrhythmias occurring in the setting of calcium overload, like triggered activity induced by DAD's. This in contrast to verapamil and nifedipine, which suppress both arrhythmogenic mechanisms $(11,15,27,39-40)$.

Acceleration of the rhythms based on (ab)normal automaticity seen after flunarizine administration is probably caused by a sympathetic reflex as a result of the vasodilatation of the peripheral vessels often seen in calcium blockers with an action on vascular smooth muscle. In the infart-induced arrhythmias this increase in rate was less pronounced. This may be due to the already high sympathetic activity following the recent myocardial infarction.

\section{Clinical implications:}

The ability to differentiate between arrhythmogenic mechanisms is important to improve our insight in the pathophysiology underlying the arrhythmia. This understanding may open new ways for a more rational treatment. Although we have a wide variety of antiarrhythmic drugs, their use in the clinical setting is frequently empirical. As with antibiotic therapy, there is a clear advantage in selecting specific anti-arrhythmic drugs for specific mechanisms. To develop these drugs better understanding of the pathophysiologic mechanisms of the different arrhythmias is required.

We think that flunarizine is an example of a clinically available drug which is able to differentiate between arrhythmogenic mechanisms. General application of this drug in human arrhythmias has to be awaited to assess its proper value in clinical cardiology. 


\section{REFERENCES}

1. Wellens HJJ. Electrical stimulation of the heart in the study and treatment of tachycardlas. Untwersity Park Press, Baltimore, 1971: 14-22.

2. Hoffman BF, and Rosen MR. Cellular mechanisms for cardlac arrhythmias. Circ. Res. $1981 ; 49: 1-15$.

3. De Bakker JMT, van Capelle FJL, Janse MJ, Wllde AAM, Coronel A. Becker AE, Dingemans

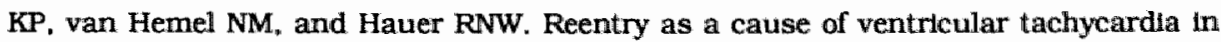
patients with chronic ischemic heart disease: electrophysiologic and anatomic correlation. Circulation 1988; 77: 589-606.

4. Wellens HJJ, Brugada $P$, and Penn $O C$. The management of the preexcitation syndromes. JAMA 1987; 257: 2325-2333.

5. Gorgels APM, Vos MA. Brugada P. and Wellens HJJ. The clinical relevance of abnormal automaticity and triggered activity. In "Cardiac Arrhythmias: Where to go from here?" eds. Brugada P, and Wellens HJJ, Futura Publishing Company Inc., Mount KIsco, New York. 1987: 147-169.

6. Rosen MR. Is the response to programmed electrical stimulati on diagnostic of mechanisms for arrhythmias? Circulation 1986; 73 (II): 19-27.

7. Priori SG, Mantica M, and Schwartz P. Delayed afterdepolarkation ellitted in vivo by left stellate ganglion stimulation. Circulation 1988, 78: 178-185.

8. Franz MR. Long term recording of monophasic action potentials from human endocardium. Arn. J. Cardilol. 1983; 51: 1629-1634.

9. LeMarec $H$, Spinell $W$, and Rosen MR. The effects of doxorubicine on ventricular tachycardla. Circulation 1986; $74: 881-889$.

10. Dangman KH, and Hoffman BF. Antlarrhythmic effects of ethmozin in cardiac Purkinje flbers: suppression of automaticity and abolition of triggering. J. Pharmacol. Exp. Ther. 1983; 227: 578-586.

11. Rosen MR, and Dandlo Jr. P. Effects of tetrodotoxin, Hidocalne, verapamil, and AHR-2666 on ouabain-induced delayed afterdepolarkations in canine Purkinje fibers. Circ. Res. $1980 ; 46: 117-124$.

12. LeMarec $\mathrm{H}_{w}$ Dangman $\mathrm{KH}_{*}$ Danilo $\mathrm{P}$, and Rosen MR. An evaluation of automatictty and triggered activity in the canine heart one to 4 days after myocardial infarction. Circulation 1985; 71 : 1224-1236. 
13. Holmes $B$, Brogden RN, Heel RC, speight TM, and Avery GS. Flunarzine:" a revtew of its pharmacodynamic and pharmacokinetic propertles and therapeutic use. Drugs $1984 ; 27$ : 6-44

14. Borgers M. de Clerck Fan Reempts J, Xhonneux $R$ and van Nueten J. Selective blockade of cellular calcium overload by funarizine. Int. Angllol. 1984; 3: 25-31.

15. Jonkman FAM, Boddeke HWGM, and van Zwieten PA. Protective activity of calcium entry blockers against ouabain intoxication in anaesthetized guinea pigs. J. Cardiovasc. Pharmacol. 1986; 8: 1009-1013.

16. Ferrier GR, Saunders JH, and Mendez C. A cellular mechanism for the generation of ventricular arrhythmias by acetylstrophanthidin. Circ. Res. 1973; 32: 600-609.

17. Rosen MR, Gelband H, Merker C. and Hoffman BF. Mechanisms of digitalis toxicity. Effects of ouabain on phase four of canine Purkinje fiber transmembrane potentlals. Circulation $1973 ; 47: 681-689$.

18. Gorgels APM, Beekman HDM, Brugada P, Dassen WRM, Richards DAB, and Wellens HJJ. Extrastimulus related shortening of the first postpacing Interval in digitalis induced ventricular tachycardia. J. Am. Coll. Cardiol. 1984; 1: 840-857.

19. Gorgels APM, de Wit B, Beekman HDM, Dassen WRM, and Wellens HJJ. Trigggered activity Induced by pacing during digitalls intoxication: observations during programmed electrical stimulation in the consclous dog with chronic complete AV- block PACE 1987; 10: 1309-1321.

20. Kass RS, Lederer WJ. Tsten RW, and Weingart R. Role of calcium fions in transient inward currents and aftercontractions induced by strophantidin in cardlac Purkinje fibers. J. Physilol. 1978; 281: 187-208.

21. Dangman $\mathrm{KH}$, and Holfiman BF. Studies on overdrive stimulation of cardiac Purkinje fibers: maximal diastolic potentlal as a determinant of the response. J. Am. Coll. Cardiol. 1983; 2: $1183-1190$.

22. Friedman PL, Stewart JR, and WIt AL. Spontaneous and induced cardlac arrhythmias in subendocardial Purkdnje fibers surviving extensive myocardial infarction. Circ. Res. 1973; 33: $612-620$.

23. Scherlag BJ, Kabell $G$, Brachmann J, Harrison $L_{n}$ and Lazzara R. Mechanisms of spontaneous and induced ventrlcular arrhythmias in the 24-hour infarcted dog heart. Am. J. Cardiol. 1983; 51: 207-213, 24. El-Sherff N. Gough wB, Zeller RH. and Mehra R. Triggered ventricular rhythms in 1-day-old myocardial infarction in the dog. Circ. Res. $1983 ; 52: 566-579$. 
25. Stemer $C_{\text {n }}$ and Kovalik TW: A simple technique for production of chronic complete heart block in dogs. J. Appl. Physiol. 1968; 25: 631-632.

26. Vasalle M, Knob RE, Cummins M, Lara GA, Castro C, and Stuckey JH. An analysis of fast Idioventricular rhythm in the dog. Circ. Res. 1977; 41:218-226.

27. Ilvento JP, Provet J, Danilo $P$, and Rosen MR. Fast and slow Idioventricular rhythms in the canine heart; a study of their mechanism using antiarrhythmic drugs and ellectrophyslological testing. Am. J. Cardiol. 1982; 49: 1909-1916.

28. Harris AS. Delayed development of wentricular ectople rhythms following experimental coronary occlusion. Circulation 1950; 1: 1318-1324.

29. Van der Steld A, Dassen W, Gorgels A, Beekman H, and Wellens HJJ. Flexible multiprocessor system to support electrophysiological investigation in animals. Computers in Cardiol. 1984: 525-528.

30. Johnson NJ, and Rosen MR. The distinction between triggered activity and other cardiac arrhythmias. In "Cardiac Arrhythmias: Where to go from here ?" eds. Brugada P, and Wellens HeJ, Futura Publishing Company Inc., Mount Kisco, New York, 1987: 129-145.

31. Vos MA, Gorgels APM, Leunissen HDM, van Deursen RTAM, and Wellens HJJ. Significance of the number of stimull to induce triggered arrhythmias in the intact heart. Submitted for publication.

32. Rhee HM, Dutta $S$, and Marks BH. Cardiac $\mathrm{Na}^{+} / \mathrm{K}^{+}$ATP-ase activity during positive Inotropic and toxdc actions of ouabain. Eur. J. Pharmacol. 1976; 37: 141-153.

33. VerDonck L, Pauwels PJ, Vandeplassche $G$, and Borgers M. Isolated rat cardiac myocytes as an experimental model to study calclum overload: the effect of calclum entry blockers. Life Sciences 1986; 38: 765-772.

34. Malfatto G, Rosen TS, and Rosen MR. The response to overdrive pacing of triggered atral and ventricular arrhythmias in the canine heart. Circulation 1988; 77: 1139-1148.

35. Orchard $\mathrm{CH}$, Eisner DA, and Allen DG. Oscillations of intracellular Calcium in mammamallan cardiac muscle. Nature 1983; 304: 735-737.

36. Tytgat J, Vereecke $\mathrm{J}$, and Carmellet $\mathrm{E}$. Differential effects of verapamil and flunarizine on cardlac L-type and T-type channels. Arch. Pharmacol. 1988; 337: 690-692.

37. Bean BP. Two kinds of calcium channels in atrial cells. Differences in kinetics, selectivity, and pharmacology. J. Gen. Physiol. 1985; 86: 1-30.

38. Hagiwara N, Irssawa $H$. and Kameyama M. Contribution of two types of calclum currents to the pacemaker potentials of rabbit stno-atrial node cells. J. Physlol. 1988; 395: 233-253. 
39. Rosen MR. Itwento JP, Gielband $H$, and Merker C. Effects of verapamil on electrophysiological properties of canine cardlac Purkinje fibers. J. Pharm. Exp. Ther. 1974; 189: 414-422.

40. Dangman $\mathrm{KH}$, and Hoffman BF. Effects of nifedipine on electrical activity of cardlac cells.

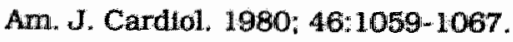


General discussion

\author{
with possible guidelines for the \\ cardiologist to distinguish among \\ mechanisms of cardiac arrhythmias
}




\section{General discussion \\ with possible guidelines for the cardiologist to distinguish among mechanisms of cardiac arrhythmias}

In the preceding chapters, we have discussed our results and compared them with those published in the literature. In this chapter, general conclusions will be drawn and rules and guidelines given to help the clinician to distinguish between the different arrhythmogenic mechanisms: reentry, triggered activity resulting from early or delayed afterdepolarization (EAD's or DAD's, respectively), and abnormal automaticity. In addition, areas which require further investigation will be indicated.

First, the value of programmed electrical stimulation to distinguish between different arrhythmogenic mechanisms will be discussed followed by a discussion about the use of anti-arrhythmic drugs for that purpose.

\section{PROGRAMMED ELECTRICAL STIMULATION}

In the literature and in this thesis, characteristics of mechanisms of arrhythmias have been described, which can be used to differentiate between mechanisms of tachycardias. Because of the variety in stimulation-protocols used, it seems appropriate to limit this discussion to 3 stimulation protocols having the highest discriminative potential:

- basic drive of 8 stimulations followed by extrastimull.

- overdirive stimulation using trains consisting of a constant number of 20 stimuli, while the interstimulus intervals are varied.

- overdrive stimulation using interstimulus intervals of $250 \mathrm{~ms}$, while varying the number of stimuli.

Pacing is performed at a site distant from the site of origin of the tachycardia. 


\section{Initiation of arrhythmias (Table 1)}

Arrhythmias based on abnormal automaticity (re)occur spontaneously, while the other mechanisms are dependent on initiating beats.

Tachycardias induced by extrastimuli are most likely based on reentry. Initiation by regular pacing is possible for both reentrant and DAD-dependent arrhythmias. When the range of the interstimulus interval(s) responsible for induction is critical, reentry is the most likely mechanism. When the inducibility and the number of induced beats per stimulation is directly related to shortening of the interstimulus interval(s) and/or increments in the number of stimuli, triggered activity resulting from DAD's is most. likely (chapter 3).

During the initiation-protocol, the behavior of the first postpacing interval of the induced arrhythmia can also be helpful. Lengthening of this intervall on increasing the prematurity of the extrastimulus suggests reentry, while in case of DAD's dependent arrhythmias a shortening of this interval is expected to occur on decreasing the interstimulus interval and/or increasing the number of stimuli (chapter 3).

Table 1. Initlation

\begin{tabular}{|c|c|c|c|}
\hline AA & TA/EAD & TA/DAD & Reentry \\
\hline \multirow[t]{3}{*}{$\begin{array}{l}\text { - Appears } \\
\text { sponteaneously }\end{array}$} & $\begin{array}{l}\text { Dependent on slow } \\
\text { rates and/or long } \\
\text { pauses }\end{array}$ & $\begin{array}{l}\text { Dependent on fast } \\
\text { rates and/or hlgh } \\
\text { number of stimull }\end{array}$ & $\begin{array}{l}\text { - Dependent on critical } \\
\text { stimulus interval }\end{array}$ \\
\hline & $\begin{array}{l}\downarrow \text { stimulue Interval } \\
\downarrow \text { induciblity } \\
\downarrow \text { number of beatss } \\
\uparrow \text { Vs-V }\end{array}$ & $\begin{array}{l}\downarrow \text { stimulus interval } \\
\uparrow \text { inducibility } \\
\uparrow \text { number of beats } \\
\downarrow \mathrm{Vs}-\mathrm{V}\end{array}$ & $\begin{array}{l}\downarrow \text { Stimulus interval } \\
\text { no results untll critical } \\
\text { conditions for block } \\
\text { appear than } \uparrow \mathrm{V}_{\mathrm{S}-\mathrm{V}}\end{array}$ \\
\hline & $\begin{array}{l}\uparrow \text { Number of stimuli } \\
? \text { Induclbility } \\
? \text { number of beats } \\
? \text { Vs-V }\end{array}$ & $\begin{array}{l}\uparrow \text { Number of atimuli } \\
\uparrow \text { inducibility } \\
\uparrow \text { number of beats } \\
\downarrow \mathrm{Vs}-\mathrm{V}\end{array}$ & $\begin{array}{l}\uparrow \text { Number of atimull } \\
\text { no result untll crittcal } \\
\text { conditions for block } \\
\text { appear than ? Vs-V }\end{array}$ \\
\hline
\end{tabular}

Vs-V = first postpacing interval; $A A=$ abnormal automatictty: $T A / \mathbb{E A D}=$ triggered activity resulting from early afterdepolarizations; $T A / D A D=$ triggered activity resulting from delayed afterdepolarizations; $\downarrow=$ decrease; $\uparrow=$ increase; $?=$ unknown. 
Arrhythmias resulting from triggered activity based on EAD's are bradycardlla dependent: their inducibility, the number of induced beats and the first postpacing interval are related to slow rates and/or long pauses. The relevance of the number of (extra-)stimuli for induction of these arrhythmias has not yet been investigated.

\section{Termination of arrhythmlas (Table 2)}

Reproductble termination using extrastimuli and/or overdrive pacing is expected to occur in arrhythmias based on reentry and triggered activity resulting from EAD's. Arrhythmias as a result of abnormal automaticity can reproducibly be terminated depending on the diastolic membrane potential from which they originate and the rate and duration of overdrive pacing. Single extrastimuli will not be effective. In the intact heart, data suggesting the existence of different diastolic membrane potentials have been presented in this thesis (chapter 7). Following termination, these arrhythmias will reoccur spontaneously, in contrast to reentrant and EAD-dependent tachycardias which need a specific trigger.

For DAD-dependent tachycardias, generalization is difficult. In vitro, irrespective of the cause, triggered arrhythmias can be terminated by pacing. The ability to terminate is positively related to the rate and duration of the stimulation. In the intact heart (chapter 5), however, it was virtually impossible to terminate ouabain-induced ventricular tachycardia by pacing. The reason for this discrepancy is not clear.

Before termination occurs (if possible), several specific patterns have been described. For reentrant tachycardias, this includes resetting by extrastimuli and entrainment during short drives. The first postpacing interval will be identical (in case of entrainment) or longer than the (extra-jstimulus interval (in case of resetting). In the latter the response curve of this interval will show an increase, flat, or mixed behavior when the stimulus interval is decreased depending on the electrophysiological properties of the reentry circuit. Ouabain-induced ventricular tachycardia did not demonstrate any of the criteria defined for transient entrainment, suggesting that this phenomenon is indeed specific for reentry (chapter 4).

The GRS-configuration of the first postpacing interval and the rate of the tachycardia in ventricular reentrant arrhythmias will not be modified by pacing. This is in contrast to DAD-dependent ventricular arrhythmias, which firstly can demonstrate an acceleration in rate depending on the duration and rate of stimulation (chapter 5). Secondly, pacing performed distant to the site of origin of the tachycardia will result in the induction of QRS-complexes close to the pacing site. Because also the original tachycardia continues, frequently fusion is observed. The amount of fusion is also dependent on duration and rate of stimulation. Finally, the length of the first postpacing interval shows a concordant relation to the interstimulus interval. 
Table 2. Termination

\begin{tabular}{|c|c|c|c|}
\hline AA & TA/EAD & TA/DAD'S & Roentiry \\
\hline $\begin{array}{l}\text { Dependent on } \\
\text { diastolle membrane } \\
\text { potential } \\
\text { - when possiblie also } \\
\text { dependent on rate } \\
\text { and duration of } \\
\text { pacing }\end{array}$ & $\begin{array}{l}\text { - frequent observation } \\
\text { following extrastimull } \\
\text { or overdivive } \\
\text { - dependient on faster } \\
\text { rates }\end{array}$ & $\begin{array}{l}\text { not dependent on } \\
\text { rate and/or duration } \\
\text { of pacing }\end{array}$ & $\begin{array}{l}\text { frequent observation } \\
\text { following extrastimuli } \\
\text { or overditue } \\
\text { - dependent on critical } \\
\text { stumulus interval }\end{array}$ \\
\hline $\begin{array}{l}\text { - reproducible } \\
\text { spontaneous } \\
\text { (re)occurence }\end{array}$ & $\begin{array}{l}\text { - reproducible } \\
\text { - needis trigger for } \\
\text { relinitiation }\end{array}$ & $\begin{array}{l}\text { - not reproducible } \\
\text { - needs trigger for } \\
\text { neinitation }\end{array}$ & $\begin{array}{l}\text { reproducible } \\
\text { needs trigger for } \\
\text { relnitiation }\end{array}$ \\
\hline $\begin{array}{l}\text { The length of the Vs-V } \\
\text { - Vs-V }>\text { Vs-Vs }\end{array}$ & & $\begin{array}{l}\text { The length of the Vs-V } \\
-V_{s-V}>V_{s-V s}\end{array}$ & $\begin{array}{l}\text { The length of the Va-V } \\
-V_{s-V}=V_{s-V s} \\
\text { entrainment }\end{array}$ \\
\hline $\begin{array}{l}\text { - will } \downarrow \text { on } \downarrow \text { Vs-V until } \\
\text { termination occurs }\end{array}$ & & - will $\downarrow$ on $\downarrow$ Vs.Vs & $\begin{array}{l}\text { - whll } \downarrow \text { on } \downarrow V s-V s \\
\text { - Vs-V }>V_{s}-V_{s} \\
\text { (resetting) } \\
=\text { or } \uparrow \text { on } \downarrow \text { Vs-Vs }\end{array}$ \\
\hline $\begin{array}{l}\text { The rate of the } \\
\text { arrhythmia } \\
\text { - will = on pacing } \\
\text { - gRS-configuration } \\
\text { Vs-V is identical to } \\
\text { tachycardia }\end{array}$ & & $\begin{array}{l}\text { The rate of the } \\
\text { arrhythmila } \\
\text { - will } \uparrow \text { on pacing } \\
\text { - gRS-configuration } \\
\text { Vs } V \text { is dependent on } \\
\text { site of stimulation }\end{array}$ & $\begin{array}{l}\text { The rate of the } \\
\text { arrhythmia } \\
\text { will = on pacing } \\
\text { - grs-configuration Vis.V } \\
\text { Is identical to } \\
\text { tachycardla }\end{array}$ \\
\hline
\end{tabular}

Vs-V = flrst postpacing interval; Vs-Vs = interstimulus interval; $A A=$ abnormal automatloity: $T A / E A D=$ triggered activity resulting from early afterdepolarkations; TA/DAD $=$ triggered activity resulting from delayed afterdepolartzations:" $\downarrow$ = decrease; $\uparrow$ m increase: " $?=$ unknown: = = equal.

The latter finding was also observed in arrhythmias resulting from abnormal automaticity, which could not be terminated (group NT in chapter 7). Differentiation between the latter two arrhythmogenic mechanisms is possible by other characteristics, which are specific for abnormal automaticity: 1) the $Q R S$-configuration of the first postpacing interval which is, identical to the QRS-complexes of the arrhythmias, and 2) no change in rate of the arrhythmia postpacing. Concerning EAD-dependent arrhythmias, they can be terminated by pacing at faster rates. However, the rate of stimulation required to achieve this is much slower than in the other mechanisms. Quantification of these kind of data is lacking. 


\section{ANTIARRHYTHMIC DRUGS}

As pointed out in chapter 2, most anti-arrhythmic drugs are effective against more than one, sometimes even against all arrhythmogenic mechanisms. For many reasons, the search for specific drugs affecting one mechanism of cardiac arrhythmias should be a challenge for researchers in the years to come. Availability of such drugs would: 1) provide (more) knowledge about pathophysiology of the mechanisms, 2) inform us about incidence and clinical relevance of the different mechanisms, and 3) optimize (pharmacologic) treatment of arrhythmias. In this thesis, a first step is made by suggesting flunarizine as specific against DAD-dependent arrhythmias (chapters 8 and 9). Definite proof requires study of flunarizine on reentrant and on EAD-dependent arrhythmias.

Until drugs specifically affecting other mechanisms have become available, the application of combinations of drugs to differentiate between mechanisms can be useful. Combinations of lidocaine and ethmozin have been proposed to identify arrhythmias resulting from either abnormal automaticity or triggered activity based on DAD's. Promising results may also come from combinations of drugs, which are administered simultaneously. For instance, the combination of flunarizine and verapamil may be useful to identify the involvement of a (specific) calcium channel in the perpetuation of an arrhythmia. 


\section{Summary}

Cardiac arrhythmias are one of the main causes of morbidity and mortality in many parts of the world. Experimental evidence has been provided that these tachycardias can result from different arrhythmogenic mechanisms, like 1) reentry, 2) triggered activity, and/or 3) abnormal automaticity. Clinically, the contribution of each mechanism for the initiation and perpetuation of arrhythmias is unknown. Identification of the responsible mechanism may lead to a more rational treatment for patients suffering from cardiac arrhythmias. To assess their respective clinical relevance, it is necessary that specific diagnostic tools are developed which allow identification of the underlying mechanism.

In this thesis, conscious dogs with permanent atrio-ventricular block were used to study two mechanisms: 1) triggered activity resulting from delayed afterdepolarizations, and 2) abnormal automaticity. Using programmed electrical stimulation and the drug flunarizine, an attempt was made to find characteristics which could possibly be used as methods to identify these mechanisms.

In chapter 2 , the literature concerning the different arrhythmogenic mechanisms is reviewed starting with a short introduction on the normal electrical activation of the heart.

The results presented in chapter 3 demonstrated that initiation of ventricular tachycardias resulting from triggered activity is positively related to the rate and the duration of the preceding (paced) rhythm.

Transient entrainment of a tachycardia is an increase in rate of all tissue responsible for sustaining the tachycardia to the faster pacing rate, with resumption of the intrinsic rate of the tachycardia upon either abrupt cessation or slowing of the pacing rate below the intrinsic rate of the tachycardia. This phenomenon is exclusively described in reentrant arrhythmias and is considered to be specific for this mechanism. In chapter 4 , we investigated whether a tachycardia resulting from triggered activity could show phenomena which fulfill any of the electrocardiographic criteria for entrainment. It was found that overdrive stimulation of these tachycardias did not result in ECG-findings compatible with entrainment. In addition, we noticed that these triggered arrhythmias could not be terminated; instead acceleration of the rate of the tachycardias was seen.

Using more extensive pacing protocols, we further investigated these findings (chapter 5). The results were similar: 1) no termination, and 2) acceleration of the tachycardia were observed. The acceleration was positively related to the duration of stimulation. 
Normally, overdrive pacing of the idioventricular rhythm in dogs with complete AV-block will result in overdrive suppression. Using fast and short stimulation-trains, we frequently observed another response to overdrive: gRS-complex(es) with an unexpectedly short first postpacing interval followed by normal overdrive suppression. We have termed these GRS-complexes premature escape beats (PEB's). In chapter 6, the results are presented from experiments using programmed electrical stimulation solely or in combination with different drugs, suggesting that these PEB's are based on triggered activity. These observations suggest that this model can be used to study triggered activity in the untreated, intact heart.

On the effect of overdrive stimulation of ventricular tachycardias resulting from abnormal automaticity is reported in chapter 7 . The majority $(60 \%)$ of these tachycardias could be terminated by pacing. Termination was dependent on rate of the tachycardia and the stimulation mode. These results suggest that these arrhythmias originate from different diastolic membrane potentials.

In chapters 8 and 9 , the effect of flunarizine on: 1) sinus node automaticity. 2) normal automaticity originating in the ventricle, 3) triggered activity, and 4) abnormal automaticity is discussed. Flunarizine slowed and terminated triggered arrhythmias, but accelerated rhythms based upon normal and abnormal automaticity. Therefore, flunarizine can be used to identify triggered activity in the intact heart. Using our findings and the results from the literature, guidelines are given in chapter 10, which may be of help to identify the specific underlying mechanism of arrhythmias in the human heart. 


\section{Samenvatting}

In Nederland sterven jaarlijks 25.000 mensen aan een plotse dood ten gevolge van hartritmestoornissen. Uit (dier)experimenteel onderzoek is gebleken dat deze aritmieên kunnen worden veroorzaakt door verschillende mechanismen, zoals 1) reentry, 2) triggered activity of 3) abnormale automaticiteit.

Bij patiēnten is het echter nog niet duidelijk welke betekenis aan leder afzonderlijk mechanisme moet worden toegekend, omdat er voor een aantal mechanismen geen diagnostische methoden beschikbaar zijn die klinische identificatie mogelijk maken. Herkenning van het verantwoordelijke mechanisme zou moeten leiden tot verdere optimalisering van de behandeling van de patiënt met hartritmestoornissen.

In dit proefschrift is geprobeerd methoden te ontwikkelen om twee van deze mechanismen, nl. 1) triggered activity veroorzaakt door vertraagde na-potentialen (delayed afterdepolarizations) en 2) abnormale automaticiteit, te herkennen. Bij honden met AV-blok werden kamerritmestoornissen onderzocht die veroorzaakt worden door deze twee mechanismen. Het onderzoek werd uitgevoerd met behulp van 1) geprogrammeerde electrische prikkeling van het hart en 2) het geven van medicamenten. Door het hart van buitenaf een hogere frequentie op te leggen-via electrische prikkeling (stimuleren)-dan het spontaan bezit, is het mogelijk hartritmestoornissen in een gecontroleerde situatie op te wekken, te bestuderen en te beëindigen. Tevens bledt deze techniek de gelegenheid om het effect van geneesmiddelen op deze tachycardieën te onderzoeken.

In hoofdstuk 2 wordt de bestaande literatuur met betrekking tot de verschillende mechanismen die aan normale en abnormale impulsworming ten grondslag liggen kort besproken.

De resultaten, gepresenteerd in hoofdstuk 3 , hebben betrekking op het ontstaan van ritmestoornissen gebaseerd op triggered activity. Onderzoek heeft aangetoond dat de initiatie van deze aritmieen frequentie afhankelijk is, d.w.z. de kans op het ontstaan van triggered activity wordt groter als het voorafgaande hartritme sneller is. Hoe lang een dergelijke versnelling in hartritme moet duren was in het intacte hart echter onbekend. Deze studie geeft aan dat de duur van grote betekenis is, d.w.z. hoe langer het versnelde ritme bestaat des te groter wordt de kans dat ritmestoornissen gebaseerd op triggered activity kunnen ontstaan.

"Entrainment" is een tijdelijke versnelling van de aritmie die alleen optreedt tjjdens stimuleren. Meteen na het beêindigen van de stimulatie, keert de oude frequentie van de aritmie weer terug. Dit fenomeen is uitsluitend beschreven bij ritmestoornissen die berusten op het reentry mechanisme. Om na te gaan of deze eigenschap specifiek is voor reentry, is in hoofdstuk 4 geprobeerd ritmestoornissen gebaseerd op triggered activity te "entrainen". Dat bleek niet 
mogelijk. Bovendien viel op dat deze aritmieēn na stimulatie in frequentie toenamen (accelereerden), terwijl de beëindiging van de ritmestoornis juist niet optrad. In hoofdstuk 5 is dit fenomeen met uitgebreidere stimulatie-protocollen nader onderzocht. Hierbij werd hetzelfde resultaat verkregen. Ook met dit protocol kon de artimie niet worden gestopt. De optredende versnelling was direct gerelateerd aan de duur van het stimuleren.

Indien een "pacemaker" sneller wordt gestimuleerd dan zijn eigen frequentie, treedt er na beëindiging van het prikkelen onderdrukking van het oorspronkelijke ritme op ("overdrive suppression"), d.w.z. er is gedurende een bepaalde tijd geen spontane impuls (QRS-complex) op het electrocardiogram zichtbaar. $\mathrm{Na}$ dit lange eerste interval, volgen de impulsen elkaar steeds sneller op totdat de normale frequentie, die voor het stimuleren aanwezig was, weer is bereikt. Zeer snelle, kortdurende stimulatie-treinen kunnen echter ook impulsen opwekken met relatief korte intervallen gevolgd door "overdrive suppression". Deze laatste QRS-complexen zijn door ons "premature escape beats" (PEB's) genoemd. In hoofdstuk 6 wordt het gedrag van deze PEB's beschreven in relatie tot geprogrammeerde stimulatie. Tevens wordt het effect van verschillendle medicamenten getest. De resultaten van deze experimenten tonen aan dat het ontstaan van deze PEB's waarschijnlijk berust op het mechanisme triggered activity veroorzaakt door delayed afterdepolarizations.

In hoofdstuk 7 staat het mechanisme abnormale automaticiteit centraal. Verschillende experimenten uitgevoerd in geïsoleerde hartcellen hebben aangetoond dat dit soort ritmestoornissen eigenschappen bezitten die veelal gerelateerd zijn aan het niveau van de membraanpotentiaal vanwaar de abnormale impulsen ontstaan. Zo is de snelheid van de aritmie, als ook de mogelijkheid om de ritmestoornis te beëindigen door middel van stimuleren afhankelijk van het niveau van deze membraanpotentiaal. Onbekend is het of ook in het intacte hart aritmieên bestaan die afkomstig zijn van deze verschillende niveaus van membraanpotentiaal. Gegevens gepresenteerd in dit hoofdstuk suggereren dat dit inderdaad het geval is.

In de hoofdstukken 8 en 9 wordt het effect besproken van het medicament flunarizine op: 1) normale automaticiteit afkomstig uit de sinusknoop. 2) normale automaticiteit die ontstaat in de kamer van het hart, 3) triggered activity en 4) abnormale automaticiteit. Flunarizine is onderzocht omdat het mogelijk specifiek werkzaam zou zijn tegen ritmestoornissen gebaseerd op triggered activity. Flunarizine blijkt inderdaad in staat om deze kamertachycardieën te vertragen en te stoppen. De ritmen gebaseerd op normale of abnormale automatictteit worden daarentegen nlet beïnvloed door dit medicament. De specifleke werking van flunarizine is dus van diagnostische waarde om ritmestoornissen gebaseerd op triggered activity te kunnen identificeren.

In hoofdstuk 10 worden tenslotte de verschillende resultaten van dit proefschrift geplaatst tegen de achtergrond van informatie uit de bestaande literatuur. 
Samenvattend kan gesteld worden dat dit onderzoek een aantal nieuwe gezichtspunten heeft opgeleverd in de identificatie van mechanismen verantwoordelijk voor hartritmestoornissen in het intacte hart. Met name flunarizine blijkt in staat te zijn om hartritmestoornissen veroorzaakt door triggered activity te herkennen. 


\section{Nawoord}

Het verrichten van onderzoek is tegenwoordig niet meer mogelijk zonder de betrokkenheid en hulp van velen. Gelukkig biedt het verschijnen van dit proefschrift mij de gelegenheid een aantal mensen met name te bedanken. Prof. Dr. Hein Wellens is (eind)verantwoordelijk voor de in deze dissertatie beschreven experimenten. Zijn manier van leidinggeven die wetenschappelijke prestaties mogelijk maakt met behoud van individuele vrijheild werkt enorm stimulerend. Daarnaast vormt zijn streven om de resultaten van dierexperimenteel onderzoek direct toe te passen in de klinische situatie een geweldige ultdaging, die enorm veel voldoening kan geven. Het is dan ook deze integratie die mijns inziens verdere ontwikkeling, vervolmaking en ook zeker navolging verdient.

Dr. Ton Gorgels begeleidde de dagelijkse gang van zaken rondom dit onderzoek, waaraan zijn ideeën ten grondslag liggen. Tevens heeft hij milj ingewijd in in de beginselen van de electrofysiologie en cardiologie. Vele uren werden samen doorgebracht, waarbij de zorgvuldigheid waarmee Ton de experimenten omgaf mij enorm aansprak. Op dit moment heeft hij de eerste klinische onderzoeken gestart die de in dit proefschrift geformuleerde richtlljnen op hun geldigheid moeten toetsen. Naast hem wil ik ook zijn vrouw Janneke bedanken voor de vele malen dat $\mathrm{k}$ van hun gastvrifheid mocht genieten om zaken rond etenstijd (verder) door te spreken.

Mevrouw Jet Leunissen vormt een andere niet te missen schakel in het team dat dit onderzoek verrichtte. Haar handigheid, inzicht en betrokkenheld vormden een stevig fundament voor het slagen van dit project. Bovendien verdient de wijze waarop zij de honden tijdens en tussen de experimenten met zorg omringde veel bewondering; zeker als men zich realiseert dat alle honden bij bewustzijn werden onderzocht. Ook was zij verantwoordelijk voor de vele, mooie illustraties opgenomen in dit proefschrift. Het doet me dan ook veel plezier dat zij als paranymf beschikbaar is.

Vele discussies over de inhoud en klinische toepasbaarheid van dit proefschrift zijn gevoerd met Prof. Dr. Pedro Brugada en Dr. Joep Smeets. Hun enthouslasme, ideeën en kritische opstelling hebben zeer bijgedragen aan de totstandkoming van deze dissertatie. Daarvoor ben $\mathrm{ik}$ beiden erkentelijk. Tevens is het me een genoegen om Joep als paranymf te mogen begroeten.

De leden van de beoordelingscommissie: Prof. Dr. R.S. Reneman (voorzitter), Prof. Dr. M.A. Allessie, Prof. Dr. M. R. Rosen, Prof. Dr. H.A.J. Struyker Boudier en Dr. M. Borgers wil lk bedanken voor het beoordelen van het manuscript en hun waardevolle commentaren. Especially, I wish to express my gratitude to Dr. Michael Rosen whose advises, throughout the years, have resulted in important contributions in the preparation of the manuscript. It is a great honour that he will be present on the day I will defend this thesis. 


\section{Curriculum vitae}

\section{MARC A. VOS}

1958

geboren op 16 februari te Tilburg. Nederland.

1978

eindexamen VwO-B aan het Tilburgs Avondcollege.

1978 - 1984 studie aan de InterFaculteit Lichamelijke Opvoeding (IFLO), Vrije Universiteit te Amsterdam.

1984

doctoraal examen IFLO

hoofdvak: inspanningsfysiologie

bijvakken: biochemie en sportpsychologie

eerstegraads onderwijsbevoegdheid fysiologie en anatomie.

1984 - 1985 wetenschappelijk medewerker bij de vakgroep Cardiologie, William Beaumont Hospital te Royal Oak, Verenigde Staten.

1986 - 1989 wetenschappelijk medewerker bij de vakgroep Cardiologie, Academisch Ziekenhuis Maastricht, Rijksuniversiteit Limburg te Maastricht. 